


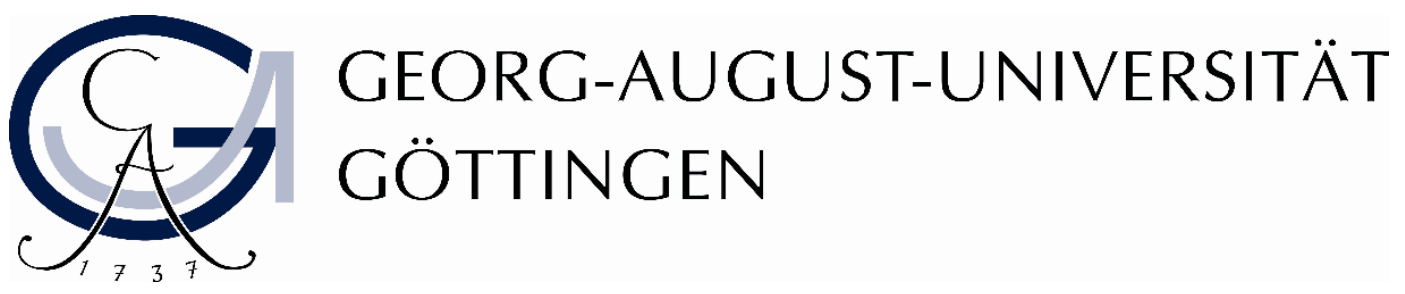

- CENTRE OF BIODIVERSITY AND SUSTAINABLE LAND USE -

SECTION: BIODIVERSITY, ECOLOGY AND NATURE CONSERVATION

\section{Fungal Responses to Grazers}

Dissertation for the award of the degree

"Doctor rerum naturalium"

Divisions of Mathematics and Natural Sciences

of the Georg-August-Universität Göttingen

submitted by

Silvia Caballero Ortiz

from Valencia, Spain

Göttingen, October 2014 
Referee I: PD. Dr. Marko Rohlfs

Referee II: Prof. Dr. Stefan Scheu

Date of the disputation: $1^{\text {st }}$ of October, 2014 
A mis padres, Lohe y Lola,

Gracias por creer en mí 


\section{Contents}

Summary

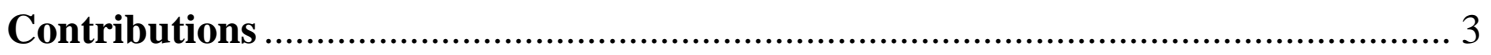

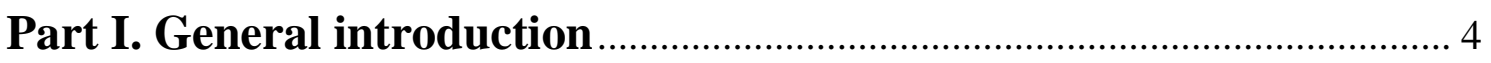

Chapter 1 ............................................................................................................... 5

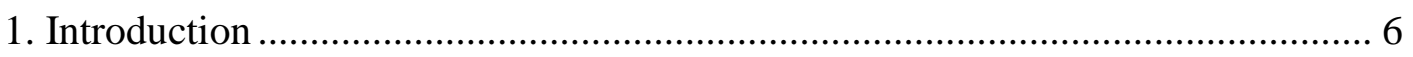

2. Inducible anti-herbivore resistance in plants...................................................... 9

3. Regulation of anti-fungivore resistance mechanisms......................................... 10

4. Different fungivores may induce different fungal responses ............................... 12

5. Fungal allelopathy plays a role in fungi-fungivore interactions ............................ 13

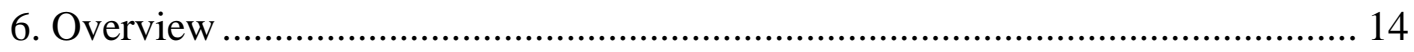

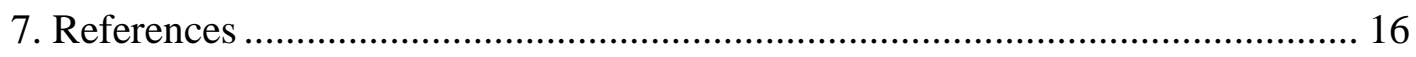

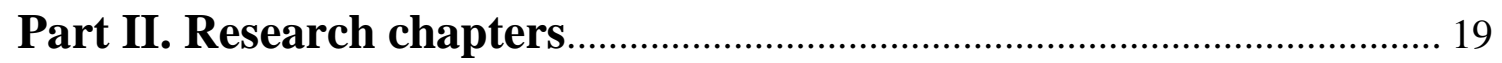

\section{Chapter 2}

Induced fungal resistance to insect grazing: reciprocal fitness consequences and fungal gene expression in the Drosophila-Aspergillus model system....................... 20

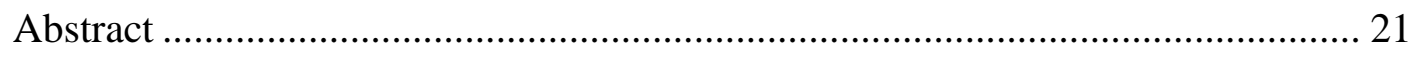

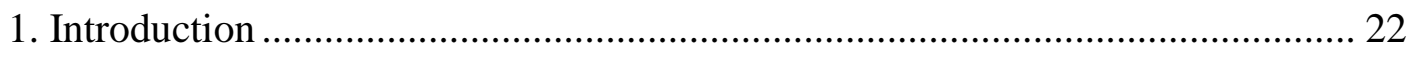

2. Material and methods ………………………………….......................... 26

2.1. Culture of organisms and experimental conditions .................................................. 26

2.2. Insect-induced resistance to fungivory …………………………………………..... 27

2.3. Larval grazing on wild type and chemical deficient A. nidulans ............................. 28

2.4. A. nidulans $-D$. melanogaster confrontation assay for gene expression analysis.

Fungal tissue handling and RNA extraction............................................................. 28

2.5. Quantitative Real-Time Reverse Transcription PCR (qRT-PCR)............................ 30

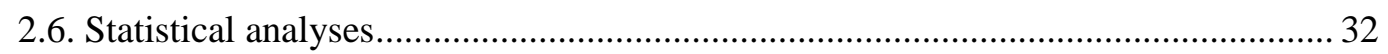

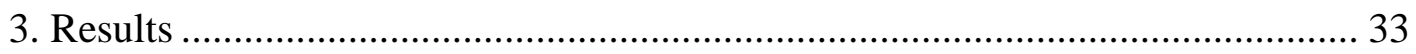


3.1. Insect-induced resistance to fungivory.

3.2. A. nidulans gene expression response to D. melanogaster larval grazing ............... 34

3.3. Larval grazing on wild type and chemical deficient A. nidulans ............................ 35

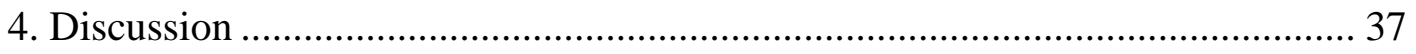

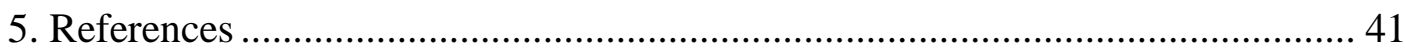

\section{Chapter 3}

Aspergillus nidulans response to variation in fungivore feeding damage............. 45

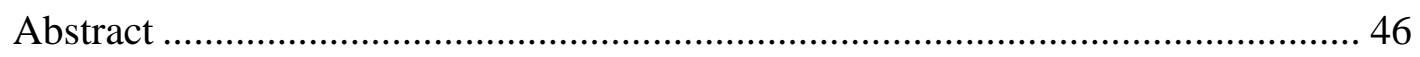

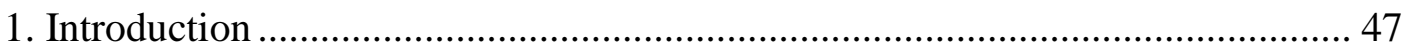

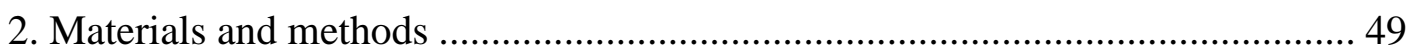

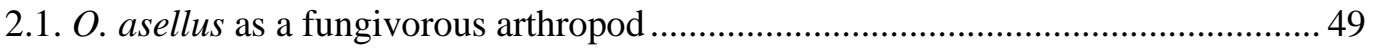

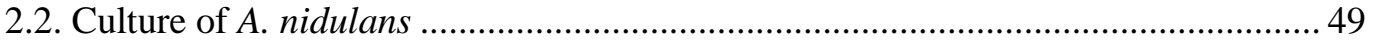

2.3. Handling of A. nidulans and fungus-fungivore confrontation assay ....................... 49

2.4. Handling of fungal tissue for RNA extraction and gene expression analysis .......... 50

2.5. Quantitative Real-Time Reverse Transcription PCR (qRT-PCR)............................ 51

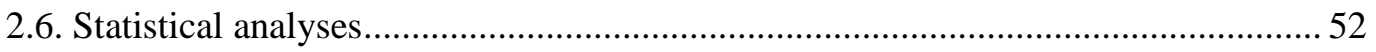

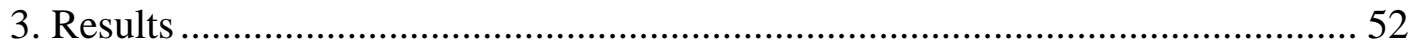

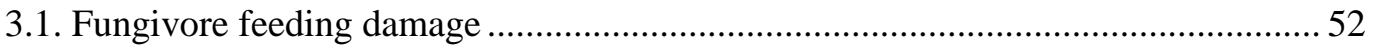

3.2. A. nidulans gene expression response to $O$. asellus feeding damage....................... 54

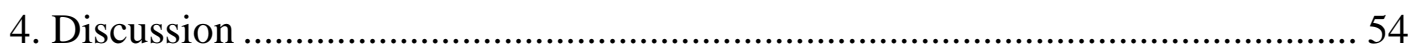

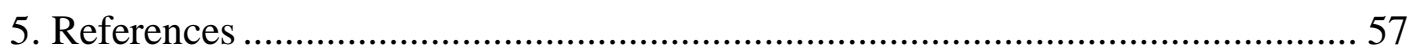

\section{Chapter 4}

Fungal allelopathy influences fungus-fungivore interactions by suppressing Aspergillus nidulans anti-fungivore defence ............................................................. 59

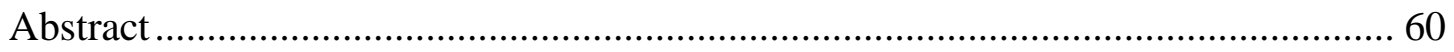

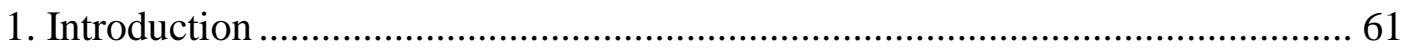

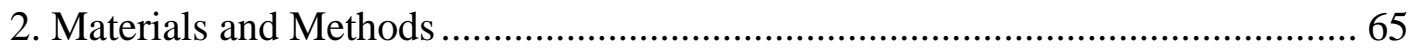


2.1. Culture of organisms

2.2. Yeast volatile profile analysis in sucrose-rich and sucrose-deficient media.

2.3. Effect of single yeast volatile on A. nidulans fitness parameters. 66

2.4. Yeast volatile influenced $A$. nidulans metabolic profile analysis 68

2.5. Yeast volatile influenced $A$. nidulans gene expression analysis. 69

2.6. Inducible resistance in the yeast volatile influenced mould by larval grazing......... 71

2.7. Larval development on yeast volatile influenced A. nidulans colonies. .................. 71

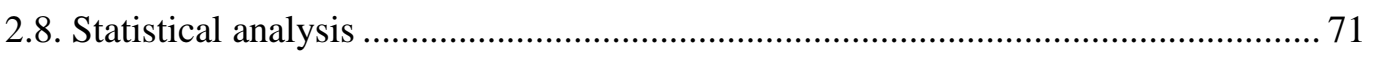

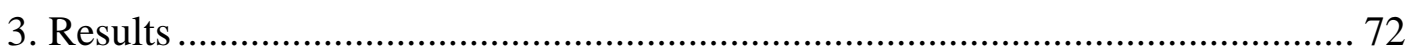

3.1. Yeast volatile profile analysis on sucrose-rich and sucrose-deficient media ........... 72

3.2. Effect of single yeast volatile on A. nidulans fitness parameters............................ 73

3.3. Yeast volatile influenced $A$. nidulans metabolic profile analysis............................. 76

3.4. Yeast volatile influenced A. nidulans gene expression analysis. ............................. 77

3.5. Inducible resistance in the yeast volatile influenced mould by larval grazing......... 77

3.6. Larval development on yeast volatile influenced A. nidulans colonies. .................. 78

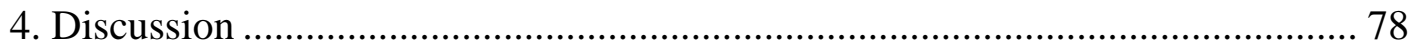

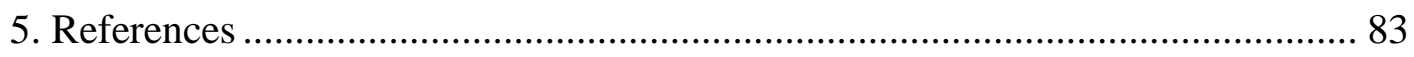

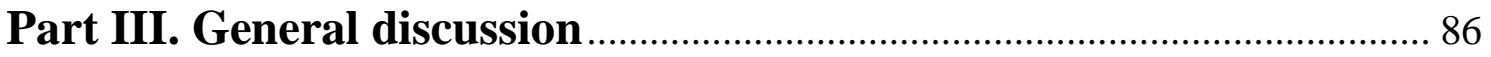

Chapter 5 .................................................................................................................................... 87

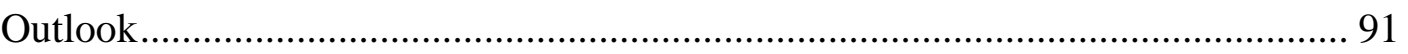

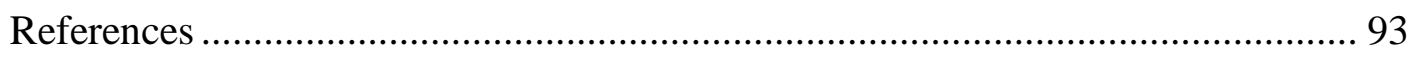

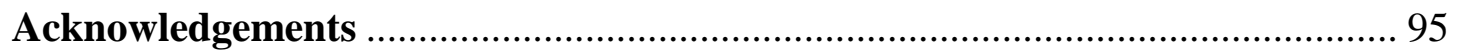

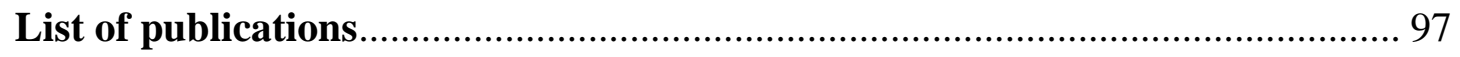

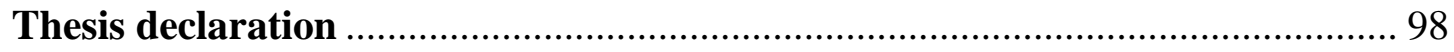




\section{Summary}

Fungi are organisms that due to their inability of moving are highly exposed to suffer predation. As a consequence, fungi have evolved different defence strategies to keep fungivores in check. Among these strategies, fungi are thought to synthesize secondary metabolites as a chemical defence against fungivores. The toxicity of some of these fungal compounds have been tested against different invertebrates, however, it remains unknown whether grazers induce the anti-fungivore defence in moulds.

In this thesis it is hypothesized that fungivory enhances the capacity of the fungi to kill or repel fungivores. The more resistant fungal phenotype is expected to show changes at the molecular genetic and biochemistry level. Specifically, changes at the expression levels of those genes related with the biosynthesis of secondary metabolites and changes at the fungal metabolic profile were expected.

To test for an inducible anti-fungivore defence, Aspergillus nidulans was exposed to the grazing of Drosophila melanogaster larvae (Chapter 2). In this chapter it is shown that the grazing of the D. melanogaster larvae induces the anti-fungivore defence on the mould A. nidulans. The induction of the anti-fungivore defence is accompanied by a shift at the transcriptome level where the expression levels of some genes involved in the biosynthesis of secondary metabolites were up-regulated compare to their constitutive expression levels.

In chapter 3 was investigated whether the variation in fungivore feeding damage induces different fungal responses. It has been previously suggested that the mechanisms underlying the anti-fungivore defence in the mould $A$. nidulans are suppressed by intense grazing. Therefore, in this chapter, it was hypothesized that the intense feeding damage produced by the isopod Oniscus asellus negatively affects the expression levels of those genes involved in the anti-fungivore defence of A. nidulans. Results of this chapter revealed that the intense grazing produced by the isopod down-regulates the antifungivore defence of the mould.

Notably, different interactions in which fungi are engaged despite fungivory, may affect the anti-fungivore defence and therefore, the fungal capacity to harm fungivores. It is known that fungi compete chemically for resources and space against other microorganisms e.g. yeast. This chemical interference competition is commonly known as allelopathy and it is widespread between fungi e.g. mould and yeast. Yeast has the 
potential to release volatile organic compounds with antifungal activity that negatively affect mould growth. In chapter 4 it was hypothesized that yeast volatile organic compounds (VOCs) induce changes at the organismic, genetic and biochemistry level which influences the anti-fungivore defence of A. nidulans. A common response of moulds to microbial volatiles is a reduced production of conidiospores combined with a fluffy vegetative growth. This fluffy phenotype turned out to have modified levels of secondary metabolites, impaired capabilities to launch an induced defence response, which in combination leads to a significantly reduced capacity to resist fungivory. Results from this chapter show for the first time that fungal allelopathy affects the sign and strength of fungus-fungivore interactions.

In conclusion, the results of this thesis demonstrates that fungivores have the capacity to enhance the anti-fungivore defence of the mould A. nidulans and thus affects the outcome of fungus-fungivore interactions. Moreover, the plasticity in the anti-fungivore defence is susceptible to variation in grazing intensity and chemically mediated intra-guild interactions. All these results indicate that the dynamics of fungus-fungivore interactions are more complex than thought and therefore further studies are required to determine the role of the inducible fungal defence in multi-species communities. 


\section{Contributions to the chapters of this thesis}

Chapter 2: Induced fungal resistance to Insect Grazing: Reciprocal Fitness Consequences and Fungal Gene Expression in the Drosophila-Aspergillus Model System.

Silvia Caballero Ortiz, Monika Trienens, Marko Rohlfs.

Dr. Monika Trienens and Dr. Marko Rohlfs conducted and analysed the data from the experiment insect-induced resistance to fungivory and from the experiment larval grazing on wild type and chemical deficient Aspergillus nidulans. Silvia Caballero Ortiz conducted and analysed the data from the experiment Aspergillus nidulans gene expression response to Drosophila melanogaster larval grazing and wrote the manuscript.

\section{Chapter 3: Aspergillus nidulans Response to Variation in Fungivore Feeding}

\section{Damage.}

Silvia Caballero Ortiz, Marko Rohlfs.

Silvia Caballero Ortiz conducted the experiments, analysed the data, generated the graphs and wrote the manuscript.

\section{Chapter 4: Fungal allelopathy suppresses anti-fungivore defence in the}

\section{filamentous fungi Aspergillus nidulans}

Silvia Caballero Ortiz, Monika Trienens, Katharina Döll, Gerrit Holighaus, Marko Rohlfs.

Yeast volatile profile analysis in sucrose-rich and sucrose-deficient media experiment was conducted by Dr. Marko Rohlfs and analysed in collaboration with Dr. Gerrit Holighaus. Silvia Caballero Ortiz conducted and analysed the data of the three following experiments; effect of single yeast volatile on A. nidulans fitness parameters, yeast volatile influenced $A$. nidulans gene expression analysis and inducible resistance in the yeast volatile influenced mould by larval grazing. Yeast volatile influenced A. nidulans metabolic profile experiment was conducted by Silvia Caballero Ortiz and analysed in collaboration with Dr. Katharina Döll. Larval development on yeast volatile influenced A. nidulans colonies experiment was conducted and analysed by Dr. Monika Trienens. Silvia Caballero Ortiz generated all the graphs and wrote the manuscript. 


\section{Part I.}

\section{General introduction}




\section{Chapter 1}

General introduction 


\section{Introduction}

Life in terrestrial ecosystems is dominated by the activity of fungal organisms. The life cycles of fungi are not separated from those of other organisms; on the contrary, animals, plants and microorganisms are engaged in multiple interactions with fungi, which are thought to be essential determinants of ecosystem functioning. There is consensus that the environmental changes caused by these interactions have, at least in part, shaped the evolution of fungal life-history strategies. Many of such changes in the fungal environment are brought about by predatory, competitive or mutualistic interactions with invertebrate animals (Begon et al., 2006). Predation, i.e. fungivory, is probably the most dominant interaction in which invertebrates and fungi are engaged. In consequence, fungi are assumed to have evolved defence strategies to withstand or avoid fungivory (Böllmann et al., 2010). Among other mechanisms, chemical defence based on secondary metabolite production is a widespread and often-cited hypothesis for anti-fungivore resistance, that is the ability of fungi to repel or harm grazers (Nakamori and Suzuki, 2007; Spiteller, 2008; Tanney and Hutchison, 2012).

Generally, defensive compounds are formed by specialised or secondary metabolism. Secondary metabolism comprises biosynthetic pathways that produce small-molecular weight compounds not required for normal development, reproduction or survival of an organism (Keller et al., 2005), but play a major role in coping with ecological challenges, e.g. fungivory (Rohlfs et al., 2007; Trienens and Rohlfs, 2012; Trienens et al., 2010). Flexibility in the expression of defence mechanisms is a characteristic of many species interactions, which has, for example, intensively been investigated in plant-herbivore interactions (Karban and Baldwin, 1997). Adaptive plasticity in anti-grazer resistance has also been suggested to have evolved in fungal organisms (Spiteller, 2008). To date, however, it has remained unknown whether fungivore grazing induces the activation of chemical compound-based resistance mechanisms.

Inducible resistance is generally assumed to reduce the costs of defence and benefit the fitness of the organisms. Activation of resistance mechanisms only if required, i.e. in the presence of predators, is thought to allow organisms to save energy for other processes such as growth and reproduction (Cipollini and Heil, 2010; Harvell, 1990; Karban et al., 1999; Agrawal and Karban., 1999). Knowledge about the extent to which fungi are capable of adjusting their anti-fungivore resistance to environmental changes will 
enhance our understanding of the mechanisms determining the structure and dynamics of populations associated with fungi.

The fundamental hypothesis of the present thesis is that fungivory enhances the capacity of fungi to kill or repel grazers. This shift in resistance is expected to be characterised by changes in properties on the molecular genetic and biochemistry level of the affected fungus. In particular, a link between variation in anti-fungivore resistance and changes in the expression levels of genes involved in different molecular pathways tightly connected with the biosynthesis of secondary metabolites was expected. In consequence, variation in resistance can be related to changes in the fungal secondary metabolite profile. To elucidate this underexplored aspect of interspecific interactions the research chapters of this thesis fall into three areas (Figure 1):

\section{a) Inducible resistance - also in fungi?}

Testing for inducible anti-fungivore resistance is the first goal of this thesis. In order to investigate this, Aspergillus nidulans was challenged with fungivorous Drosophila melanogaster larvae. RNA analyses were performed to study the expression levels of candidate genes from different molecular pathways, incl. those involved in secondary metabolite biosynthesis in response to insect grazing. This molecular genetic analysis was combined with organismic assays to explore changes in the capacity of the fungus to kill the grazers.

b) Do different fungivores trigger different fungal response?

Different fungivores may cause, due to variation in grazing intensity, different fungal responses. In this chapter it was hypothesized that the expression of the regulatory mechanisms of anti-fungivore resistance are not or even negatively affected by the strong feeding damage imposed by isopod grazing. To test this hypothesis, A. nidulans was challenged with the isopod Oniscus asellus. RNA analyses were employed to study changes in the expression levels of candidate genes related with anti-fungivore resistance.

\section{c) Does fungal allelopathy affect fungus-fungivore interactions?}

Bipartite fungus-fungivore interactions are likely to be affected by intra-guild interactions that may additionally influence anti-fungivore resistance. Chemically mediated interference competition, often called allelopathy, is one of such wide-spread interactions between fungi which may influence the capacity of a target fungus to harm or repel fungivores. In the Drosophila system, the insects are associated with mutualistic yeasts 
which are well-known for producing anti-mould metabolites. Whether this fungal allelopathy helps the flies to cope better with toxin-producing mould is the third area of this thesis. This chapter combines organismic experiments with molecular genetic and biochemical analyses to test whether fungal allelopathy influences the anti-fungivore resistance of $A$. nidulans and whether it affects the grazing success of $D$. melanogaster larvae.

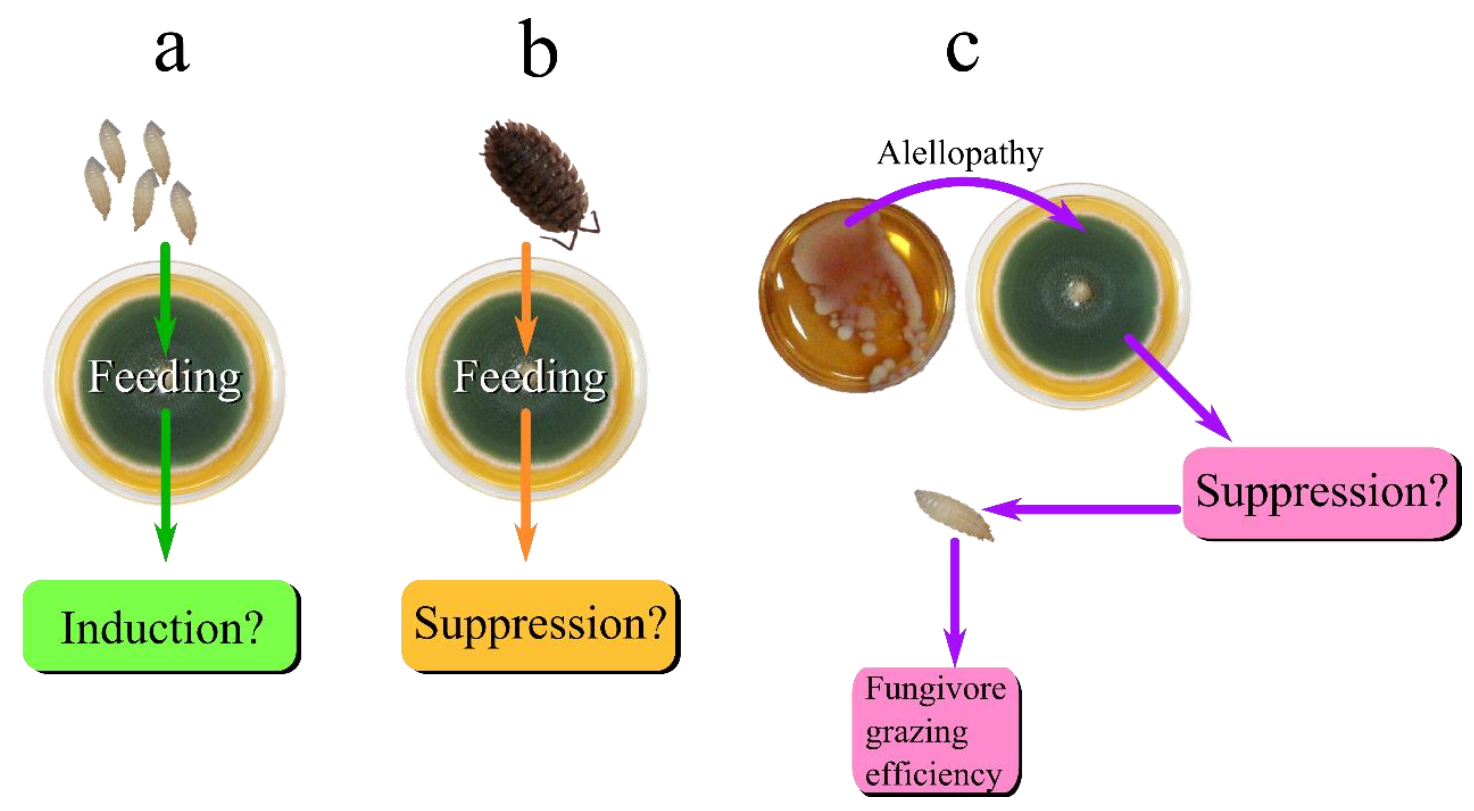

Figure 1. Scheme illustrating the three areas of this thesis. The first area is represented by (a) and hypothesizes that the anti-fungivore resistance of $A$. nidulans is induced by the grazing of $D$. melanogaster. The second area of the thesis (b) hypothesizes that the anti-fungivore resistance is suppressed by severe isopod feeding damage. And the third area of the thesis (c) hypothesizes that the anti-fungivore resistance of $A$. nidulans is negatively affected by yeast volatiles and in consequence, fungal allelopathy positively influences fungivore grazing efficiency.

Inducible resistance has been thoroughly investigated and well documented in plantherbivore interactions (Howe and Schaller, 1995). Because plants and fungi share many ecological features e.g. modular growth and the way they are predated (Begon et al., 2006), fungi may have evolved defence strategies comparable to those in plants. Many assumptions of this thesis are based on the results obtained from the analysis of plantherbivore interactions. Thus, in the following paragraph some detailed information on inducible anti-herbivore resistance in plants will be provided and related to putative mechanisms determining the capacity of fungi to harm fungivores. 


\section{Inducible anti-herbivore resistance in plants}

Inducible anti-herbivore resistance is tightly regulated by the cross-talk of several molecular pathways (Figure 2). In order to activate these molecular pathways plants need to detect grazing by perceiving herbivore-specific chemical cues called "elicitors" (Zhao et al., 2005). Such elicitors (Mattiacci et al., 1995; Turlings et al., 2000) activate protein kinases e.g. MAPKinases (mitogen-activated protein kinase) and hormonal signalling e.g. jasmonates, which are responsible for transmitting the "grazing" signal to the nucleus (Wasternack, 2007). In the nucleus, activation of genes involved in the biosynthesis of secondary metabolites takes places. Some of the anti-herbivore compounds are constitutively present at low levels under predator-free conditions, but they are massively produced under predatory conditions; some compounds are even synthesized de novo. Such compounds either repel the grazers, reduce the digestibility of plant tissue, or are immediately toxic (Gatehouse, 2002).

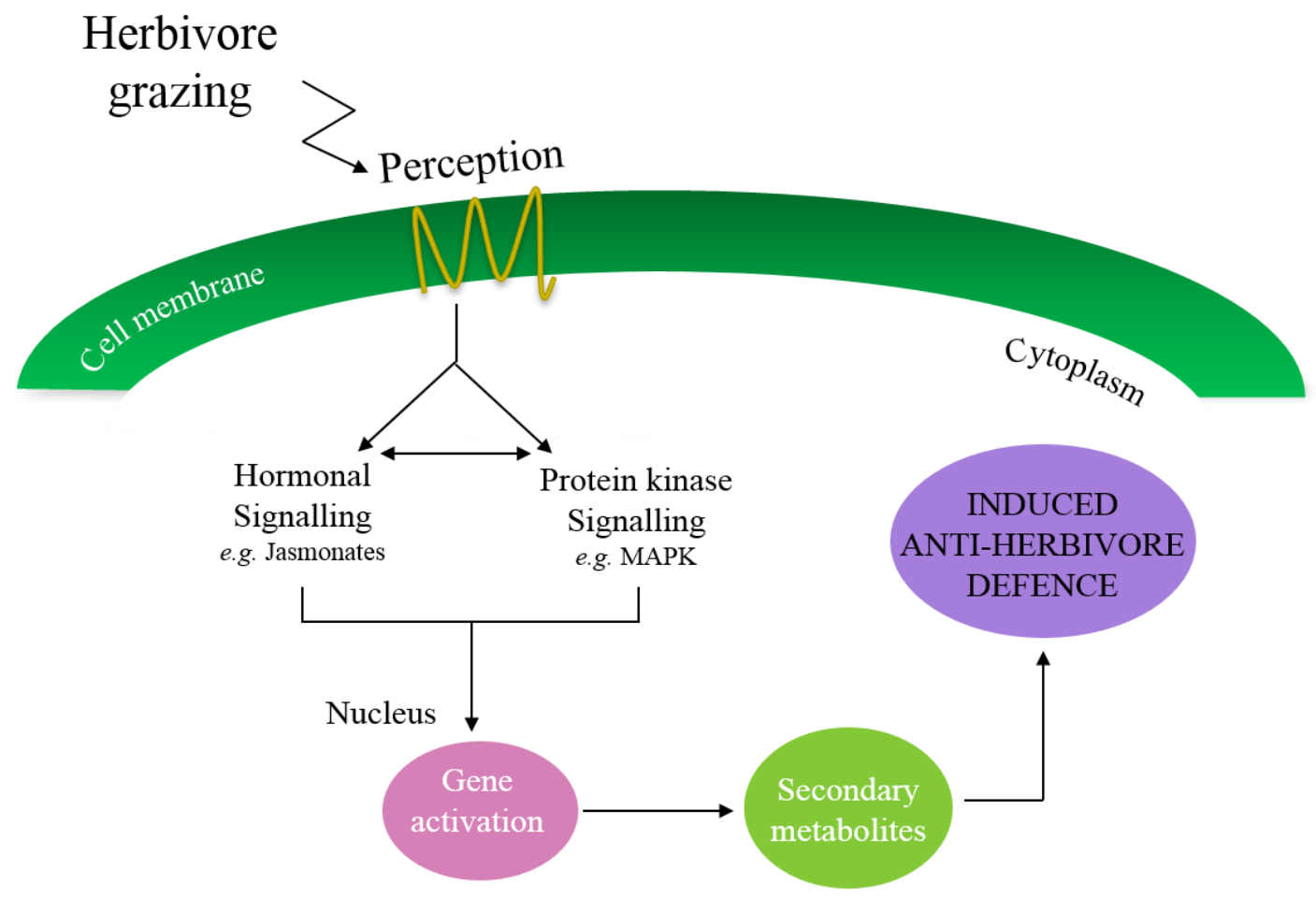

Figure 2. Mechanisms underlying the regulation of induced plant resistance against herbivore grazing. Herbivory is the combined effect of mechanical wounding and the release of specific chemical cues associated with herbivores. These chemical compounds also called "elicitors" are found, for instance, in the oral secretions of herbivores e.g. $\beta$-glucosidase and volicitin (Mattiacci et al., 1995; Turlings et al., 2000). Such compounds activate signal transduction pathways (e.g. MAPKinases) and hormonal signalling (e.g. jasmonates) that regulate the expression of different genes involved in the biosynthesis of insecticidal secondary metabolites (Bruxelles and Roberts, 2001; Wu and Baldwin, 2009; Zhang and Memelink, 2009). 


\section{Regulation of anti-fungivore resistance mechanisms}

Secondary metabolite biosynthesis in fungi appears to be as tightly regulated as secondary metabolites biosynthesis in plants (compare Fig. 1 and 2). Coordinated fungal secondary metabolite biosynthesis requires proper functioning of signal transduction pathways, epigenetic and pathway-specific activation of biosynthetic genes, as well as the activity of hormone-like compounds originated from oxylipins pathways (Figure 2). Numerous genes in some model fungi, e.g. Aspergillus, have been found to be involved in the regulation of secondary metabolite production. One of these is the laeA gene, which encodes for a methyltransferase-domain protein. This protein is part of the heterotrimeric velvet protein complex (LaeA/VeA/VelB). This complex is essential for the coordination of secondary metabolism and sexual development in the mould Aspergillus nidulans. The complex is activated by a MAPK interacting directly with VeA in the nucleus (Bayram et al., 2012, Bayram et al., 2008). VeA-VelB promotes morphological differentiation (sexual development) and, together with LaeA, co-regulates secondary metabolite formation (Bayram et al., 2008). Moreover, LaeA is also involved in forming sexual fruiting bodies, where it has been found to be required for Hülle cell development (Sarikaya Bayram et al., 2010). Hülle cells are assumed to nurse and protect the developing ascospores. While the absence of LaeA does not have severe repercussions on sexual ascospore formation, mutants that do not express laeA have reduced expression of several gene clusters that code for secondary metabolites including sterigmatocystin, aflatoxin, penicillin, lovastatin and gliotoxin. The $\Delta l a e A$ mutant is thus chemically deficient (Bok and Keller, 2004; Bok et al., 2006; Kale et al., 2008; Keller et al., 2005).

The mechanisms underlying chemical differentiation in fungi have been shown to play an important role in anti-fungivore resistance, which has been achieved by using mutant fungi in well-controlled fungus-fungivore experiments. For example, Folsomia candida (collembola) having the choice between A. nidulans wild type and the chemical deficient $\triangle l a e A$ mutant significantly preferred the mutant over the wild type (Rohlfs et al., 2007). The arthropods also achieved higher fitness on the chemical deficient mutant strains. Similar results were obtained by Trienens et al. (2010). The authors confronted D. melanogaster larvae with both, wild type and $\triangle l a e A$ chemical deficient mutant strains of A. nidulans, A. fumigatus and A. flavus. Although D. melanogaster experimental assays showed that larvae suffered generally less from the presence of the transgenic fungi compared to the wild type, striking differences were observed on larval survivals when 
exposed to A. fumigatus and A. flavus AlaeA mutants. Both strains almost killed entire larval populations after 2 and 3 days of confrontation. Additionally, authors discovered that the wt and AlaeA A. flavus had the most detrimental effects on larval survival followed by wt and AlaeA A. fumigatus and wt and AlaeA A. nidulans, where AlaeA A. nidulans enhanced larval survival compared to the wt. Therefore, the authors suggested that although LaeA is the global regulator of secondary metabolites in different fungi $\triangle l a e A$ mutants when confronted with fungivores might be able to activate alternative secondary metabolite pathways.

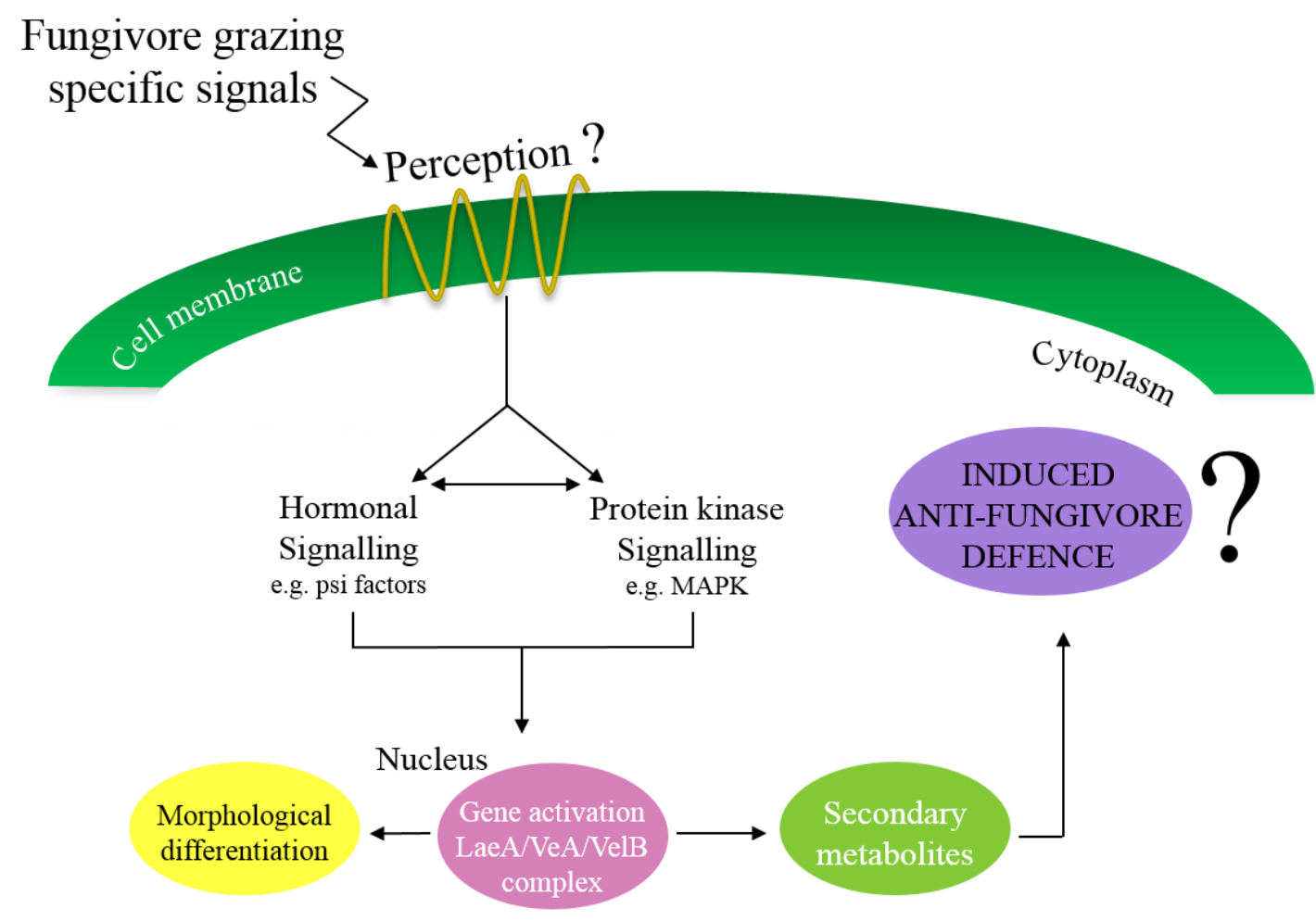

Figure 3. Scheme illustrating the mechanisms underlying the regulation of fungal secondary metabolite biosynthesis and its relationship to morphological differentiation and anti-fungivore resistance. Fungivore grazing is hypothesised to affect and to be affected by these mechanisms. Although how fungivory is perceived by the fungi is unknown, signal transduction pathways like MAPKinases (Bayram et al., 2012, Bayram et al., 2008) and hormone-like signalling psi factors have been shown to transmit environment-borne signals to the nucleus, where they interact with proteins and genes directly involved in secondary metabolite biosynthesis (Tsitsigiannis and Keller, 2006; Tsitsigiannis et al., 2004a, 2004b).

In contrast, fungivores preferred feeding on the wild type when they were offered simultaneously a mutant $A$. nidulans that over-expressed genes that regulate the formation of insecticidal compounds, such as sterigmatocystin (Yin et al., 2012). This series of studies demonstrate that variation in the ability to produce secondary metabolites has a tremendous influence on the outcome of fungi-fungivore interactions, whereas fungi 
producing a higher amount or greater diversity of secondary metabolites achieved better protection against fungivory. Therefore, fungi that are able to adjust their chemical shield in response to grazers can be expected to be better at keeping fungivore in check. Indirect evidence for such induced resistance has been provided by Stötefeld et al. (2012). The results of their study indicate that the feeding damage caused by collembolans was more evenly distributed among colonies of the wt compare to the $\Delta l a e A$. This suggests that collembolans feeding duration on individual colonies was longer on the mutant fungus. A possible explanation of the variation in feeding damage distribution would be a rapid up-regulation of fungal resistance mechanisms during grazing. Upon detection of insecticidal secondary metabolites, for example, the animals stop feeding and move to new, not yet attacked colonies. Theoretically, such a fungivore foraging response is expected to produce an even distribution of feeding damage over fungal colonies. However, when such compounds are absent, as in the AlaeA mutant, the collembola feed continually on single colonies without the need to search for alternative (non-toxic) food sources (Stötefeld et al., 2012). Despite the increasing evidence that secondary metabolites play an important role in mediating fungal resistance to fungivores, it has not been demonstrated directly whether fungi have the ability to enhance anti-fungivore resistance in response to grazing.

\section{Different fungivores may induce different fungal responses}

Many mechanistic aspects related to anti-fungivore resistance remain totally unknown. These aspects need to be resolved for a better understanding of fungal dynamics in ecosystems since they are involved in numerous interactions. For instance, it is unknown whether different fungivores induce different fungal responses, as it has been shown to be the case in plant-herbivore interactions (Walling, 2000).

The extent of damage caused by herbivores/fungivores is a major feature of speciesspecific grazing. In herbivore-plant interactions, high densities of herbivores produce intense feeding damage that may suppress plant defence. Suppressing host plant defence by such feeding damage may explain the positive correlation between herbivore density and fitness (Hambäck, 2010).

A similar phenomenon has already been described for collembolan grazing on A. nidulans. Groups of collembola that were found to cause greater feeding damage, had 
higher growth rates per capita than those that were feeding as isolated individuals (Stötefeld et al. 2012). The authors suggested that the strong feeding damage suppresses the fungus' ability to launch an efficient defence response in seriously damaged colonies down-regulating the inducible resistance mechanisms. In this thesis, this idea was tested by quantifying changes of candidate gene expression in $A$. nidulans colonies affected by a varying degree of feeding damage caused by individual isopods, Oniscus asellus. Strong inter-individual feeding activity leads to a broad range of damage variation, so that variation in animal density was excluded as a confounding factor. Variation in fungivore feeding damage to be a factor that affects fungal resistance as determined by the expression of candidate genes involved in secondary metabolite biosynthesis was expected.

\section{Fungal allelopathy plays a role in fungi-fungivore interactions}

Fungus-fungivore interactions are not merely bipartite but may be affected by interactions with other microbes such as fungal chemical interference competition, a phenomenon commonly known as allelopathy (Begon et al., 2006).

Allelopathy appears to be quite common in decomposer systems and may affect the ability of fungi to launch an efficient anti-fungivore defence, which in turn can be expected to have an immediate impact on fungus-feeding animals. Drosophila fruit flies are associated with mutualistic yeasts that are well known to produce primary and secondary metabolites with antifungal activity that affect detrimentally mould growth (Zhang et al., 2012; Calvo et al., 2003; Droby et al., 2002; Chan and Tian, 2005; Scherm et al., 2003; Spadaro et al., 2002; Wilson et al., 1993). In this chapter, it was hypothesized that fungal allelopathy has a detrimental effect on anti-fungivore resistance which helps the larvae to cope better with the mould's chemical defence.

To test this hypothesis co-cultivation experiments comprising A. nidulans and the yeast Saccharomyces cerevisiae were conducted. The effect of yeast volatiles on anti-fungivore resistance were investigated on the organismic, genetic and biochemical level. It was then tested whether exposing $A$. nidulans to yeast volatiles altered D. melanogaster development in order to elucidate whether fungal allelopathy positively influence larval development. 


\section{Overview}

This thesis focuses on inducible anti-fungivore defence in A. nidulans when the fungus is exposed to different interkingdom interactions. Chapter 2 investigates whether the grazing of $D$. melanogaster larvae induces anti-fungivore defence in the mould A. nidulans. Chapter 3 explores the inducible anti-fungivore defence in A. nidulans related to feeding damage variation by isopods. Chapter $\mathbf{4}$ addresses how inducible antifungivore resistance of $A$. nidulans is affected by fungal allelopathy and what the consequences are D. melanogaster development.

Chapter 2. Anti-fungivore defence is thought to be mediated by insecticidal secondary metabolites. Different studies have shown the role of such compounds in mediating resistance against fungivores, however, it remains unknown whether the grazing of fungivores induces the anti-fungivore defence in moulds. To test for an inducible antifungivore defence, A. nidulans was exposed to the grazing of D. melanogaster larvae. Quantitative Real-Time Reverse Transcription PCR analyses of various fungal candidate genes were coupled with quantification of both insect and fungal fitness. This study provides first evidence that insect grazing induces anti-fungivore resistance which is accompanied by a substantial shift in the fungus's transcriptome. Functional analyses of $\Delta$ laeA A. nidulans mutants verified the central role of epigenetic regulation of chemical diversity in determining the capacity of the mould to resist grazing.

Chapter 3. It has previously been suggested that strong feeding damage may suppress the mechanisms of anti-fungivore resistance in A. nidulans. In this chapter, on the level of gene expression, the anti-fungivore response of A. nidulans to feeding damage variation produced by Oniscus asellus was studied. It was expected that severe feeding damage suppresses or even down-regulates the anti-fungivore defence of A. nidulans. RNA analyses were employed to quantify the expression levels of candidate genes involved in the regulation of the anti-fungivore resistance. The results of this chapter present first evidence that the intense feeding damage can lead to down-regulation of $A$. nidulans anti-fungivore defence.

Chapter 4. Chemical interference competition, allelopathy, has been shown to affect detrimentally the fitness of filamentous fungi. The first aim of this chapter was to study the effect of fungal allelopathy on the molecular genetic and biochemical mechanisms of the anti-fungivore defence of $A$. nidulans. The second aim was to explore the consequence 
of fungal allelopathy for the grazing success of $D$. melanogaster larvae. By quantifying the biochemical, molecular genetic and organismic dynamics of the tripartite fungusfungus-insect interaction it turned out that yeast volatile organic compounds substantially influenced the morphological and chemical phenotype of A. nidulans. Importantly, yeast allelochemicals inactivated the inducible resistance of the mould, which turned the fatal fungus into a suitable food source on which the larvae were able to develop into adult flies. 


\section{References}

Agrawal., A.A., Karban., R., 1999. Why induced defenses may be favored over constitutive, in: The ecology and evolution of inducible defenses. pp. 45-61.

Bayram, Ö., Bayram, Ö.S., Ahmed, Y.L., Maruyama, J.-I., Valerius, O., Rizzoli, S.O., Ficner, R., Irniger, S., Braus, G.H., 2012. The Aspergillus nidulans MAPK module AnSte11-Ste50Ste7-Fus3 controls development and secondary metabolism. PLoS Genet. 8, e1002816.

Bayram, Ö., Krappmann, S., Ni, M., Bok, J.W., Helmstaedt, K., Yu, J., Braus, G.H., 2008. VelB/VeA/LaeA complex coordinates light signal with fungal development and secondary metabolism. Science. 320, 1504-1506.

Begon, M., Townsend, C.R., Harper, J.L., 2006. Ecology: From Individuals to Ecosystems. $4^{\text {th }}$ Edition. Wiley-Blackwell, Oxford.

Bok, J.W., Keller, N.P., 2004. LaeA, a regulator of secondary metabolism in Aspergillus spp. Eukaryot. Cell 3, 527-535.

Bok, J.W., Noordermeer, D., Kale, S.P., Keller, N.P., 2006. Secondary metabolic gene cluster silencing in Aspergillus nidulans. Mol. Microbiol. 61, 1636-1645.

Böllmann, J., Elmer, M., Jens, W., Raidl, S., Reinhard, F.H., 2010. Defensive strategies of soil fungi to prevent grazing by Folsomia candida (Collembola). Pedobiologia. 53, 107-114.

Bruxelles, Guy L., Roberts, M.R., 2001. Signals regulating multiple responses to wounding and herbivores. Crit. Rev. Plant Sci. 20, 487-521.

Calvo, J., Calvente, V., Orellano, M.E. de, Benuzzi, D., Tosetti, M.I.S. de, 2003. Improvement in the biocontrol of postharvest diseases of apples with the use of yeast mixtures. BioControl 48, 579-593.

Chan, Z., Tian, S., 2005. Interaction of antagonistic yeasts against postharvest pathogens of apple fruit and possible mode of action. Postharvest Biol. Technol. 36, 215-223.

Cipollini, D.F., Heil, M., 2010. Costs and benefits of induced resistance to herbivores and pathogens in plants. CAB Rev. Perspect. Agric. Vet. Sci. Nutr. Nat. Resour. 5, 1-25.

Droby, S., Vinokur, V., Weiss, B., Cohen, L., Daus, a, Goldschmidt, E.E., Porat, R., 2002. Induction of resistance to Penicillium digitatum in grapefruit by the yeast biocontrol agent Candida oleophila. Phytopathology 92, 393-9.

Gatehouse, J.A., 2002. Plant resistance towards insect herbivores: a dynamic interaction. New Phytol. 156, 145-169.

Hambäck, P.A., 2010. Density-dependent processes in leaf beetles feeding on purple loosestrife: aggregative behaviour affecting individual growth rates. Bull. Entomol. Res. 100, 605-11.

Harvell, D.C., 1990. The Ecology ad Evolution of Inducible Defenses. Chicago Journals 65, 323340.

Howe, G.A., Schaller, A., 1995. Direct defenses in plants and their induction by wounding and insect herbivores, in: Fungal Ecology. pp. 7-29. 
Kale, S.P., Milde, L., Trapp, M.K., Frisvad, J.C., Keller, N.P., Woo, J., 2008. Requirement of LaeA for secondary metabolism and sclerotial production in Aspergillus flavus. Fungal Genet. Biol. 45, 1422-1429.

Karban, R., Agrawal, A.A., Thaler, J.S., Adler, L.S., 1999. Induced plant responses and information content about risk of herbivory. Trends Ecol. Evol. 14, 443-447.

Karban, R., Baldwin, I.T., 1997. Induced Responses to Herbivory. Chicago: University of Chicago Press.

Keller, N.P., Turner, G., Bennett, J.W., 2005. Fungal secondary metabolism-from biochemistry to genomics. Nat. Rev. Microbiol. 3, 937-47.

Mattiacci, L., Dicke, M., Posthumust, M.A., 1995. B-Glucosidase: An elicitor of herbivoreinduced plant odor that attracts host-searching parasitic wasps. Proc. Natl. Acad. Sci. USA 92, 2036-2040.

Nakamori, T., Suzuki, A., 2007. Defensive role of cystidia against Collembola in the basidiomycetes Russula bella and Strobilurus ohshimae. Br. Mycol. Soc. 111, 1345-1351.

Rohlfs, M., Albert, M., Keller, N.P., Kempken, F., 2007. Secondary chemicals protect mould from fungivory. Biol. Lett. 3, 523-5.

Sarikaya Bayram, O., Bayram, O., Valerius, O., Park, H.S., Irniger, S., Gerke, J., Ni, M., Han, K.-H., Yu, J.-H., Braus, G.H., 2010. LaeA control of velvet family regulatory proteins for light-dependent development and fungal cell-type specificity. PLoS Genet. 6, e1001226.

Scherm, B., Ortu, G., Muzzu, A., Budroni, M., Arras, G., Migheli, Q., 2003. Biocontrol activity of antagonistic yeasts against Penicillium expansum on apple. J. Plant Pathol. 85, 205-213.

Spadaro, D., Vola, R., Piano, S., Gullino, M.L., 2002. Mechanisms of action and efficacy of four isolates of the yeast Metschnikowia pulcherrima active against postharvest pathogens on apples. Postharvest Biol. Technol. 24, 123-134.

Spiteller, P., 2008. Chemical defence strategies of higher fungi. Chemistry 14, 9100-9110.

Sticher, L., Mauch-Mani, B., Métraux, A.J., 1997. Systemic acquired resistance. Annu. Rev. Phytopathol. 35, 235-270.

Stötefeld, L., Scheu, S., Rohlfs, M., 2012. Fungal chemical defence alters density-dependent foraging behaviour and success in a fungivorous soil arthropod. Ecol. Entomol. 37, 323329.

Tanney, J.B., Hutchison, L.J., 2012. The production of nematode-immobilizing secretory cells by Climacodon septentrionalis. Mycosciencie 53, 31-35.

Trienens, M., Keller, N.P., Rohlfs, M., 2010. Fruit, flies and filamentous fungi - experimental analysis of animal - microbe competition using Drosophila melanogaster and Aspergillus mould as a model system. Oikos 119, 1765-1775.

Trienens, M., Rohlfs, M., 2012. Insect-fungus interference competition-The potential role of global secondary metabolite regulation, pathway-specific mycotoxin expression and formation of oxylipins. Fungal Ecol. 5, 191-199. 
Tsitsigiannis, D.I., Keller, N.P., 2006. Oxylipins act as determinants of natural product biosynthesis and seed colonization in Aspergillus nidulans. Mol. Microbiol. 59, 882-92.

Tsitsigiannis, D.I., Kowieski, T.M., Zarnowski, R., Keller, N.P., 2004a. Endogenous Lipogenic Regulators of Spore Balance in Aspergillus nidulans. Eukaryot. Cell 3, 1398-1411.

Tsitsigiannis, D.I., Zarnowski, R., Keller, N.P., 2004b. The lipid body protein, PpoA, coordinates sexual and asexual sporulation in Aspergillus nidulans. J. Biol. Chem. 279, 11344-53.

Turlings, T.C.J., Alborn, H.T., Loughrin, J.H., Tumlinson, J.H., 2000. Volicitin, an elicitor of maize volatiles in oral secretion of Spodoptera exigua: Isolation and bioactivity. J. Chem. Ecol. 26, 189-202.

Walling, L., 2000. The myriad plant responses to herbivores. J. Plant Growth Regul. 19, 195216.

Wasternack, C., 2007. Jasmonates: an update on biosynthesis, signal transduction and action in plant stress response, growth and development. Ann. Bot. 100, 681-97.

Wilson, C.L., Wisniewski, M.E., Droby, S., Chalutz, E., 1993. A selection strategy for microbial antagonists to control postharvest diseases of fruits and vegetables. Sci. Hortic. 53, 183189.

Wu, J., Baldwin, I.T., 2009. Herbivory-induced signalling in plants: perception and action. Plant. Cell Environ. 32, 1161-74.

Yin, W., Amaike, S., Wohlbach, D.J., Gasch, A.P., Chiang, Y., Wang, C.C., Bok, J., Rohlfs, M., Keller, N.P., 2012. An Aspergillus nidulans bZIP response pathway hardwired for defensive secondary metabolism operates through aflR. Mol. Microbiol. 83, 1024-1034.

Zhang, D., Spadaro, D., Valente, S., Garibaldi, A., Lodovica, M., 2012. Cloning, characterization, expression and antifungal activity of an alkaline serine protease of Aureobasidium pullulans PL5 involved in the biological control of postharvest pathogens. Int. J. Food Microbiol. 153, 453-464.

Zhang, H., Memelink, J., 2009. Regulation of secondary metabolism by jasmonate hormones. Springer US, New York, NY.

Zhao, J., Davis, L.C., Verpoorte, R., 2005. Elicitor signal transduction leading to production of plant secondary metabolites. Biotechnol. Adv. 23, 283-333. 


\section{Part II.}

Research chapters 


\section{Chapter 2}

\section{Induced fungal resistance to insect}

grazing: reciprocal fitness consequences and fungal gene expression in the DrosophilaAspergillus model system

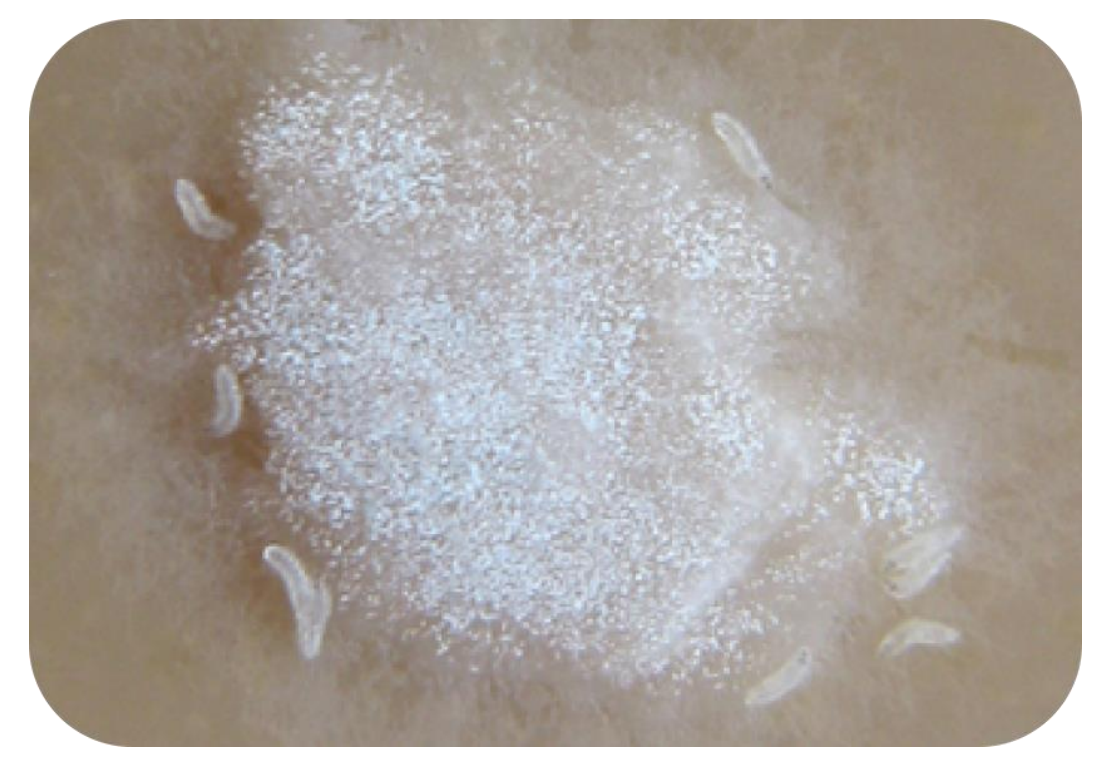

Published in:

Silvia Caballero Ortiz, Monika Trienens, Marko Rohlfs, 2013. Induced fungal resistance to Insect Grazing: Reciprocal Fitness Consequences and Fungal Gene Expression in the Drosophila-Aspergillus Model System. PLOS ONE. 8, e74951 


\begin{abstract}
Fungi like other organisms, frequently suffer interkingdom interactions, e.g. predation. In consequence, they have evolved physical and chemical resistance traits that may impair or repel predators. Chemical defence in fungi is thought to be mediated by fungal secondary metabolites. Some of them have been tested against different organisms, however, these assays do not reveal whether these compounds are indeed synthesized by fungi as an inducible anti-fungivore defence. Therefore, the aim of this work was to study the inducible anti-fungivore defence on fungi when exposed to grazing by means of changes at the transcriptome level. To investigate this, Aspergillus nidulans was exposed to the grazing of Drosophila melanogaster larvae. After larval grazing there were significant changes in the expression levels of several genes involved in secondary metabolism (e.g. laeA), signal transduction and oxylipin biosynthesis, which indicates the activation of anti-fungivore resistance mechanisms. Furthermore, Drosophila larvae exposed to previously grazed A. nidulans colonies died significantly earlier than larvae exposed to unchallenged colonies. Larvae developed normally when they fed on the chemical deficient mutant that lacks the global secondary metabolite regulator, LaeA, and hence the ability to produce several toxic compounds. This study therefore demonstrates that fungi have the potential to enhance anti-fungivore resistance in response to earlier grazing, which allows them to maintain high fitness in fungivore rich niches.
\end{abstract}




\section{Introduction}

Fungi, as non-mobile organisms, are highly vulnerable to predation. As a consequence, fungi have evolved physical and chemical traits that mediate resistance against fungivory (Spiteller, 2008; Tanney and Hutchison, 2012). Chemical compound-based antifungivore resistance has been suggested to be mediated by insecticidal secondary metabolites as the lack of such compounds in mutant fungi enhanced fungivore fitness (Rohlfs et al., 2007). Moreover, numerous pharmaceutical assays have revealed detrimental effects of such compounds against several insect species (Castillo et al., 1999; Ondeyka et al., 2003; Paz et al., 2011). However, the results of these assays do not show whether chemical compounds-based resistance is induced by the presence of fungivores, or whether they are synthesized constitutively regardless of fungivore presence.

Regulation of fungal secondary metabolism is complex and involves several molecular pathways e.g. signal transduction, gene transcription regulation and hormonal signalling (Bayram et al., 2012; Brakhage, 2013; Tsitsigiannis and Keller, 2006). Before secondary metabolites can be synthesized, several essential genes have to be transcribed. One of these genes is called laeA (Bok and Keller, 2004). The laeA gene codes for the methyltransferase protein LaeA that is thought to contribute to the epigenetic control of secondary metabolite biosynthesis in A. nidulans as well as in many other filamentous fungi (Kosalková et al., 2009). This protein is of particular interest because, together with two of the velvet proteins, VeA and VelB, it forms the heterotrimeric velvet protein complex (LaeA/VeA/VelB) that coordinates secondary metabolite formation (Bayram et al., 2008). This complex is essential for the frequently observed synchronisation of secondary metabolism and sexual development in A. nidulans (Bayram and Braus, 2012; Bayram et al., 2008). Interestingly, the presence of this complex has been demonstrated in different filamentous fungi as well e.g. Fusarium and Penicillium (Hoff et al., 2010; López-berges et al., 2013).

The velvet complex is activated by a mitogen-activated protein kinase (MpkB), which directly interacts with VeA in the nucleus (Bayram et al., 2012). These proteins (MAPKinases) receive the signals from G-protein coupled receptors that perceive external environmental stimuli. Together with MAPKinases, oxylipins, polyunsaturated fatty acids produced by the activity of dioxygenase enzymes coded by the so-called ppo genes, might also be involved in this signalling (Affeldt et al., 2012; Tsitsigiannis and Keller., 2007). 
If grazing by fungivores induces changes in anti-fungivore resistance of a mould, these changes can be expected to be detectable on the level of transcription variation, which affects those genes that encode for the different molecular pathways underlying the regulation and biosynthesis of insecticidal secondary metabolites (Figure 1).

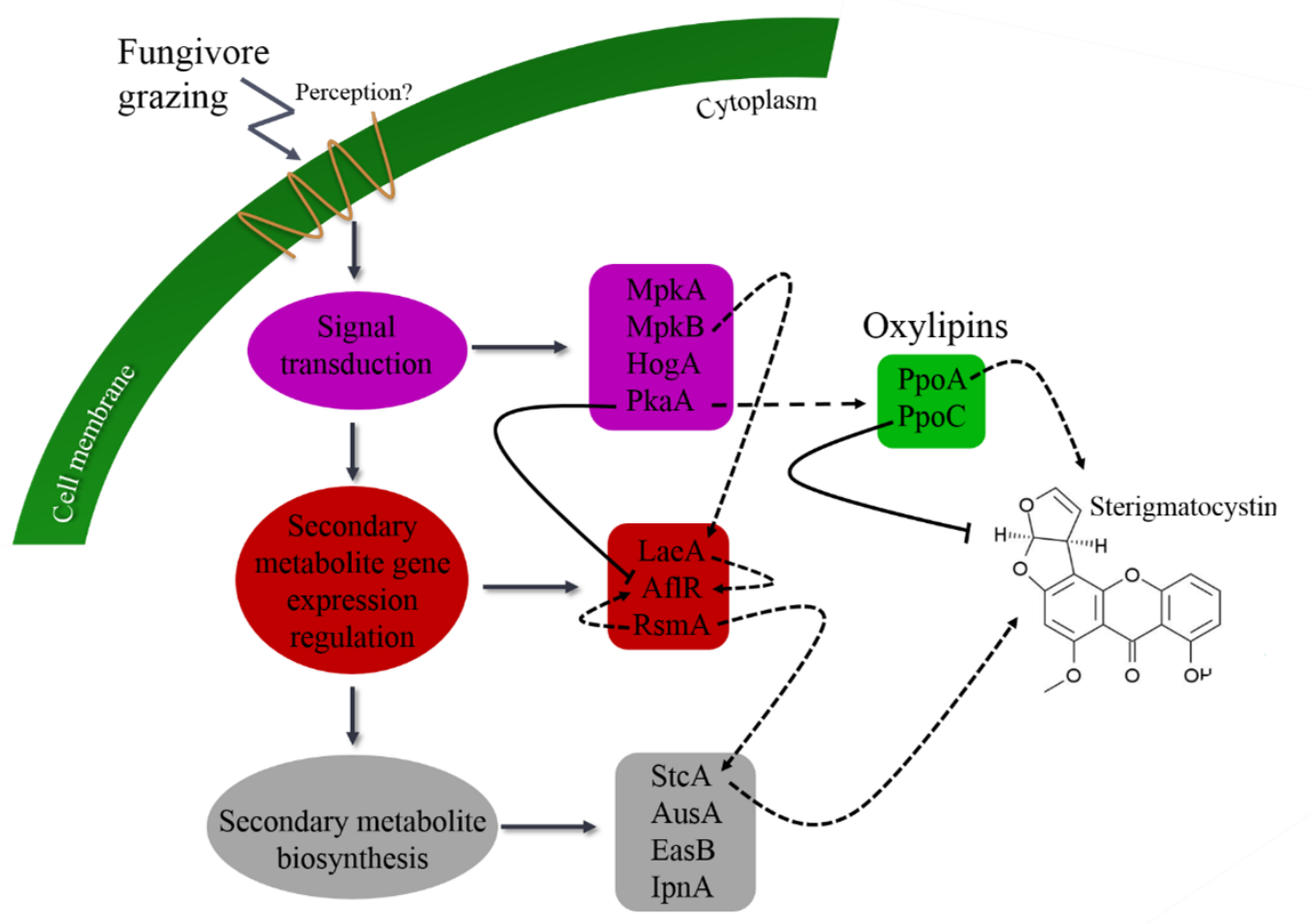

Figure 1. Mechanisms underlying the regulation and biosynthesis of sterigmatocystin, a fungal secondary metabolite. Colours represent the different molecular "modules" involved in the A. nidulans phenotype. Violet represents signal transduction (MpkA), dark red represents transcription regulation (LaeA), grey represents secondary metabolite biosynthesis (StcA) and green represent oxylipin formation (PpoA). GPCRs receptors transmit the extracellular stimulus through protein kinases. Mitogen-activated proteins are involved in signal transduction e.g. MpkA, MpkB, HogA and PkaA. The MpkB positively influence mycotoxin biosynthesis because it interacts with VeA in the nucleus activating the velvet complex, complex that coordinates secondary metabolite biosynthesis in A. nidulans (Bayram et al., 2008). The PkaA protein negatively affects mycotoxins production by negatively regulating AflR, a pathwayspecific transcription factor for sterigmatocystin biosynthesis. Moreover, the protein kinase PkaA appears to regulate the ppoA, $C$ genes. These genes code for the fatty acid oxygenases predicted to produce oxylipins. Oxylipins could be ligands of cell surface receptors activating downstream signalling cascades (Affeldt et al., 2012; Tsitsigiannis and Keller., 2007). They are involved in the regulation of sexual and asexual development and secondary metabolism in moulds of the genus Aspergillus (Bayram and Braus, 2012; Brakhage, 2013; Fernandes et al., 1998).

Notably, several studies have shown that some of the mechanisms regulating fungal chemical diversity play an important role in anti-fungivore resistance. Differences in insect response have been observed by exposing the insects to A. nidulans wild type and to chemical deficient mutants. These differences, mainly based on insect fitness, demonstrate that fungal secondary metabolites mediate resistance against fungivores. For 
example, a $\triangle l a e A$ mutant that lacks the expression of several secondary metabolites, (Bok and Keller, 2004), was preferred by Folsomia candida (Collembola) over the wild type fungus (Rohlfs et al., 2007). Moreover, the collembola also achieved higher fitness on the chemical deficient mutant strains. Likewise, a greater proportion of D. melanogaster larvae developed into adults on such chemical deficient mutants of several Aspergillus species (Trienens et al., 2010). The A. nidulans $\Delta v e A$ mutant lacks veA gene. Like LaeA, $\mathrm{VeA}$ is also required for the synthesis of secondary metabolites as both proteins together with VelB form the velvet complex. Survival assays revealed that the A. nidulans $\Delta v e A$ mutant caused minor mortality effects in D. melanogaster larvae relative to the wt. Moreover, A. nidulans $\triangle p p o B$, mutant lacking the $p p o B$ gene coding for the fatty acid oxygenase involved in suppressing mycotoxin synthesis (Tsitsigiannis and Keller, 2006) caused higher larval mortality relative to the wild type. These findings directly link both proteins VeA and PpoB with the anti-fungivore resistance (Trienens and Rohlfs, 2012).These studies thus provide genetic evidence for the often suggested role of fungal secondary metabolites in mediating resistance against fungivores (Rohlfs et al., 2007; Trienens and Rohlfs, 2012; Trienens et al., 2010). However, it is still unknown whether the anti-fungivore resistance is induced by fungivory.

Saprophagus insects like Drosophila develop on decaying plant tissue where they interact with antagonistic and mutualistic fungi. Importantly, Drosophila flies play an important role as a vector dispersing unicellular yeast to new patches (Gilbert, 1980). This is of particular interest since yeast have only limited spore dispersal. Once yeasts have reached the new habitat, they grow rapidly and become an essential food source for the developing fly larvae (Stamps et al., 2012). In contrast, moulds are able to rich new patches by wind dispersion of conidia (asexual spore-like structures). Additionally, it is likely that Drosophila flies may contribute as well to dispersing filamentous fungi e.g. Aspergillus, Botrytis, and Penicillium to the D. melanogaster breeding sites (Batta, 2006; Louise et al., 1995).

Interestingly, moulds generally have a negative impact on Drosophila larval development. The severity of this impact is determined by insect density, fungal species or fungal toxins (Hodge et al., 1999; Rohlfs et al., 2005a). Once moulds have invaded the larval habitat, they negatively affect larval fitness by increasing pre-adult mortality or seriously impairing the reproductive capabilities of those individuals that were able to develop into adult flies (Wölfle et al., 2009). Even though moulds have this detrimental 
effect on the larvae, the insects are frequently found grazing on mould colonies (Rohlfs, 2005b) (Figure 2). This phenomenon is probably due to a broad overlap of larvae being attracted by volatile organic compounds produced by both insect mutualistic yeast and antagonistic mould (Stötefeld, 2014). Nevertheless, despite the damage produced by the larvae, Aspergillus moulds appear to recover rapidly from the insect attack (Trienens et al., 2010).

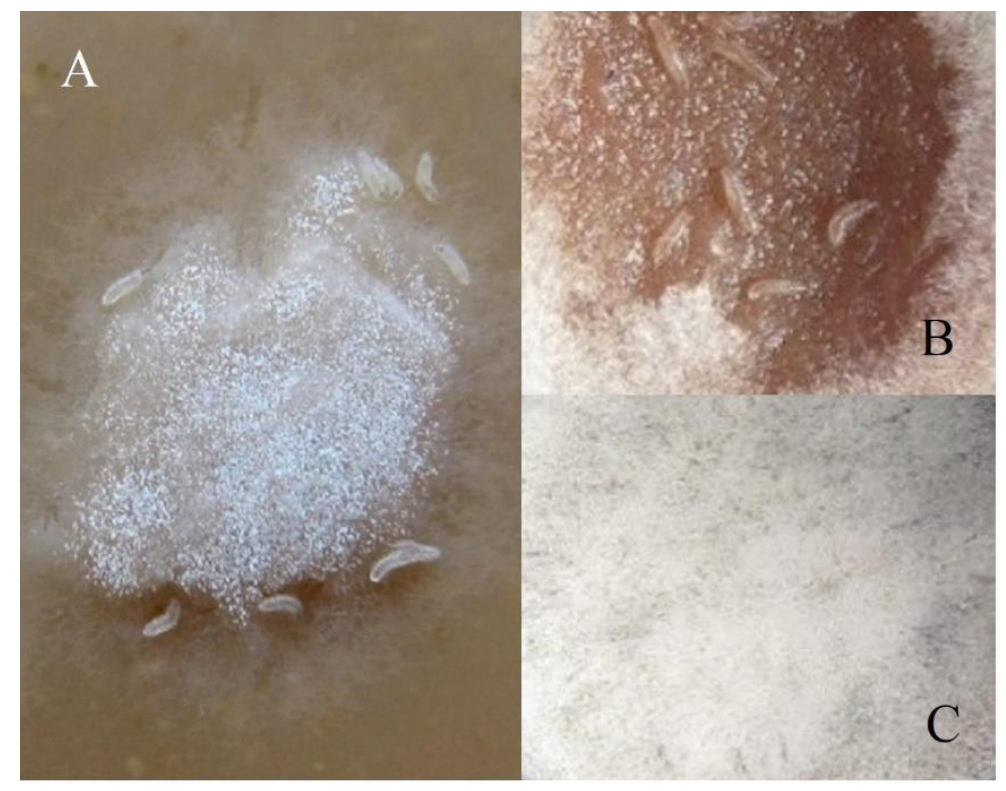

Figure 2. Drosophila melanogaster larvae grazing on A. nidulans colony. (A) D. melanogaster larvae are attracted to A. nidulans colonies. (B) D. melanogaster larvae eradicating hyphal tissue from an A. nidulans colony. (C) Fungal growth under undisturbed conditions. Images were taken after 72 hours of fungal incubations at $25^{\circ} \mathrm{C}$ on nutrient-poor fruit agar. Arena diameter: $10 \mathrm{~mm}$.

In this context, two novel suggestions were addressed in this chapter; (i) larval aggregation on mould colonies is an adaptive feeding response to extract essential nutrients from fungal tissue on an otherwise nutrient-poor fruit substrate. However, the ability of moulds to produce efficient insecticidal secondary metabolites confers strong resistance to fungivores and this negatively affects larval fitness (ii). Because larvae fitness is heavily affected when feeding on hyphae, it was hypothesized that moulds are able to enhance their anti-fungivore resistance by shifting their phenotype to a more resistant one that seriously impairs $D$. melanogaster larvae. In order to generate such a resistance phenotype, changes in the expression levels of different genes are required. Therefore, the expression levels of genes coding for proteins that positively influence the synthesis of insecticidal secondary metabolites are hypothesized to be up-regulated e.g. laeA. Whereas genes coding for proteins that negatively affect mycotoxin biosynthesis are expected to be down-regulated (Table 1). 
Table 1.

Genes potentially involved in the inducible anti-fungivore defence of Aspergillus nidulans against Drosophila melanogaster larva.

\begin{tabular}{|c|c|c|c|}
\hline Gene & Protein-Function & Biological Process & $\begin{array}{c}\text { Hypothesized } \\
\text { expression changes }\end{array}$ \\
\hline \multicolumn{4}{|c|}{ Signal transduction } \\
\hline$m p k A$ & MAP Kinase & $\begin{array}{l}\text { Cell wall integrity signalling, } \\
\text { polarized growth }\end{array}$ & $?$ \\
\hline$m p k B$ & MAP Kinase & $\begin{array}{l}\text { Coordination of development } \\
\text { and secondary metabolism }\end{array}$ & Up-regulation \\
\hline $\operatorname{hog} A$ & MAP Kinase & $\begin{array}{l}\text { Osmotic stress response, sexual } \\
\text { development and sporulation }\end{array}$ & $?$ \\
\hline pkaA & Protein Kinase & $\begin{array}{l}\text { Conidiation, and secondary } \\
\text { metabolite regulation }\end{array}$ & Down-regulation \\
\hline \multicolumn{4}{|c|}{ Regulation of gene transcription } \\
\hline laeA & $\begin{array}{l}\text { Methyltransferase- } \\
\text { domain protein }\end{array}$ & $\begin{array}{l}\text { Chromatin remodelling, control } \\
\text { of development and secondary } \\
\text { metabolism }\end{array}$ & Up-regulation \\
\hline aflR & $\begin{array}{l}\text { C6 transcriptional } \\
\text { activator }\end{array}$ & $\begin{array}{l}\text { Regulation of sterigmatocystin } \\
\text { pathway gene expression }(e . g . \\
\text { stcA) }\end{array}$ & Up-regulation \\
\hline$r m s A$ & $\begin{array}{l}\text { bZIP transcription } \\
\text { factor, binds to aflR } \\
\text { promotor region }\end{array}$ & $\begin{array}{l}\text { Regulation of sterigmatocystin } \\
\text { pathway gene expression }\end{array}$ & Up-regulation \\
\hline \multicolumn{4}{|c|}{ Oxylipin signalling } \\
\hline ppoA & Fatty acid dioxygenase & $\begin{array}{l}\text { Oxylipin synthesis, sexual } \\
\text { development, secondary } \\
\text { metabolite regulation }\end{array}$ & Up-regulation \\
\hline ppoC & Fatty acid oxygenase & $\begin{array}{l}\text { Oxylipin synthesis, asexual } \\
\text { development, secondary } \\
\text { metabolite regulation }\end{array}$ & Down-regulation \\
\hline \multicolumn{4}{|c|}{ Secondary metabolite biosynthetic genes } \\
\hline stcA & Polyketide synthase & Sterigmatocystin biosynthesis & Up-regulation \\
\hline ausA & Polyketide synthase & $\begin{array}{l}\text { Austinol and dehydroaustinol } \\
\text { biosynthesis }\end{array}$ & $?$ \\
\hline easB & Polyketide synthase & Emericellamides Biosynthesis & $?$ \\
\hline ipnA & $\begin{array}{l}\text { Isopenicillin-N } \\
\text { synthase }\end{array}$ & Penicillin biosynthesis & $?$ \\
\hline
\end{tabular}

This chapter shows first data indicating that the grazing of D. melanogaster enhances the anti-fungivore resistance of $A$. nidulans. The inducible defence of $A$. nidulans was confirmed by substantial changes in the expression levels of several genes involved in signalling, oxylipin biosynthesis, and secondary metabolite regulation.

\section{Material and methods}

\subsection{Culture of organisms and experimental conditions}

The D. melanogaster culture used in the experiments originated from 113 isofemale lines caught in Kiel, Germany, in 2006. Cultivation and generation of sterile larvae followed 
standard methods (Trienens et al., 2010). A banana-agar medium (50\% mashed banana/50\% demineralised water, v/v) (Anagnostou et., 2010) was used for all the experiments except for the gene expression assays.

The A. nidulans strains used in the experiments were a wild type (RDIT 2.3) and a chemical deficient $\Delta l a e A$ mutant (RJW 46.4). Both have the same veAl genetic background (Bok and Keller, 2004). Cultivation of fungi and conidia for all the experiments follow published protocols (Trienens et al., 2010). Briefly, A. nidulans was cultured on sterilised malt extract agar medium (MEA) (9 g malt, $1.5 \mathrm{~g}$ peptone and $6 \mathrm{~g}$ agar in $300 \mathrm{ml}$ deionised water) at $25^{\circ} \mathrm{C}$ and constant darkness. After 7 days, time enough to get mature conidia (asexually produced spores), the conidia were scraped off with a sterilized scoop into $5 \mathrm{ml}$ of autoclaved ringer solution $(2.58 \mathrm{~g} \mathrm{NaCl}, 90 \mathrm{mg} \mathrm{CaCl}, 105$ $\mathrm{mg} \mathrm{KCl}$ in $300 \mathrm{ml}$ deionised water) containing the surfactant Tween 80 (0.1\%). A haemocytometer (Neubauer Improved) was used to count and subsequently adjust the suspension to a titre of 1000 conidia per $\mu 1$ for organismic experiments and 10,000 conidia per $\mu l$ for gene expression experiments. Conidia suspensions were not kept longer than 2 weeks at $4^{\circ} \mathrm{C}$.

\subsection{Insect-induced resistance to fungivory}

To test whether D. melanogaster larvae induce resistance in A. nidulans, the survival of larvae was compared when insect were exposed to untouched control colonies and to colonies previously challenged with conspecific larvae. For this test, $2 \mathrm{ml}$ microtubes filled with banana agar were inoculated with wild type $A$. nidulans conidia (Anagnostou et al, 2010; Trienens et al., 2010). After 24 hours incubation a single larva was added to each tube. These larvae were removed after a further 24 hours and replaced by a new one. At the same time, larvae were added to unchallenged colonies. In addition, the survival of individual larvae in fungal free substrate under two treatments was recorded. One treatment was without previous feeding by conspecific larvae and the other with previous feeding. To test whether physical damage alone is sufficient to induce resistance in A. nidulans independently of larval foraging, a wounding treatment was included. For this, 36 hours after inoculation with conidia, the hyphal mats were touched four times with autoclaved needles to produce marks resembling the "feeding marks" left by larvae (Figure 3). 

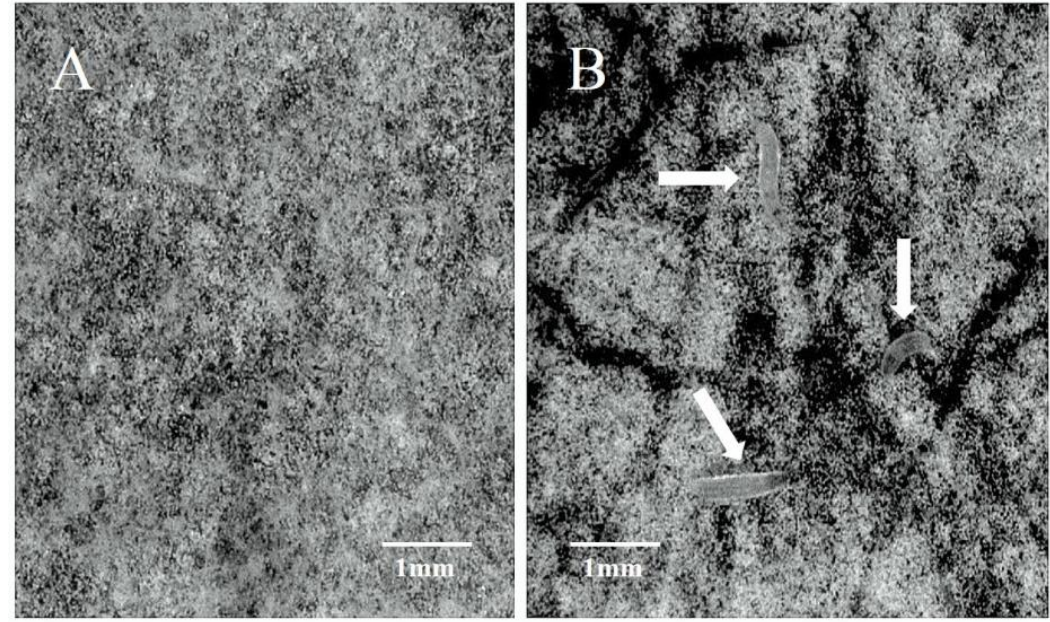

Figure 3. Effect of 20 hours $D$. melanogaster larval grazing on $\mathbf{4 8}$ hours old colony of $A$. nidulans compare to an A. nidulans unchallenged control colony. Thick hyphal mat of undisturbed A. nidulans (A) compared to larval damage (dark tracks) (B). Arrows point at the D. melanogaster larvae. Images were taken with stereomicroscope, Discovery V8, Zeiss, Germany, equipped with a digital camera system, AxioCam Icc1, Zeiss, Germany.

Twelve hours later larvae were added. It was then recorded whether larvae were alive or dead every day for a maximum of 14 days after inoculation.

\subsection{Larval grazing on wild type and chemical deficient Aspergillus nidulans}

Experimental units containing wild type or chemical deficient AlaeA A. nidulans of different age were prepared (Anagnostou et al., 2010; Trienens et al., 2010). Fungal age at larval transfer was manipulated in order to provide different amounts of fungal tissue for the larvae. Ten first-instar larvae were added to each experimental unit and the unit was then sealed with a sterile cotton plug. In parallel, a mould-free control treatment and a treatment with yeast, Saccharomyces cerevisiae (Anagnostou et., 2010), were set up. There were $n=200$ replicates in total with $n=20$ replicates for each treatment. The number of emerging flies was counted and the time was recorded (days after larval transfer) when the flies eclosed from their puparia. Following established protocols (Trienens et al., 2010), mould growth was quantified by image analysis at 24, 48 and 72 hours after the introduction of larvae.

\subsection{Aspergillus nidulans - Drosophila melanogaster confrontation assay for gene expression analysis. Fungal tissue handling and RNA extraction.}

Plates $(\varnothing=35 \mathrm{~mm})$ were filled with $3 \mathrm{ml}$ of autoclaved MEA medium. Then a piece of sterilised cellophane was placed on the solid medium. The cellophane was used to ensure that only fungal tissue was scraped without traces of medium. This is important because the medium interacts with RNA precluding its isolation. To ensure that the fungal colony 
was able to take up nutrients through the cellophane, the cellophane was cooked in $\mathrm{KOH}$ (1\%) so increasing its porosity. Each plate was then inoculated with $100 \mu 1$ conidia suspension from 10,000 conidia per $\mu 1$ suspension. There were thus $\sim 10^{6}$ conidia on each plate. Afterwards, the plates were rotated to spread the suspension across the whole cellophane. Plates were closed with lids and incubated for 24 hours at $25^{\circ} \mathrm{C}$ in constant darkness. Each single colony of 24 hour old fungal tissue was exposed to 40 sterile D. melanogaster larvae for 24 hours. After this period, larval damage could be clearly seen as elongated "feeding marks" (Figure 3).

For the RNA analysis, challenged fungal colonies with larval damage and unchallenged fungal colonies were scraped off with a scalpel and snap-frozen in liquid nitrogen. Liquid nitrogen was used because it is critical to rapidly inactivate endogenous ribonucleases prior to lyophilisation. Three fungal colonies were combined to generate one biological replicate. Finally there were 5 biological replicates for insect challenged fungal colonies and 5 biological replicates for unchallenged fungal colonies. Afterwards, the tissue was lyophilized for 24 hours with a lyophilizer (Zirbus VaCo 2, Germany). The lyophilized tissue was powdered with a mortar and pestle. For RNA isolation $10 \mathrm{mg}$ tissue was treated with $1 \mathrm{ml}$ TRIzol® Reagent (Ambion) according to the manufacturer's instructions. Ten mg of tissue were enough to obtain RNA of sufficiently high quality. Possible genomic DNA contamination was removed by digestion with TURBO DNA-free (Ambion). RNA quantity and purity were determined by measuring absorbance at $\mathrm{A}_{260 / 280}$ with a plate reader (Tecan M200, Germany). RNA purity was shown by ratios of 1.8-2.0 of absorbance at $\mathrm{A}_{260 / 280}$ meaning that the RNA samples were free of organic contaminations e.g. proteins, organic compounds and others. RNA integrity was determined by formaldehyde de-naturating agarose gel $(0.65 \%)$. The intensity and the distance of the 28S/18S bands verified intact RNA. Nevertheless, to ensure that the RNA samples were completely free of DNA contaminations after DNA digestion, a standard PCR combined with polyacrylamide (PAA) gel analysis was run. Because PAA gels are better for separation of low molecular weight fragments (80bp and 300bp), these were chosen to check for potential DNA contaminations. Routinely, no DNA bands were revealed on the gels meaning that RNA samples were free of genomic DNA. 

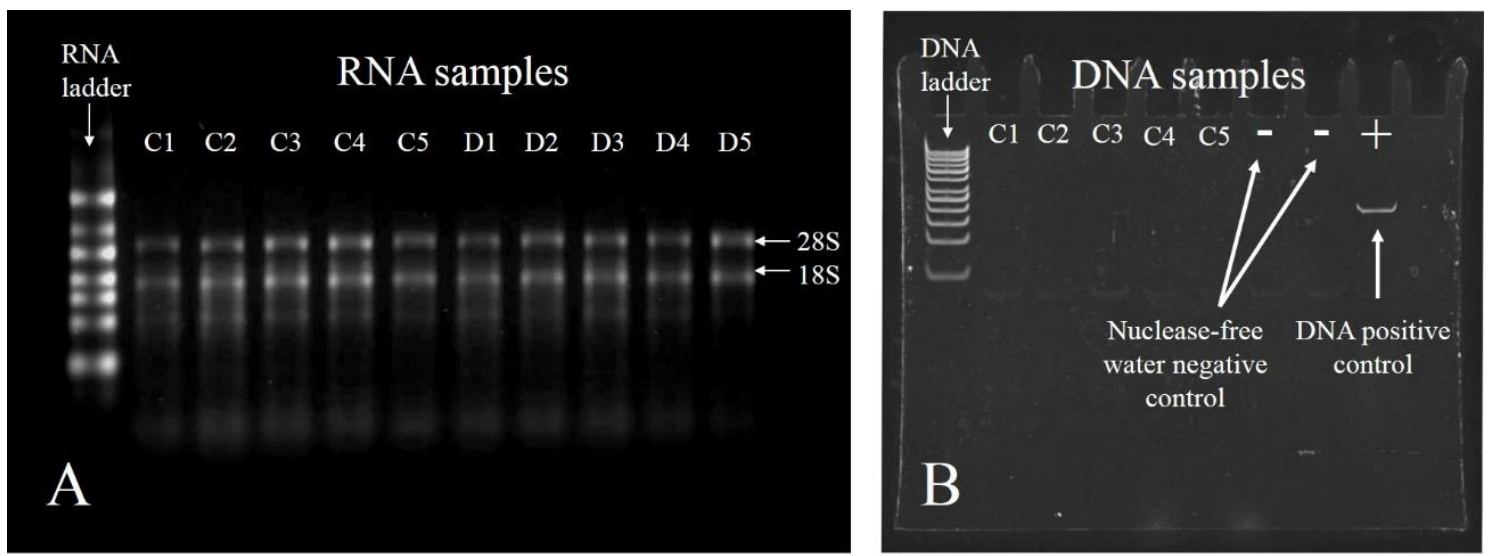

Figure 4. A) Denaturating agarose gel electrophoresis analysis of RNA integrity from unchallenged A. nidulans samples (C1-C5) and challenged A. nidulans samples (D1-D5). The gel was stained with ethidium bromide and shows the $28 \mathrm{~S}$ and $18 \mathrm{~S}$ ribosomal RNA bands with a ratio of 2:1, which indicates an intact RNA. B) Polyacrylamide gel electrophoresis with 5 unchallenged A. nidulans samples, 2 negative control (water) and 1 positive control (A. nidulans DNA). PCR was ran with RNA samples after DNA digestion to ensure that no DNA contamination was present in the RNA samples. The absence of bands at the unchallenged samples (C1-C5) revealed that there were no DNA contaminations. Positive band of A. nidulans DNA control on the right side of the gel indicates that the PCR ran properly.

\subsection{Quantitative Real-Time Reverse Transcription PCR (qRT-PCR)}

Forward $(\mathrm{F})$ and reverse $(\mathrm{R})$ oligonucleotide primer sequences were designed with Primer Premier Software (Premier Biosoft) and synthesized and provided by Eurofins (http://www.eurofins.de). Primer sequences (Table 2) were free of introns, hairpins and dimers (self and cross dimers). Sequence information was retrieved from exon only sequences provided by http://www.aspgd.org/. BLAST searches were conducted for all primers using the NCBI GenBank database and http://www.aspgd.org/ to ensure specificity of amplification. Gel electrophoresis of PCR products detected single bands of the expected size (Figure 5). Additionally, melting curve analysis of all PCR products was carried out via qRT-PCR. All PCR products were sequenced to ensure that only gene products of interest were amplified.

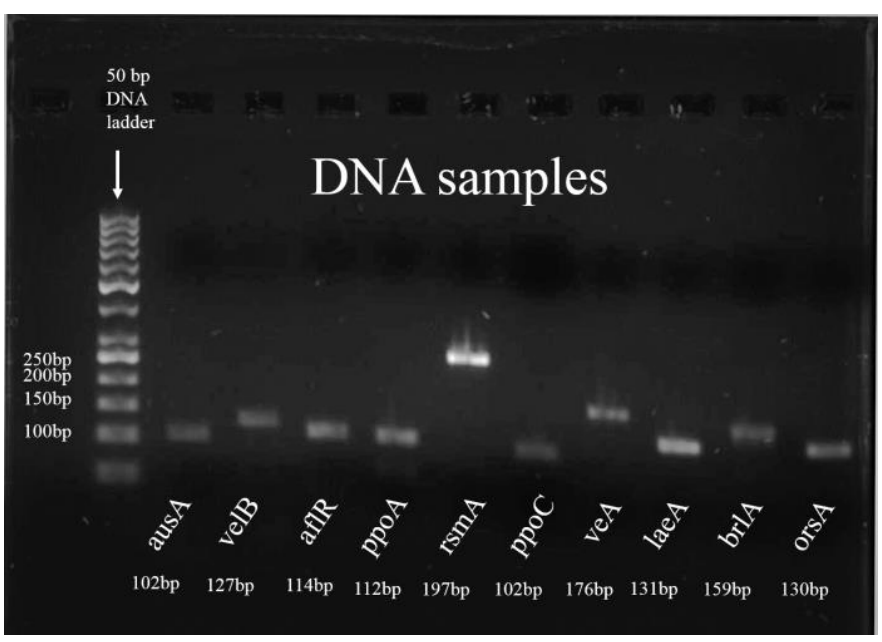

Figure 5. Agarose gel electrophoresis analysis of $A$. nidulans PCR products for amplicon size verification. Primer sequences were designed with Primer Premier Software (Premier Biosoft) and the amplicon sized predicted by the software was verified by running the PCR products into an agarose gel electrophoresis and compare them with the 50 bp DNA ladder bands (Qiagen). 
Table 2. Primer list with predicted amplicon size and melting temperature.

\begin{tabular}{|c|c|c|c|}
\hline $\begin{array}{l}\text { Gene } \\
\text { (ID) }\end{array}$ & $' 5 \rightarrow 3$ ' & $\begin{array}{c}\text { Predicted } \\
\text { amplicon size }\end{array}$ & $\begin{array}{c}\text { Melting } \\
\text { temperature } \mathbf{T}_{\mathbf{m}} \\
\left({ }^{\circ} \mathrm{C}\right)\end{array}$ \\
\hline $\begin{array}{l}\text { aflR } \\
\text { (AN7820) }\end{array}$ & $\begin{array}{l}\text { (F)GTCTCCGAATACTTCCACCT } \\
\text { (R)ATGCCATCCATACCCTCA }\end{array}$ & $114 \mathrm{bp}$ & 86.0 \\
\hline $\begin{array}{l}\text { ausA } \\
\text { (AN8383) }\end{array}$ & $\begin{array}{l}\text { (F)TGCTGTCCGCTACCTTC } \\
\text { (R)AGACCTGCTCTGCCTCC }\end{array}$ & 102 bp & 86.8 \\
\hline $\begin{array}{l}\text { easB } \\
\text { (AN2547) }\end{array}$ & $\begin{array}{l}\text { (F)AAAGCCAAGCCCGTTAG } \\
\text { (R)CGTAGTGCCTGCGAGAA }\end{array}$ & $137 \mathrm{bp}$ & 88.0 \\
\hline $\begin{array}{l}\operatorname{hog} A \\
(\text { AN1017) }\end{array}$ & $\begin{array}{l}\text { (F)TTGCCGAAGTTCCTGG } \\
\text { (R)TCATCTGTCTCATCGTGGTAT }\end{array}$ & $176 \mathrm{bp}$ & 88.3 \\
\hline $\begin{array}{l}i p n A \\
\text { (AN2622) }\end{array}$ & $\begin{array}{l}\text { (F)CTTGCGATTCGTGCCTAC } \\
\text { (R)GCGTGAAGTTCGGGTT }\end{array}$ & $118 \mathrm{bp}$ & 87.7 \\
\hline $\begin{array}{l}\text { laeA } \\
\text { (AN0807) }\end{array}$ & $\begin{array}{l}\text { (F)GCTCCTATTCAGCCTCCG } \\
\text { (R)ATGACACTACCGCAACCC }\end{array}$ & $131 \mathrm{bp}$ & 89.6 \\
\hline $\begin{array}{l}m p k A \\
\text { (AN5666) }\end{array}$ & $\begin{array}{l}\text { (F)CACTTTGAGGTGGTTGACG } \\
\text { (R)TGTTGCCTATTTGCTGTTG }\end{array}$ & $130 \mathrm{bp}$ & 89.4 \\
\hline $\begin{array}{l}m p k B \\
\text { (AN3719) }\end{array}$ & $\begin{array}{l}\text { (F)CGGGAAGCCCTTGTT } \\
\text { (R)CCGTCGGGACTTGATT }\end{array}$ & $109 \mathrm{bp}$ & 85.0 \\
\hline $\begin{array}{l}p k a A \\
\text { (AN6305) }\end{array}$ & $\begin{array}{l}\text { (F)AACCACCGCTACTATGCC } \\
\text { (R)GGAAAGGATGCCTGACG }\end{array}$ & $115 \mathrm{bp}$ & 84.7 \\
\hline $\begin{array}{l}\text { ppoA } \\
\text { (AN1967) }\end{array}$ & $\begin{array}{l}\text { (F)GATTATGTCCGAACGATTT } \\
\text { (R)CGGTTGCCATTGCTG }\end{array}$ & 112 bp & 83.4 \\
\hline $\begin{array}{l}\text { ppoC } \\
\text { (AN5028) }\end{array}$ & $\begin{array}{l}\text { (F)TCAGTGCCAACGACGAG } \\
\text { (R)TGCCAAGACCCATAAGC }\end{array}$ & 102 bp & 88.0 \\
\hline $\begin{array}{l}r s m A \\
\text { (AN4562) }\end{array}$ & $\begin{array}{l}\text { (F)CGACGAGTTTCTTGCTGTG } \\
\text { (R)CGGCGAGTAAGTTTGAGGATT }\end{array}$ & 197 bp & 89.8 \\
\hline $\begin{array}{l}s t c A \\
\text { (AN7821) }\end{array}$ & $\begin{array}{l}\text { (F)AAATCGCCGCAGTTCATC } \\
\text { (R)GCAACAAGCCACTTATTCTCAA }\end{array}$ & $155 \mathrm{bp}$ & 88.0 \\
\hline Luciferase & $\begin{array}{l}\text { (F)CCAGGGATTTCAGTCGATGT } \\
\text { (R)AATCTGACGCAGGCAGTTCT }\end{array}$ & 183 bp cDNA & 81.2 \\
\hline
\end{tabular}

Because insect grazing has been suspected to affect the constancy of housekeeping-genes expression in plants (Rehrig et al., 2011), an external luciferase control RNA spike (Promega, L4561) was used for normalizing candidate RNA quantification rather than common fungal house-keeping genes. Luciferase primer sequences were blasted against the A. nidulans genome and no homologues were found. The qRT-PCR was done in a 
Strategen Mx3000P engine (Agilent) using SYBR Green (Lonza) under following PCR conditions: $50{ }^{\circ} \mathrm{C}$ to activate the reverse transcriptase for $30^{\prime}, 94^{\circ} \mathrm{C}$ to activate the HotStarTaq DNA Polymerase for $15^{\prime}$, followed by 35 cycles of $95{ }^{\circ} \mathrm{C}$ denaturation for $30^{\prime \prime}, 56^{\circ} \mathrm{C}$ annealing for $30^{\prime \prime}, 72{ }^{\circ} \mathrm{C}$ extension for $30^{\prime \prime}$. A final $10^{\prime}$ extension at $72{ }^{\circ} \mathrm{C}$ followed by a complete melting curve analysis from $72{ }^{\circ} \mathrm{C}$ to $95{ }^{\circ} \mathrm{C}$ was conducted to verify that only target genes were amplified and to ensure the absence of primer dimers. PCR efficiencies (E), threshold fluorescence ( $\mathrm{R}_{\mathrm{CT}}$-values), and initial fluorescence $\left(\mathrm{R}_{0}\right)$ were determined directly from the PCR kinetic curves using LinRegPCR 12.12 (http://LinRegPCR.HFRC.nl) (Ruijter et al., 2009). To compare the expression of candidate genes in unchallenged and D. melanogaster fungivory samples, $\mathrm{R}_{0}$ which is the equivalent of the initial amount of candidate mRNA in a sample was used (Schefe et al., 2006). For the results of each qRT-PCR the quantity equivalent, $\mathrm{R}_{0}$, of the candidate gene was considered relative to independent $\mathrm{R}_{0}$ for the reference gene. The resulting $\mathrm{R}_{\text {norm }}$ (unchallenged) is the initial fluorescence of the candidate gene normalized to the reference gene in the unchallenged sample and $\mathrm{R}_{\text {norm }}$ (D. melanogaster larval grazing) is that in the insect-challenged sample.

\subsection{Statistical analyses}

Larval developmental success, fungal growth, and daily larval survival were analysed using generalized linear models in SAS 9.3 (Trienens et al., 2010). Two factors are likely to affect overall variation in the expression of candidate A. nidulans genes. These are fungivory by $D$. melanogaster larvae and constitutive gene-specific differences. In order to test the effect of larval fungivory separately from that of constitutive gene-specific differences, gene-specific effects were removed by standardizing individual $\mathrm{R}_{0}$ values. To do this, the mean $\mathrm{R}_{0}$ for all replicates of candidate gene $x$ was subtracted from the individual $\mathrm{R}_{0}$ of each candidate gene $x$. The resulting values were subsequently divided by the standard deviation for all replicates of candidate gene $x$ (Sokal and Rohlf, 1995). Because normality and variance homogeneity criteria were not met, standardized $\mathrm{R}_{0}$ values to ranks were assigned to achieve both normality and homogeneous variances. A multivariate general linear model was applied to test the influence of $D$. melanogaster feeding on A. nidulans gene expression. The factor "insect treatment" was nested within "technical replicate" to account for variation between technically replicated qRT-PCR runs. 


\section{Results}

\subsection{Insect-induced resistance to fungivory}

To test whether insect-damage A. nidulans colonies impair D. melanogaster larvae more efficiently than those that had not been fed on, single larvae were exposed to wild type colonies that (i) had been previously confronted with conspecific larvae, (ii) remained undisturbed or (iii) were artificially wounded. The effect of fungi on daily larval mortality was compared to mortality rates on fungal-free fruit substrate. Cox regression analyses revealed a grand effect of fungal infestation $\left(\chi^{2}=14.02, \mathrm{P}=0.0002\right)$ and a significant interaction between fungal infestation and whether or not the mould had been challenged $\left(\chi^{2}=4.09, \mathrm{P}=0.0432\right)$ (Figure 3). Compared to mould-free condition, substrate infestation with $A$. nidulans significantly increased larval mortality rates (Wald $\chi^{2}=29.02, \mathrm{P}<0.0001$, hazard ratio: 4.02). In addition, the preceding presence of conspecifics further increased the chance of dying (Wald $\chi^{2}=16.72, \mathrm{P}=0.0005$, hazard ratio=3.25). However artificial wounding of mould colonies did not affect the mortality rates (Wald $\chi^{2}=0.10, \mathrm{P}=0.7556$ ). Mortality rates were also unaffected by earlier feeding by conspecifics in mould-free fruit agar (Wald $\chi^{2}=0.1732, \mathrm{P}=0.6773$ ). Aspergillus nidulans is thus phenotypically plastic in its ability to resist, i.e. kill, D. melanogaster larvae.

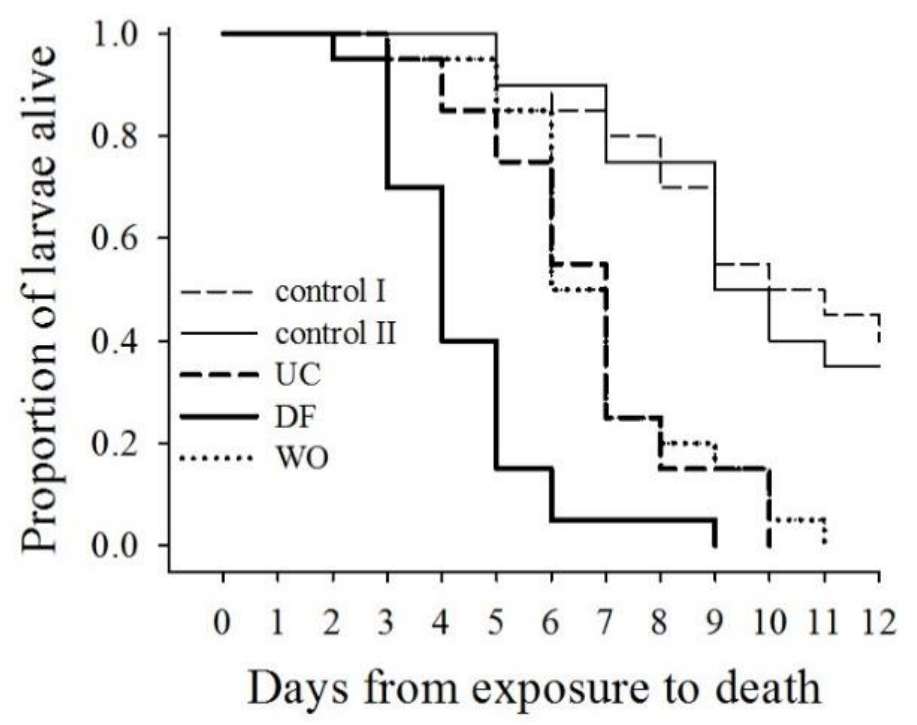

Figure 6. Insect grazing enhances the ability of Aspergillus nidulans to kill Drosophila melanogaster larvae. Daily survival of larvae exposed to mould colonies that were previously treated with conspecific larvae (DF), artificially wounded (WO), or remained untouched (UC). Fungal free fruit substrate without (control I) and with preceding presence of larvae (control II) were included to assess background mortality rates on the nutrient-poor fruit substrate. 


\subsection{Aspergillus nidulans gene expression response to Drosophila melanogaster larval} grazing

The mRNA levels of several genes were quantified to test whether induced resistance to insect grazing is accompanied by differential expression of genes known to be involved in determining the (chemical) phenotype of A. nidulans (Figure 1, Table 1). The expression of genes representative of the different molecular "modules" putatively involved in resistance to fungivores was indeed affected by D. melanogaster larval grazing (Figure 7). These genes have functions in secondary metabolite gene expression regulation, secondary metabolite biosynthesis, oxylipin formation, and signal transduction. Twelve out of the 13 genes tested were significantly up-regulated. Only 1 biosynthetic gene was not differentially expressed (Figure 7). This gene encodes an early step of the sterigmatocystin pathway (stcA). Even though expression of some of the candidate genes were expected to be repressed by fungivory (e.g. ppoC or pkaA, see Figure 1 and Table 1), they exhibited significantly enhanced expression when A. nidulans was exposed to grazing. This data indicates the induction of a substantial fungal phenotypic shift in response to insect grazing.

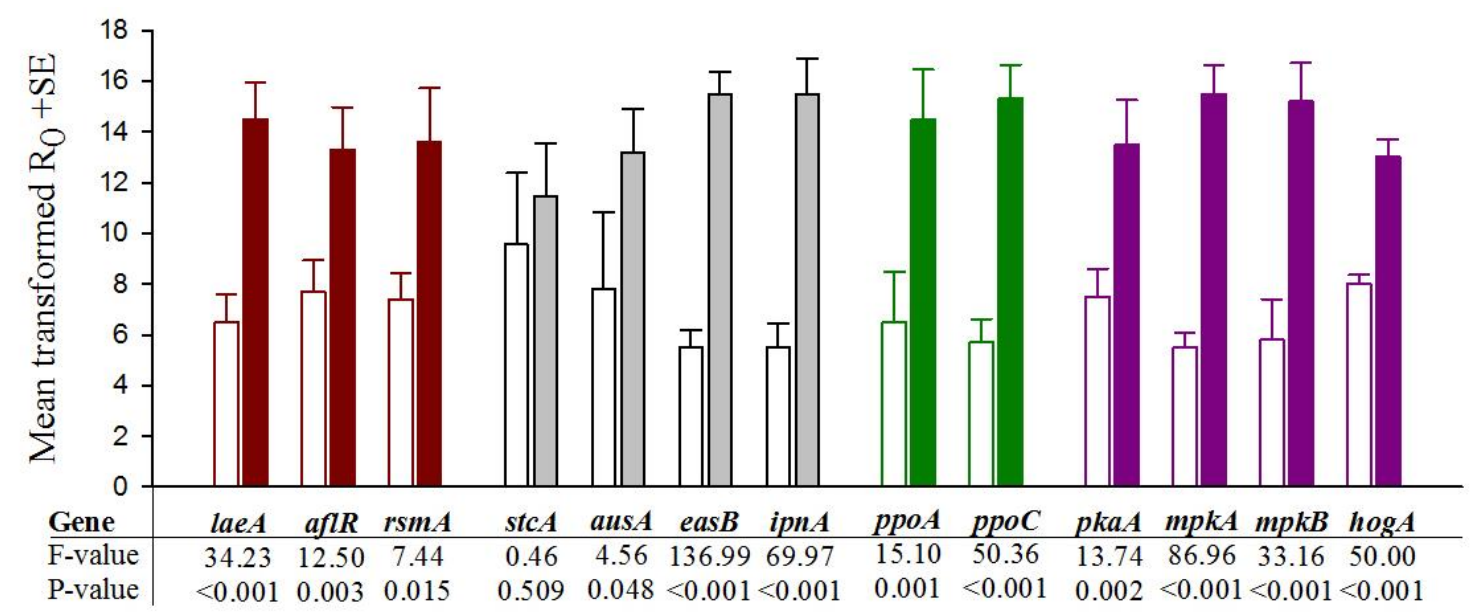

Figure 7. Influence of Drosophila melanogaster larval grazing on Aspergillus nidulans gene expression. Gene expression differences between wild type A. nidulans exposed to D. melanogaster larval grazing (filled bars) and unchallenged (open bars) colonies. Mean values are shown for initial SYBR green fluorescence amount $\left(\mathrm{R}_{0}\right)$ proportional to initial amount candidate gene mRNA in the qRT-PCR runs $(\mathrm{N}=5$ per treatment). Colours represent different molecular "modules" involved in determining the fungal phenotype: transcription regulation (dark red), secondary metabolite biosynthesis (grey), oxylipin formation (green), signal transduction (violet) (see Figure 1 for details). Data were transformed to eliminate gene-specific variation in expression differences and to achieve normality and variance homogeneity. Statistics refer to results of the between-subject effect analysis of the multivariate nested analysis of variance on ranks; Drosophila larval grazing had an overall effect on fungal gene expression, $\mathrm{P}=0.025$. 


\subsection{Larval grazing on wild type and chemical deficient Aspergillus nidulans}

To test whether the LaeA-dependent ability of resisting fungivore attack is the key fungal trait that deters D. melanogaster larvae from using A. nidulans as food, we offered larvae a chemical deficient $\triangle l a e A$ or a wild type $A$. nidulans strain as the only micro fungal diet on sterile fruit substrate and recorded larval development and fungal growth. Wild type A. nidulans strain scarcely supported development to the adult (Figure 8A) and fungalfree control substrate did not support development at all (data not shown). In contrast, larvae developed into adult flies on the chemical deficient $\Delta l a e A$ mutant strain, yet survival was not as high as on fruit agar infested with S. cerevisiae (Figure 8B). Survival was very low in the treatment where A. nidulans had no developmental "head start", and the initial fungal biomass was virtually zero (generalised linear model, $\mathrm{P}<0.0001$ ). Even though survival probabilities were the same in the other $\Delta l a e A$ A. nidulans treatments, development time to the adult stage was negatively related to fungal age and hence the amount of fungal food available to the larvae $(\mathrm{P}<0.0001$; Figure $8 \mathrm{C})$. Compared with development on 3 day old $A$. nidulans, time to adult exclusion was significantly shorter when larvae were offered S. cerevisiae $(\mathrm{P}<0.0001)$.
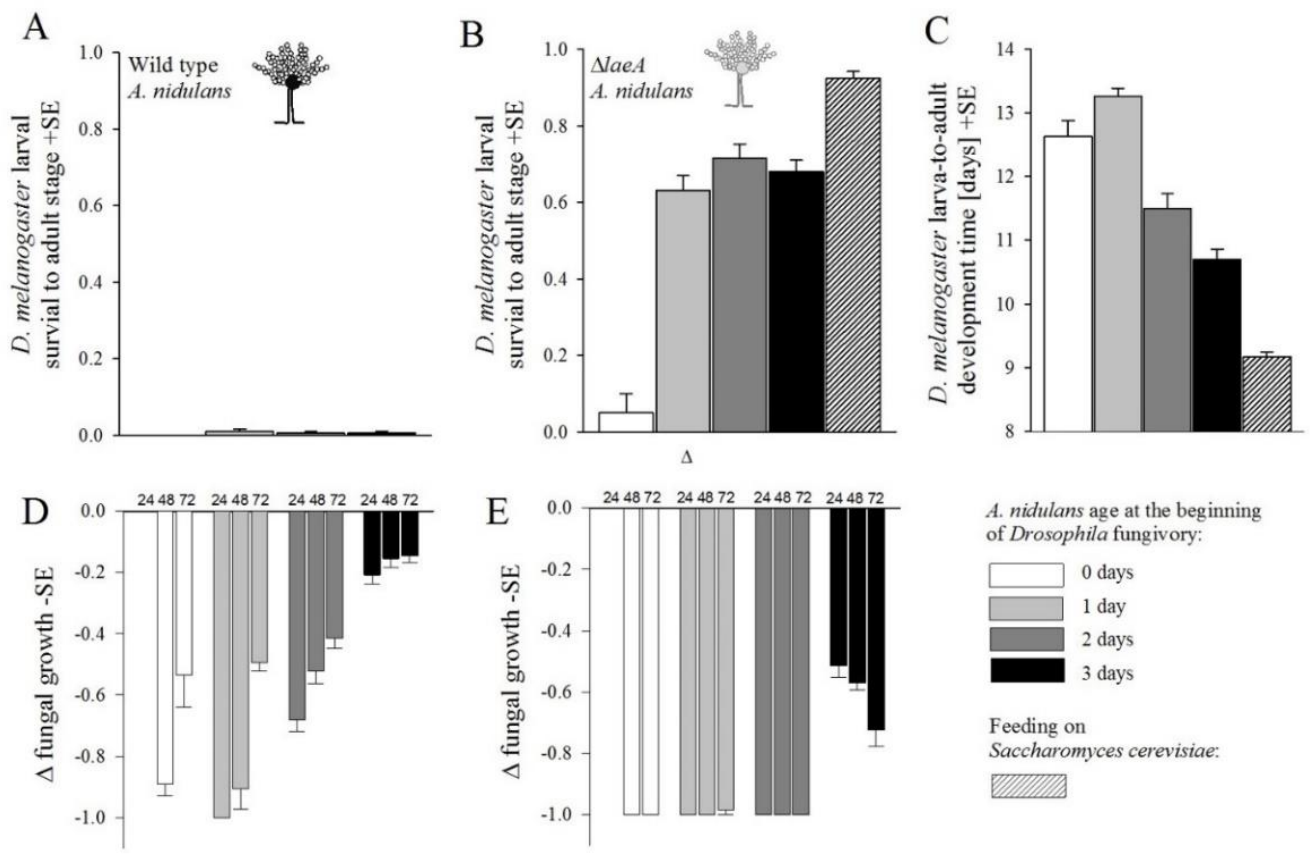

Figure 8. Reciprocal fitness consequences of Drosophila melanogaster larval feeding on Aspergillus nidulans. (A) and (B) Mean survival of D. melanogaster larvae to the adult stage on wild type, chemical deficient $\triangle$ laeA a. nidulans, and yeast Saccharomyces cerevisiae. Availability of potential A. nidulans food to larvae was controlled by varying the time between inoculation of conidia and transfer of larvae (A. nidulans age: 0 to 3 days). Initial yeast inoculum was 1000 cells. (C) Mean larva-to-adult development times on $\Delta l a e A$ and S. cerevisiae. (D) and (E) Mean suppression of wild type and AlaeA A. nidulans surface growth relative to undisturbed control colonies 24,48 and 72 hours after the transfer of larvae. $\Delta$-values may range from 0 (no suppressive influence of insect grazing relative to undisturbed colonies) to -1 (100\% suppression of mould development). See text for statistical details. 
Larvae strongly suppressed the development of $\triangle l a e A$, and the fungus did not recover, e.g. there was no positive relationship between changes in fungal growth and time (24, 48, 72 hours) after larval transfer. Although hyphal fragments were visible, the development of aerial hyphae was almost eliminated in zero to 2 day old colonies (Figure $8 \mathrm{E})$. Aerial hyphae were clearly visible in 3 day old colonies but suppression tended to increase over time (repeated mixed model, $\mathrm{P}=0.0025$; Figure 8E). Moreover, we observed no conidiophore (asexual reproductive organs) formation in insect-challenged colonies. The wild type strain, however, was less strongly affected and clearly recovered from larval feeding activity with increasing time $(\mathrm{P}<0.0001$; Figure $8 \mathrm{D})$. All replicate colonies also developed conidiospores.

In contrast to the generally negative influence of insects on mould growth, the dietary yeast $S$. cerevisiae reached higher cell population densities when exposed to D. melanogaster larvae feeding compared to a non-insect treatment (see Figure 9).

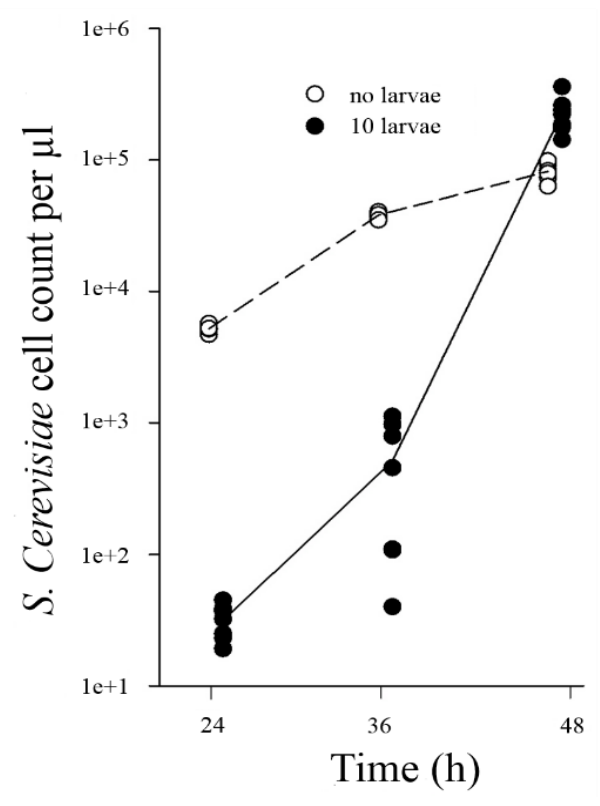

Figure 9. Saccharomyces cerevisiae cell population development with and without the influence of Drosophila melanogaster larval feeding. To quantify the influence of $D$. melanogaster fungivory on growth of $S$. cerevisiae, $2 \mathrm{ml}$ tubes filled with $1 \mathrm{ml}$ banana agar were inoculated with 10,000 cells of $S$. cerevisiae (DSM 70449) in $1 \mu \mathrm{l} \mathrm{NaCl}$ solution. After inoculation, 10 D. melanogaster larvae were added to each tube. From three cohorts (after 24, 36 and 48 hours incubation) of $\mathrm{N}=7$ randomly chosen replicates for each treatment yeast cells were washed off the substrates surface. For this, the same $1 \mathrm{ml}$ saline solution was pipetted 15 times into each tube to flush out the yeast cells. Yeast cell population sizes were analyzed with the BD AccuriC6 Flow Cytometer (BD Biosciences, USA). It was specified a fast flow rate and set the run limits to 10,000 events. Compared to larval-free yeast control washes it was specified the polygonal area for particle quantification. Generalized linear model; larvae, time, larvae*time interaction, all $\mathrm{P}<0.0001$; post hoc comparison at time $48 \mathrm{~h}$, larvae: $\mathrm{P}<0.0001$. 
Thus, these results reveal two important aspects of Drosophila fungivory: (i) filamentous mould, if impaired in secondary metabolite production, can serve as a suitable but rapidly diminishing resource, and fungivory entails costs of strong insect competition, (ii) unicellular yeast is a re-growing food source that is effective in mediating high insect fitness.

\section{Discussion}

Results from this chapter demonstrate the ability of $A$. nidulans to kill $D$. melanogaster larvae more rapidly when the mould colony has been previously exposed to insect grazing. Artificially wounded A. nidulans colonies did not affect the mortality rates of D. melanogaster, suggesting the existence of insect-specific "elicitors" involved in the anti-fungivore fungal resistance. In plant-herbivore interactions it has been demonstrate that herbivore-specific elicitors trigger the anti-herbivore defence in plants (Mattiacci et al., 1995; Turlings et al., 2000), however, fungivore-specific elicitors remain unknown. Despite the need to identify the nature of such elicitors in the Drosophila system, it would be of interest to explore whether different fungivores produce differences in the inducible anti-fungivore defence, as different fungivores may have different elicitors.

The gene expression data obtained from A. nidulans colonies challenged with D. melanogaster larvae shows that the enhanced capacity of the fungus to kill the insects is accompanied by a fundamental shift in the expression levels of candidate genes. Twelve of 13 genes were significantly up-regulated, where laeA gene was of particular interest as it has been frequently suggested to play an important role in mediating the anti-fungivore resistance of A. nidulans (Stötefeld et al., 2012; Trienens et al., 2010). Additionally, the expression levels of different genes involved in coordinating the biosynthesis of secondary metabolites were significantly up-regulated in the challenged mould colonies e.g. $r s m A$ and $a f l R$. The $r s m A$ gene is of special interest because it has been recently shown to be involved in direct regulation of the sterigmatocystin gene cluster. Overexpression of $r s m A$ enhances sterigmatocystin biosynthesis, which leads to strong feeding avoidance by fungivorous collembolans (Yin et al., 2012); sterigmatocystin also negatively affects D. melanogaster development (Trienens and Rohlfs, 2011). In addition, the aflR gene encodes for a binuclear zinc cluster $\left(\mathrm{Zn}(\mathrm{II})_{2} \mathrm{Cys}_{6}\right)$ transcription factor regulating transcription of the sterigmatocystin biosynthetic genes (Brown et al., 1996; Fernandes et al., 1998) and the enhanced expression of this gene in insect-challenged 
colonies suggests that the machinery involved in the synthesis of sterigmatocystin is activated. However, the stcA gene encoding for an early biosynthetic enzyme of the sterigmatocystin cluster was not differentially expressed, which contradicts the above interpretation of the observed changes in the expression of aflR. It could well be though that biosynthetic genes of the sterigmatocystin cluster are activated in somewhat older fungal colonies. qRT-PCR analyses of such colonies, however, would require the development of new protocols that separate efficiently melanin and other pigments from fungal RNA. Pigments produced by moulds older than 48 hours co-purifies with RNA, which is still a technical problem difficult to overcome without accepting serious impairment of the PCR reactions.

Even though sterigmatocystin has been proposed to be the most relevant A. nidulans compound mediating resistance against fungivores, other compounds possibly play an even more important role. The work recently published by Trienens and Rohlfs (2012) demonstrates that mutants lacking specific steps along the sterigmatocystin pathway were even more detrimental to the fungivores than the wild type. Therefore, Trienens and Rohlfs (2012) suggested that there must be other compounds involved in fungal defence. This assumption is supported by the results in this chapter where genes encoding enzymes of other secondary metabolite pathways e.g. easB, ausA and ipnA were significantly upregulated in the Drosophila treatment. The eas $B$ gene codes for a putative polyketide synthase required for emericellamides biosynthesis (Chiang et al., 2008) and ipnA codes for the isopenicillin-N-synthase involved in penicillin biosynthesis (Maccabe et al., 1990). Moreover, the polyketide synthase gene ausA, is involved in the formation of meroterpenoids, austinol and dehydroaustinol (Lo et al., 2012). Interestingly, penicillin and emericellamides, have antimicrobial properties (Fleming, 1929; Oh et al., 2007; Sanchez et al., 2012) and fungal meroterpenoids have been shown to exhibit neurotoxicity to insects (Kataoka et al., 2011). The up-regulation of the transcription levels of these genes suggest that the grazing of $D$. melanogaster activates several secondary metabolite pathways that have been recently discovered in fungi (Nielsen et al., 2011). The apparent activation of the penicillin pathway might be related to anti-bacterial defence since wounding by fungivores may provoke the entrance of parasitic bacteria.

Independently of their demonstrated role in the biosynthesis of secondary metabolites (Figure 1, table 1), the expression of genes involved in MAPKinases (mitogen activated protein kinases) and PKA (protein kinase A) signalling ( $m p k B, m p k A, h o g A$ and $p k a A)$ 
was enhanced in D. melanogaster-challenged A. nidulans colonies. Although protein kinase activity measurements are required for disentangling the relative contribution of each signalling cascade to the induced phenotype, this data suggest that insect fungivory triggers a reshuffle of large parts of the signalling network. Here it is postulated that accumulation of signal amplifiers is a prerequisite for enhanced defence gene expression and development of induced resistance to fungivores (Conrath, 2011).

The expression levels of $p p o C$ and $p p o A$ genes coding for the dioxygenase enzymes involved in the oxylipin production were enhanced in the challenged colonies. These molecules are implicated in cell communication but also in secondary metabolite formation. Therefore, the changes observed in the oxylipin profile suggest that these compounds may play a role in mediating resistance to fungivory. Interestingly, PpoC derived fatty acid oxygenase is involved in the biosynthesis of 1-octen-3-ol (Brodhun et al., 2010) and has neurotoxic effects in D. melanogaster (Inamdar et al., 2010). In addition, overexpression of $p p o A$ amplifies mycotoxin production and is accompanied by higher D. melanogaster larval mortality, relative to the wild type (Trienens and Rohlfs, 2012).

Notably, by deleting genes coding for proteins involved in the velvet complex (LaeA/VeA/VelB) like LaeA and VeA (Trienens and Rohlfs, 2012; Trienens et al., 2010) it was demonstrated that these genes appear to be essential for the anti-fungivore defence since the mutants $\triangle l a e A$ and $\triangle v e A$ caused only minor mortality effects in the D. melanogaster larvae. The larvae were able to exploit A. nidulans as food on an otherwise nutrient-poor fruit substrate when the fungus is unable to respond to feeding by expressing laeA. Compared to the S. cerevisiae, however, the chemical deficient A. nidulans is a rapidly diminishing fungal food that causes strong larval competition. For persistence of mould in the face of insect grazing it probably requires a certain degree of maintenance of fungal tissue integrity. Tissue integrity appears to be completely disrupted, however, by the D. melanogaster larvae and their movement through the medium prevents the re-growth of the fragmented fungal tissue. The dramatic consequences of fungivory on undefended mould, as well as for the chemical deficient mutant, would have favoured the evolution of efficient, secondary metabolite-based resistance to insect grazing. Strong chemical defences have been proposed as being typical for many filamentous fungi exploiting short-lived resources on which they face interactions with multiple antagonists (Cray et al., 2013). 
In conclusion, the experiments shown in this chapter provide strong evidence of an adaptive connection between induced fungal resistance and the expression of genes involved in signal transduction, epigenetic regulation and secondary metabolite biosynthesis pathways. The filamentous fungus $A$. nidulans is able to perceive insect grazing, possibly by insect-specific elicitors, and turns its phenotype into a more detrimental one that is better able to keep fungivores in check. In contrast to the growth stimulating effect of insect feeding activity on a mutualistic yeast, effective eradication and ingestion of the A. nidulans $\Delta l a e A$ chemical deficient mutant by the insect larvae suggests that induced resistance in the mould may have evolved in response to an antagonistic arms race with fungivorous arthropods. 


\section{References}

Affeldt, K.J., Brodhagen, M., Keller, N.P., 2012. Aspergillus oxylipin signaling and quorum sensing pathways depend on g protein-coupled receptors. Toxins. 4, 695-717.

Anagnostou, C., Dorsch, M., Rohlfs, M., 2010. Influence of dietary yeasts on Drosophila melanogaster life history traits. Entomol. Exp. Appl. 136, 1-11.

Batta, Y.A., 2006. Quantitative postharvest contamination and transmission of Penicillium expasum (Link) conidia to nectarine and pear fruit by Drosophila melanogaster (Meig.) adults. Postharvest Biol. Technol. 40, 190-196.

Bayram, Ö., Bayram, Ö.S., Ahmed, Y.L., Maruyama, J.-I., Valerius, O., Rizzoli, S.O., Ficner, R., Irniger, S., Braus, G.H., 2012. The Aspergillus nidulans MAPK module AnSte11-Ste50Ste7-Fus3 controls development and secondary metabolism. PLoS Genet. 8, e1002816.

Bayram, O., Braus, G.H., 2012. Coordination of secondary metabolism and development in fungi: the velvet family of regulatory proteins. FEMS Microbiol. Rev. 36, 1-24.

Bayram, Ö., Krappmann, S., Ni, M., Bok, J.W., Helmstaedt, K., Yu, J., Braus, G.H., 2008. VelB/VeA/LaeA Complex coordinates light signal with fungal development and secondary metabolism. Science. 320, 1504-1506.

Bok, J.W., Keller, N.P., 2004. LaeA, a regulator of secondary metabolism in Aspergillus spp. Eukaryot. Cell 3, 527-535.

Brakhage, A.A, 2013. Regulation of fungal secondary metabolism. Nat. Rev. Microbiol. 11, 2132.

Brodhun, F., Schneider, S., Obel, C.G., Hornung, E., Feussner, I., 2010. PpoC from Aspergillus nidulans is a fusion protein with only one active haem. Biochem. J. 425, 555-565.

Brown, D.W., Yu, J.H., Kelkar, H.S., Fernandes, M., Nesbitt, T.C., Keller, N.P., Adams, T.H., Leonard, T.J., 1996. Twenty-five coregulated transcripts define a sterigmatocystin gene cluster in Aspergillus nidulans. Proc. Natl. Acad. Sci. U.S.A. 93, 1418-22.

Castillo, M., Moya, P., Cantı, A., Miranda, M.A., Primo, J., Primo-yúfera, E., 1999. Insecticidal, anti-juvenile hormone, and fungicidal activities of organic extracts from different Penicillium species and their isolated active components. J. Agric. Food Chem. 47, 2120 2124.

Chiang, Y., Szewczyk, E., Nayak, T., Davidson, A.D., Sanchez, J.F., Lo, H., Ho, W., Simityan, H., Kuo, E., Praseuth, A., Watanabe, K., Oakley, B.R., Wang, C.C.C., 2008. Molecular genetic mining of the Aspergillus secondary metabolome: discovery of the emericellamide biosynthetic pathway. Chem. Biol. 15, 527-532.

Conrath, U., 2011. Molecular aspects of defence priming. Trends Plant. Sci. 16, 524-531.

Cray, J.A., Bell, A.N.W., Mswaka, A.Y., Timson, D.J., Hallsworth, J.E., 2013. The biology of habitat dominance; can microbes behave as weeds ? Microb. Biotechnol. 6, 453-492. 
Fernandes, M., Keller, N.P., Adams, T.H., 1998. Sequence-specific binding by Aspergillus nidulans AflR, a $\mathrm{C} 6$ zinc cluster protein regulating mycotoxin biosynthesis. Mol. Microbiol. $28,1355-65$.

Fleming, A., 1929. On the antibacterial action of cultures of a Penicillium, with special reference to their use in the isolation of B. Influenzae. Br. J. Exp. Pathol. 10, 226-236.

Gilbert, D.G., 1980. Dispersal of yeasts and bacteria by Drosophila in a temperate forest. Oecologia 46, 135-137.

Hodge, S., Mitchell, P., Arthur, W., 1999. Factors affecting the occurrence of facilitative effects in interspecific interactions: an experiment using two species of Drosophila and Aspergillus niger. Oikos 87, 166-174.

Hoff, B., Kamerewerd, J., Sigl, C., Zadra, I., Kürnsteiner, H., Kück, U., Mitterbauer, R., Ku, U., 2010. Two components of a velvet-Like complex control hyphal morphogenesis, conidiophore development, and penicillin biosynthesis in Penicillium chrysogenum. Eukaryot. Cell 9, 1236-1250.

Inamdar, A. a, Masurekar, P., Bennett, J.W., 2010. Neurotoxicity of fungal volatile organic compounds in Drosophila melanogaster. Toxicol. Sci. 117, 418-26.

Kataoka, S., Furutani, S., Hirata, K., Hayashi, H., Matsuda, K., 2011. Three austin family compounds from Penicillium brasilianum exhibit selective blocking action on cockroach nicotinic acetylcholine receptors. Neurotoxicology 32, 123-129.

Kosalková, K., García-Estrada, C., Ullán, R. V, Godio, R.P., Feltrer, R., Teijeira, F., Mauriz, E., Martín, J.F., 2009. The global regulator LaeA controls penicillin biosynthesis, pigmentation and sporulation, but not roquefortine $\mathrm{C}$ synthesis in Penicillium chrysogenum. Biochimie $91,214-25$.

Lo, H., Entwistle, R., Guo, C., Ahuja, M., Szewczyk, E., Hung, J., Chiang, Y., Oakley, B.R., Wang, C.C.C., 2012. Two separate gene clusters encode the biosynthetic pathway for the meroterpenoids austinol and dehydroaustinol in Aspergillus nidulans. J. Am. Chem. Soc. $134,4709-4720$.

López-berges, M.S., Hera, C., Sulyok, M., Schäfer, K., Capilla, J., Guarro, J., Pietro, A. Di, 2013. The velvet complex governs mycotoxin production and virulence of Fusarium oxysporum on plant and mammalian hosts. Mol. Microbiol. 87, 49-65.

Louis., C, Girard, M., Kuhl, G., and Lopez-Ferber., M., 1995. Persistance of Botrytis cinerea in its vector Drosophila melanogaster. Phytopatology 86, 934-939.

Maccabe, A.P., Riach, M.B.R., Unkles, S.E., Kinghorn, J.R., 1990. The Aspergillus nidulans npeA locus consists of three contiguous genes required for penicillin biosynthesis. EMBO J. 9, 279-287.

Mattiacci, L., Dicke, M., Posthumust, M.A., 1995. B-Glucosidase: An elicitor of herbivoreinduced plant odor that attracts host-searching parasitic wasps. Proc. Natl. Acad. Sci. USA 92, 2036-2040.

Nielsen, M.L., Nielsen, J.B., Rank, C., Klejnstrup, M.L., Holm, D.K., Brogaard, K.H., Hansen, B.G., Frisvad, J.C., Larsen, T.O., Mortensen, U.H., 2011. A genome-wide polyketide 
synthase deletion library uncovers novel genetic lincks to polyketides and meroterpenoids in Aspergillus nidulans. FEMS Microbiol. Lett. 321, 157-166.

Oh, D., Kauffman, C.A., Jensen, P.R., Fenical, W., Diego, S., Jolla, L., 2007. Induced production of emericellamides A and B from the marine-derived fungus Emericella sp. in competing co-culture. J. Nat. Prod. 70, 515-520.

Ondeyka, J.G., Dombrowski, a W., Polishook, J.P., Felcetto, T., Shoop, W.L., Guan, Z., Singh, S.B., 2003. Isolation and insecticidal activity of mellamide from Aspergillus melleus. J. Ind. Microbiol. Biotechnol. 30, 220-4.

Paz, Z., Bilkis, I., Gerson, U., Kerem, Z., Sztejnberg, A., 2011. Argovin, a novel natural product secreted by the fungus Meira argovae, is antagonistic to mites. Entomol. Exp. Appl. 140, 247-253.

Rehrig, E.M., Appel, H.M., Schultz, J.C., 2011. Measuring "normalcy" in plant gene expression after herbivore attack. Mol. Ecol. Resour. 11, 294-304.

Rohlfs, M., Albert, M., Keller, N.P., Kempken, F., 2007. Secondary chemicals protect mould from fungivory. Biol. Lett. 3, 523-5.

Rohlfs, M., Obmann, B., Petersen, R., 2005a. Competition with filamentous fungi and its implication for a gregarious lifestyle in insects living on ephemeral resources. Ecol. Entomol. 30, 556-563.

Rohlfs, M., 2005b. Clash of kingdoms or why Drosophila larvae positively respond to fungal competitors. Front. Zool. 2, 1-7.

Ruijter, J.M., Ramakers, C., Hoogaars, W.M.H., Karlen, Y., Bakker, O., van den Hoff, M.J.B., Moorman, a F.M., 2009. Amplification efficiency: linking baseline and bias in the analysis of quantitative PCR data. Nucleic Acids Res. 37, e45.

Sanchez, J.F., Somoza, A.D., Keller, P., Wang, C.C.C., 2012. Advances in Aspergillus secondary metabolite research in the. R. sociaety Chem. 29, 351-371.

Schefe, J.H., Lehmann, K.E., Buschmann, I.R., Unger, T., Funke-Kaiser, H., 2006. Quantitative real-time RT-PCR data analysis: current concepts and the novel "gene expression's CT difference" formula. J. Mol. Med. 84, 901-10.

Sokal, R., Rohlf, F., 1995. Biometry New York. NY WH Free. Co.

Spiteller, P., 2008. Chemical defence strategies of higher fungi. Chemistry 14, 9100-9110.

Stamps, J. a, Yang, L.H., Morales, V.M., Boundy-Mills, K.L., 2012. Drosophila regulate yeast density and increase yeast community similarity in a natural substrate. PLoS ONE 7, e42238.

Stötefeld, 2014. Foraging behaviour of Drosophila melanogaster fruit fly larvae as a affected by fugal volatile organic compounds. Master thesis. Göttingen, Georg-August-Universität Göttingen, Johann-Friedrich-Blumenbach-Institut. 
Stötefeld, L., Scheu, S., Rohlfs, M., 2012. Fungal chemical defence alters density-dependent foraging behaviour and success in a fungivorous soil arthropod. Ecol. Entomol. 37, 323329.

Tanney, J.B., Hutchison, L.J., 2012. The production of nematode-immobilizing secretory cells by Climacodon septentrionalis. Mycosciencie 53, 31-35.

Trienens, M., Keller, N.P., Rohlfs, M., 2010. Fruit, flies and filamentous fungi - experimental analysis of animal - microbe competition using Drosophila melanogaster and Aspergillus mould as a model system. Oikos 119, 1765-1775.

Trienens, M., Rohlfs, M., 2011. Experimental evolution of defense against a competitive mold confers reduced sensitivity to fungal toxins but no increased resistance in Drosophila larvae. BMC Evol. Biol. 11, 206.

Trienens, M., Rohlfs, M., 2012. Insect-fungus interference competition - The potential role of global secondary metabolite regulation, pathway-specific mycotoxin expression and formation of oxylipins. Fungal Ecol. 5, 191-199.

Tsitsigiannis, D.I., Keller, N.P., 2006. Oxylipins act as determinants of natural product biosynthesis and seed colonization in Aspergillus nidulans. Mol. Microbiol. 59, 882-92.

Tsitsigiannis, D.I., Keller, N.P., 2007. Oxylipins as developmental and host - fungal communication signals. Trends Microbiol. 15, 109-118.

Turlings, T.C.J., Alborn, H.T., Loughrin, J.H., Tumlinson, J.H., 2000. Volicitin, an elicitor of maize volatiles in oral secretion of Spodoptera exigua: Isolation and bioactivity. J. Chem. Ecol. 26, 189-202.

Wölfle, S., Trienens, M., Rohlfs, M., 2009. Experimental evolution of resistance against a competing fungus in Drosophila melanogaster. Oecologia 161, 781-90.

Yin, W., Amaike, S., Wohlbach, D.J., Gasch, A.P., Chiang, Y., Wang, C.C., Bok, J., Rohlfs, M., Keller, N.P., 2012. An Aspergillus nidulans bZIP response pathway hardwired for defensive secondary metabolism operates through aflR. Mol. Microbiol. 83, 1024-1034. 


\section{Chapter 3}

Aspergillus nidulans response to variation in fungivore feeding damage 


\begin{abstract}
To reduce the impact of predatory animals fungi, like many other organisms have evolved physical and chemical resistance traits that either repel or kill fungivores. Parts of fungal secondary metabolite production and its underlying regulatory mechanisms are thus thought to be the outcome of a co-evolutionary process with fungivorous animals. This view has been supported by demonstrating that grazing by arthropods induces such resistance mechanisms on the level of fungal gene expression, metabolite formation, and morphology. Compared to these findings another study has shown that collembolans feeding at high densities achieved higher fitness than feeding individually. The more severe feeding damage caused by animal groups has been suggested to suppress the antifungivore defence. Based on this finding it is hypothesized that the anti-fungivore defence response of the mould Aspergillus nidulans depends on variation in fungivore feeding damage. In particular, it is hypothesized here that severe feeding damage caused by the grazing of the isopod Oniscus asellus either suppresses or down-regulates the mechanisms underlying the anti-fungivore defence. To test this hypothesis, the expression levels of two candidate genes involved in the regulation and biosynthesis of secondary metabolites were studied by RNA analysis. The results of this study indicate that grazinginduced fungal responses strongly depend on fungivore identity, and suggest a negative relationship between the severity of feeding damage and the capacity of the fungus to resist invertebrate grazing.
\end{abstract}




\section{Introduction}

Fungi suffer predation from different fungivores. This predation reduces the fitness of the fungi and, consequently, fungi have evolved physical and chemical defences to resist fungivore attacks (Böllmann et al., 2010; Spiteller, 2008; Tanney and Hutchison, 2012). The mechanisms underlying fungal chemical defences are inducible, as indicated by changes in gene expression, metabolite formation and morphology (Bleuler-Martínez et al., 2012; Döll et al., 2013; Nielsen et al., 2013). Notably, these changes lead to an increase in the resistance to fungivore grazing (Döll et al. 2013, chapter 2).

Therefore, fungal responses to grazing appear to resemble the many induced defence responses observed in plants upon herbivore attack (Karban and Baldwin, 1997). Interestingly, herbivory may also suppress plant defences, in particular, when plant feeding insects attack at high densities. Suppressing host plant defence by group-feeding in consequence results in a positive relationship between density and herbivore fitness (Hambäck, 2010). A comparable density-fitness relationship occurs in the collembolan Folsomia candida grazing on the mycotoxigenic mould Aspergillus nidulans (Stötefeld et al., 2012), a partially positive relationship between collembolan growth rate and density was observed when the animals fed on individual A. nidulans colonies. Curiously, this positive relationship was not observed when the collembolans were allowed to feed on a chemical deficient mutant that lacks the formation of many toxic metabolites. Stötefeld et al. (2012) hypothesized that collembolans at low densities, causing only minor feeding damage to the mould, induce an efficient fungal chemical defence response. However, more severe grazing damage, caused by fungivores at higher densities, may induce suppression of such a fungal response.

The aim of this work was to test whether the fungal response to feeding, in relation to inducible resistance (Chapter 2), depends on variation in fungivore feeding damage. In order to test this, the isopod, Oniscus asellus was used. These animals, in preliminary experiments, caused within a comparatively short time, different degrees of damage. This variation in fungivore feeding activity allowed to classify low and high feeding damage. This classification was used to address two novel suggestions: (i) In analogy to the findings shown in chapter 2 , it is hypothesized that low feeding damage triggers the activation of anti-fungivore resistance mechanisms (Figure 1). (ii) Based on the previously observed positive relationship between fungivore fitness and fungivore density when feeding on A. nidulans (Stötefeld et al., 2012), it is hypothesized that high 
feeding damage either suppresses the activation of mechanisms mediating inducible resistance, meaning that the fungi are not able to launch a defence response. Consequently, the inducible mechanisms underlying anti-fungivore resistance remain at the same level as if there was no grazing (i.e. constitutive level of anti-fungivore resistance). Alternatively, the fungus may down-regulate the anti-fungivore resistance mechanisms, meaning that the resistance level drops below the level of constitutive antifungivore resistance.

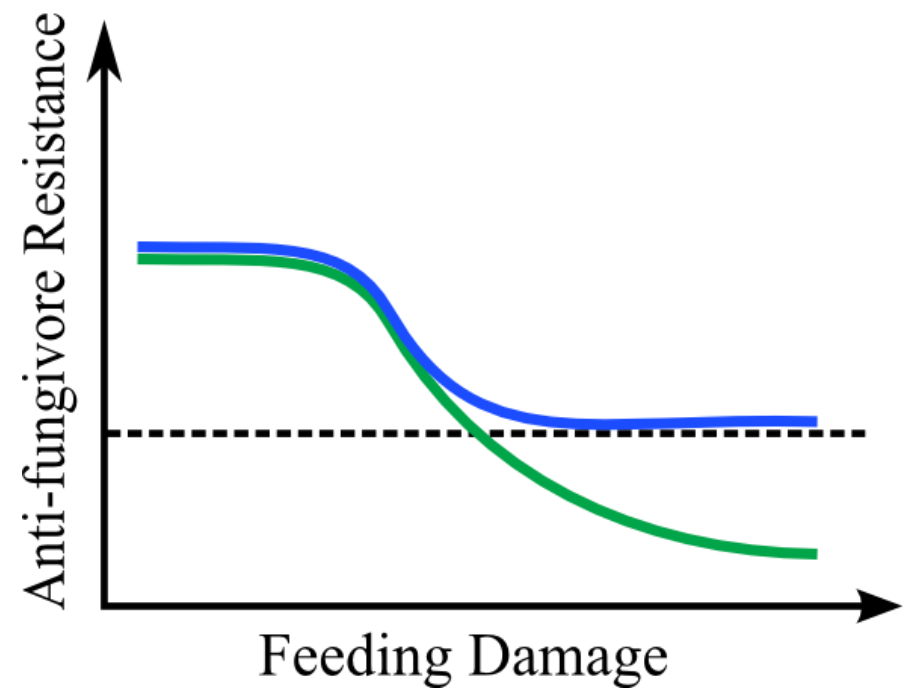

Figure 1. Hypothetical changes in anti-fungivore resistance as a function of fungivore feeding damage. Dashed line represents constitutive anti-fungivore resistance without the influence of grazing. Under the first hypothesis at low feeding damage, anti-fungivore resistance is enhanced, but at high feeding damage it is supressed to the level of the constitutive defence (blue line, hypothesis (i)). Under the second hypothesis at low feeding damage, resistance is equally enhanced but at high feeding damage, it is downregulated (green line, hypothesis (ii)).

Based on their demonstrated role in mediating inducible resistance to fungivory, the changes in expression of the two "anti-fungivore" candidate genes, laeA and aflR were analysed. The laeA gene encodes for LaeA, a putative methyltransferase, which is involved in global regulation of secondary metabolites. The aflR gene encodes for a binuclear pathway-specific transcription factor that triggers the activation of the sterigmatocystin biosynthetic genes (Chang et al., 1993; Fernandes et al., 1998; Woloshuk et al., 1994). Sterigmatocystin has strong anti-fungivore properties. By using a laeA-deletion mutant different studies have shown a functional relationship between global secondary metabolite regulation and anti-fungivore defence. This chemical deficient mutant has a positive effect on fungivore fitness when compared with the 
influence of toxin-producing wild type A. nidulans (Rohlfs et al. 2007; Trienens et al. 2010, chapter 2).

In this chapter it is shown that the transcription levels of both candidate genes laeA and $a f l R$ were significantly down-regulated at high feeding damage. Contrary to was expected, transcription levels of $l a e A$ and $a f l R$ were not significantly different from unchallenged control colonies when $O$. asellus caused low feeding damage on the filamentous fungi. This study thus provides first experimental evidence that the inducibility of fungal defence cannot only be suppressed by infliction of high feeding damage, but that the mechanisms mediating anti-fungivore resistance are even downregulated relative to their constitutive expression in unchallenged fungi.

\section{Materials and methods}

\subsection{Oniscus asellus as a fungivorous arthropod}

Aspergillus nidulans was exposed to the isopod O. asellus to test for variation in fungal responses to differences in fungivore feeding damage. Preliminary experiments showed that the isopods feed readily on the mould and cause a varying degree of feeding damage within a relatively short time. Adult animals were collect in the Göttingen forest and kept at ambient laboratory conditions in plastic boxes lined with plaster of Paris. Prior to the experiments the animals were kept for about three weeks in the lab and fed with dried baker's yeast.

\subsection{Culture of Aspergillus nidulans}

Aspergillus nidulans was cultured following published protocols (Trienens et al., 2010). In brief, A. nidulans was inoculated in MEA at $25^{\circ} \mathrm{C}$ and constant darkness. After 7 days, mature conidia were scraped off with a sterilised scoop and $5 \mathrm{ml}$ of autoclaved ringer solution. Afterwards conidia suspension was counted and adjusted to a titre of 10,000 conidia per $\mu 1$.

\subsection{Handling of Aspergillus nidulans and fungus-fungivore confrontation assay}

Plates $(\varnothing=35 \mathrm{~mm})$ were filled with $3 \mathrm{ml}$ of autoclaved MEA medium and a piece of sterilised cellophane was place over the surface of the solid medium. Then each plate was inoculated with $100 \mu \mathrm{l}$ conidia suspension. Afterwards, the plates were rotated to spread the suspension across the whole cellophane. Plates were closed with lids and incubated for 24 hours at $25^{\circ} \mathrm{C}$ in constant darkness (See chapter 2 for more details). 
Each single colony of 24 hours old fungal tissue was exposed to a single isopod for about 1-3 hours. After this period, isopod damage could easily be identified as feeding marks (Figure 2). Feeding damage produced by the isopod was monitored every 30 minutes. Because the damage was easily seen, the plates were monitored by direct observation. Low feeding damage was obtained within 10 minutes. To obtain high feeding damage, colonies were exposed to grazing for up to three hours. The isopods were removed from the plates once the desired feeding damage was obtained. After the isopods were removed, fungal colonies were incubated for approximately 24 hours at $25^{\circ} \mathrm{C}$ in constant darkness. The feeding damage was quantified using ImageJ software.
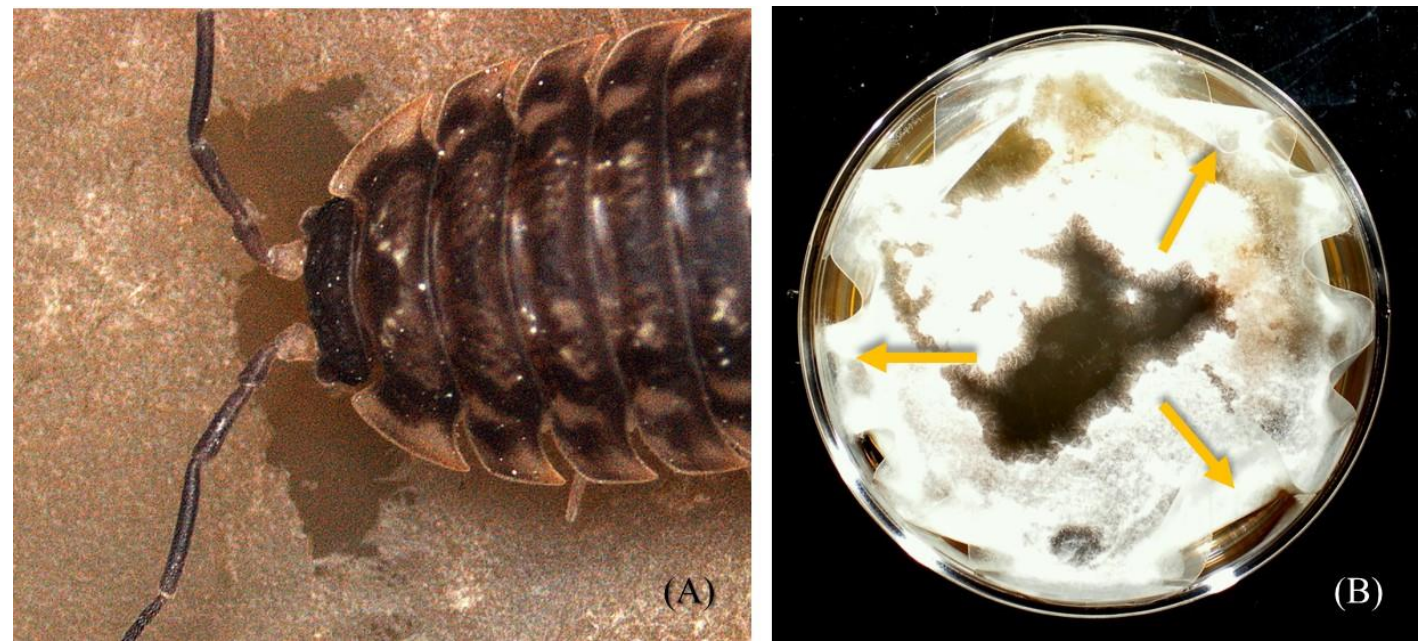

Figure 2. Feeding damage produced by Oniscus asellus. (A) O. asellus feeding on 24 hours old colony of A. nidulans. The feeding damage was produced within 10 minutes. The image was taken with a stereomicroscope, Discovery V8, Zeiss, Germany, equipped with a digital camera system, AxioCam Icc1, Zeiss, Germany. (B) A colony of A. nidulans wounded by one individual of $O$. asellus after 24 hours of "recovering". Arrows point at the cellophane used to separate the fungal colony from the medium (plate diameter $35 \mathrm{~mm}$ ). The image was taken with a digital camera, DCS-W170 (Sony, Japan).

\subsection{Handling of fungal tissue for RNA extraction and gene expression analysis}

Challenged fungal colonies with low and high feeding damage and unchallenged fungal colonies were scraped off with a scalpel and snap-frozen in liquid nitrogen. Each colony represented a biological replicate, having finally 21 biological replicates. Seven biological replicates were classified as low feeding damage, 7 biological replicates were classified as high feeding damage and 7 unchallenged fungal colonies were classified as control. Afterwards, the tissue was lyophilized for 24 hours with Zirbus VaCo 2, Germany. Fungal tissue lyophilisation, RNA isolation, DNA digestion, RNA analyses for purity and integrity and verification of DNA contamination in the RNA samples was done 
in the same manner as described in chapter 2. Briefly, fungal lyophilized tissue was powdered and $10 \mathrm{mg}$ were treated with $1 \mathrm{ml}$ of TRIzol® Reagent (Ambion). DNA contaminations were removed by digesting the DNA with TURBO DNA-free (Ambion). Purity and quantity of RNA samples was determined by measuring absorbance at A260/280 with a plate reader (Tecan M200, Germany). RNA integrity was determined by formaldehyde de-naturating agarose gel $(0.65 \%)$. Afterwards, a standard PCR and PAA gels were run to ensure that no DNA contaminations remained in the RNA samples.

\subsection{Quantitative Real-Time Reverse Transcription PCR (qRT-PCR)}

Quantitative real-time RT-PCR was essentially done in the same manner as described in chapter 2. Shortly, forward and reverse primer sequences were designed with Primer Premier Software and delivered by Eurofins. BLAST searches were conducted for all primer sequences to ensure the specificity of amplification. Afterwards, gel electrophoresis and melting curve analysis of all PCR products were run. Moreover, all PCR products were sequenced to ensure that only gene products of interest were amplified (See chapter 2 for more details). The genes studied in this experiment were laeA and aflR. Table 1 lists the primer sequences used in this experiment.

Table 1. Primer list.

\begin{tabular}{|l|l|c|c|}
\hline $\begin{array}{l}\text { Gene } \\
\text { (ID) }\end{array}$ & $\mathbf{6} \mathbf{5} \rightarrow \mathbf{3}$, & $\begin{array}{c}\text { Predicted } \\
\text { amplicon size }\end{array}$ & $\begin{array}{c}\text { Melting } \\
\text { temperature } \mathbf{T}_{\mathbf{m}} \\
\left({ }^{\circ} \mathbf{C}\right)\end{array}$ \\
\hline $\begin{array}{l}\text { laeA } \\
(\text { AN0807) }\end{array}$ & $\begin{array}{l}\text { (F)GCTCCTATTCAGCCTCCG } \\
\text { (R)ATGACACTACCGCAACCC }\end{array}$ & $131 \mathrm{bp}$ & 89.6 \\
\hline $\begin{array}{l}\text { aflR } \\
(\text { AN7820) }\end{array}$ & $\begin{array}{l}\text { (F)GTCTCCGAATACTTCCACCT } \\
\text { (R)ATGCCATCCATACCCTCA }\end{array}$ & $114 \mathrm{bp}$ & 86.0 \\
\hline Luciferase & $\begin{array}{l}\text { (F)CCAGGGATTTCAGTCGATGT } \\
\text { (R)AATCTGACGCAGGCAGTTCT }\end{array}$ & $183 \mathrm{bp} \mathrm{cDNA}$ & 81.2 \\
\hline
\end{tabular}

An external luciferase control RNA spike was used for normalizing candidate RNA quantification (See chapter 2 for details). The qRT-PCR was done in a Strategen Mx3000P engine (Agilent) using SYBR Green (Lonza) under following same PCR conditions described in chapter 2. PCR efficiencies $(\mathrm{E})$, threshold fluorescence $\left(\mathrm{R}_{\mathrm{CT}^{-}}\right.$ values), and initial fluorescence $\left(\mathrm{R}_{0}\right)$ were determined directly from the PCR kinetic curves using LinRegPCR 12.12 (http://LinRegPCR.HFRC.nl) (Ruijter et al., 2009).

To compare the expression of candidate genes in unchallenged and isopod fungivory samples, $\mathrm{R}_{0}$ which is the equivalent of the initial amount of candidate mRNA in a sample 
(Schefe et al., 2006) was used. For the results of each qRT-PCR the quantity equivalent, $R_{0}$, of the candidate gene was considered relative to independent $R_{0}$ for the reference gene. The resulting $\mathrm{R}_{\text {norm }}$ (unchallenged) is the initial fluorescence of the candidate gene normalized to the reference gene in the unchallenged sample and $\mathrm{R}_{\text {norm }}$ (isopod grazing) that in the isopod-challenged sample.

\subsection{Statistical analyses}

In order to test the effect of isopod fungivory separately from that of constitutive genespecific differences, gene-specific effects were removed by standardizing individual $\mathrm{R}_{0}$ values. For that purpose, the mean $\mathrm{R}_{0}$ for all replicates of candidate gene was subtracted from the individual $\mathrm{R}_{0}$ of each candidate gene. The resulting values were subsequently divided by the standard deviation for all replicates of candidate gene (Sokal and Rohlf, 1995). Because normality and variance homogeneity criteria were not met, the standardized $\mathrm{R}_{0}$ values were ranked and a multivariate general linear model of analysis of variance (MANOVA) on ranks was carried out.

\section{Results}

\subsection{Fungivore feeding damage}

The feeding damage caused by the isopods on A. nidulans colonies ranged from $0.7 \%$ $5 \%$ (category "low feeding damage") to $20-50 \%$ (category "high feeding damage") (Figure 3 and 4).
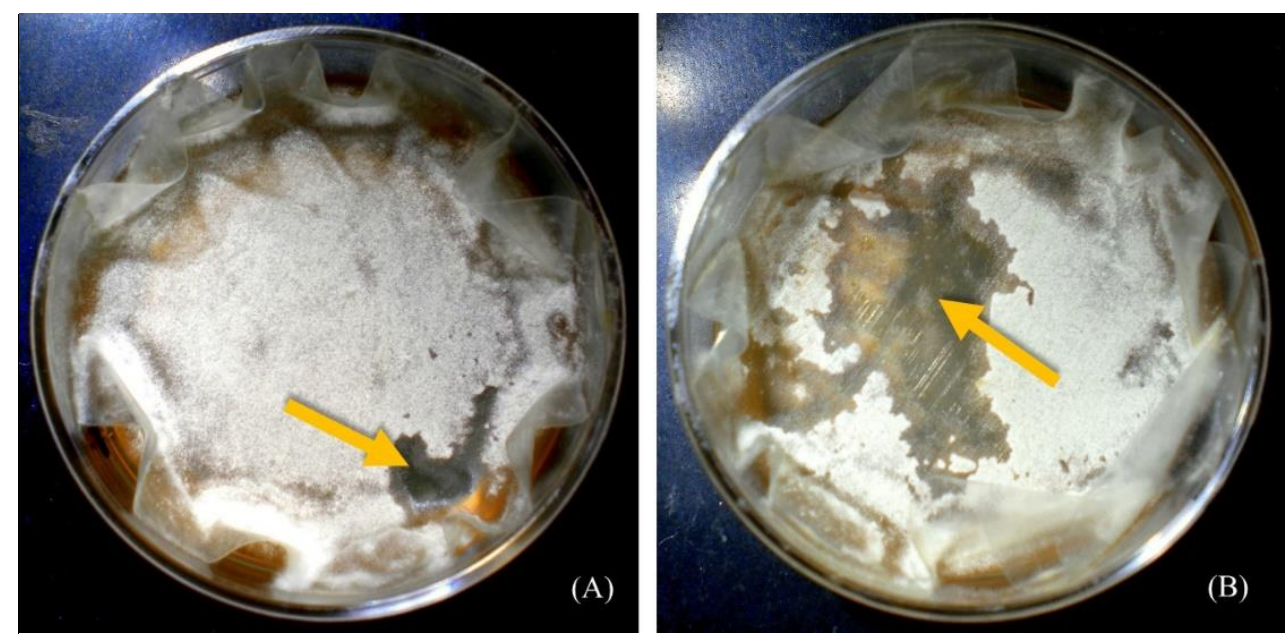

Figure 3. Low and high feeding damage on Aspergillus nidulans colonies caused by Oniscus asellus. The images show 48 hours old colonies of A. nidulans after being confronted with $O$. asellus. (A) Colony with low feeding damage. The damage was produced in less than $10 \mathrm{~min}$. (B) Colony with high feeding damage. The damage was produced in less than $3 \mathrm{~h}$. Images were taken with a digital camera, DCS-W170 (Sony, Japan). Arrows point at the feeding damage. 


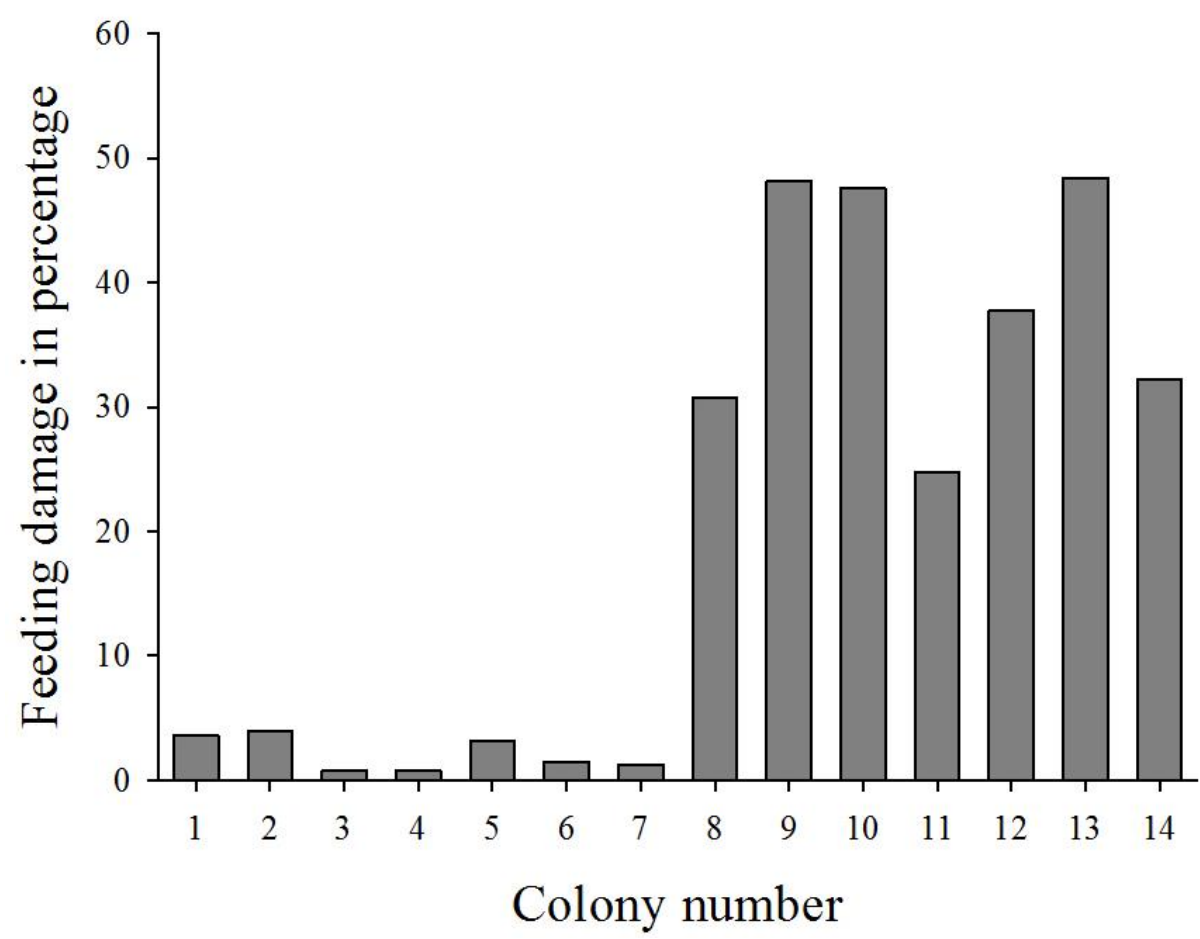

Figure 4. Feeding damage caused by single Oniscus asellus per Aspergillus nidulans colony. For colonies 1 to 7 , feeding damage ranged between $>0 \%$ and $5 \%$ (the "low feeding damage" treatment); for colonies 8 to 14 , feeding damage ranged between $20 \%$ and $50 \%$ (the "high feeding damage" treatment).

After 24 hours of incubation, it was possible to observe that new hyphae were re-growing out of the periphery of the mycelium where the damage was caused (Figure 5).

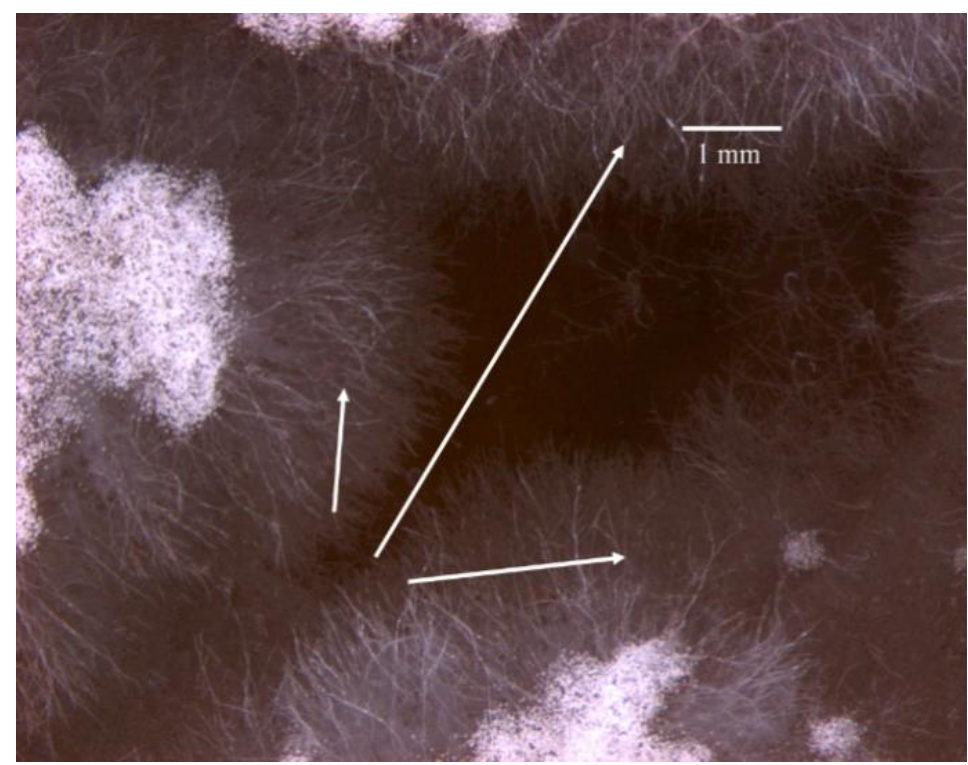

Figure 5. Fungal colony of Aspergillus nidulans re-growing after being damage. Arrows point at new hyphae at the periphery of the wounded fungal tissue formed after the isopod feeding attack. Image was taken with stereomicroscope, Discovery V8, Zeiss, Germany, equipped with a digital camera system, AxioCam Icc1, Zeiss, Germany. 


\subsection{Aspergillus nidulans gene expression response to Oniscus asellus feeding damage}

The mRNA levels of $l a e A$ and $a f l R$ genes quantified at low and high feeding damage and control treatment revealed a damage dependent response in the fungi (Figure 6). The full multivariate analysis of variance (MANOVA) model on ranks shows that feeding damage variation had a significant overall effect on candidate gene expression (Wilks' lambda $\left.\mathrm{F}_{4,34}=4.062, \mathrm{P}=0.008\right)$. Separate univariate ANOVAs on the outcome variable revealed a significant effect of fungivore damage variation on both candidate genes (Figure 6).
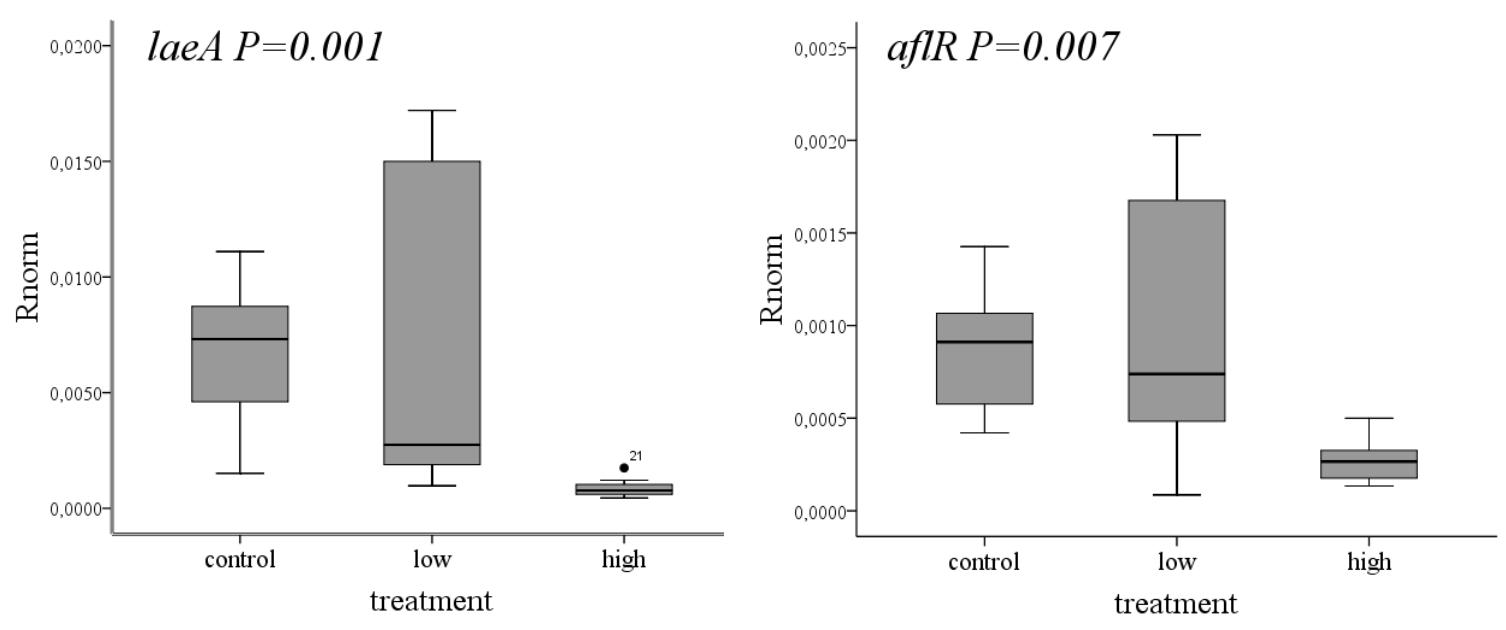

Figure 6. Box-plots depicting Rnorm values of aflR and laeA gene expression as a function of feeding damage, control (no damage), low, and high. Solid lines indicate medians.

In order to test how treatments differ from each other, a multiple comparison based on Dunnett T3 post-hoc test was used. At low feeding damage, neither gene was differentially expressed compared to the control (Figure 6). However, at high feeding damage the RNA levels of both genes was significantly lower relative to the control, laeA $(\mathrm{P}<0.001)$ and $\operatorname{aflR}(\mathrm{P}=0.001)$.

\section{Discussion}

Strong feeding damage caused by $O$. asellus caused a drop in the expression of candidate "anti-fungivore" genes $l a e A$ and $a f l R$ below the level of their constitutive expression in undamaged colonies. No response was detected in fungi exposed to low feeding damage. These findings indicate a damage-dependent response of A. nidulans.

The hypothesis that low feeding damage increases gene expression was not supported. Because gene expression was not increased significantly at low feeding damage, the difference in mould response to $O$. asellus feeding compared to that for D. melanogaster 
larvae (Chapter 2) may be due to subtle differences of the two species in the way they graze. Drosophila larvae graze across the entire fungal tissue (Figure 3, chapter 2). Indeed, larvae moved continuously across the mould and left an evenly distributed "network" of elongated feeding marks. However, they did not completely remove mycelium. In contrast, isopods caused locally severe feeding damage whereas the rest of the colony remained untouched (Figure 3). If fungal defence is only local, i.e. were the wounding occurs, Drosophila larvae may have caused an induced response spread over the entire colony. Isopods, instead, might have caused very local fungal responses. As whole colonies were harvested for gene expression analyses, rather than only those parts that were obviously affected by the animals, it is possible that the spatially constrained effect by $O$. asellus was, on average, less than that caused by the widespread damage by D. melanogaster larvae. The large amount of RNA isolated from the unaffected tissue may thus have masked the local gene expression response. If this suggestion turns out to be an adequate explanation for fungivore-dependent difference in the expression of candidate "anti-fungivore" genes, the defence response of $A$. nidulans can be hypothesized to be only local rather than systemic. As it was only measured the expression of two genes, however, it cannot be excluded that other fungal reactions, incl. other secondary metabolites pathways, are activated systemically, as it has been described for herbivore-plant interactions (Dempsey et al., 1999; Heil and Bostock, 2002; Métraux and Boller, 1986).

The gene expression results for high feeding intensity do not support hypothesis (i), namely that anti-fungivore defence remains at the same level as the constitutive antifungivore resistance (Figure 1, blue line). Rather, the results obtained support hypothesis (ii), namely that intense feeding damage by the isopods causes down-regulation of the "anti-fungivore" genes $l a e A$ and $a f l R$ below the level of their constitutive expression in control colonies (Figure 1, green line). Because of the RNA extraction procedure from entire fungal colonies, which included tissue not directly affected by the fungivore, findings possibly indicate a systemic down-regulation in the expression of $l a e A$ and $a f l R$ in the untouched tissue. If the fungus down-regulates the expression of these genes and the accompanying pathways, it may be able to use the resources liberated by the downregulation for purposes that compensate for the feeding damage, such as cell repair, regrowth, etc. The findings, nevertheless, do not preclude the possibility of local up- 
regulation in the damaged tissue of these and other genes underlying resistance to fungivores.

Wounding alone does not appear to be sufficient to increase resistance to fungivores. Thus, other factors might have caused the variation in fungal responses observed. Such factors might be fungivore-specific chemical elicitors, e.g. salivary secretions, and fungivore-associated microorganisms. Fungivore-associated microorganisms are particularly likely to be an explanatory factor because in the previous chapter the D. melanogaster larvae were sterile before use in the grazing assays but isopods were not. Thus, it might be the combined effect of feeding damage and the activity of isopodassociated microorganisms that may have led to the differences in fungal gene expression observed between the treatments in this study.

The general conclusion that can be drawn from the results obtained in this study is that the fungal response is fungivore-specific. However, it is currently difficult to show which of these species-specific factors are involved, as it has been demonstrated for herbivoreplant interactions (Leitner et al., 2005; Hambäck, 2010). Including other fungivores, such as mites and nematodes that exhibit very different modes of grazing. Future experiments may reveal the full repertoire of fungal responses to invertebrate grazing and the consequences these responses may have for the dynamics of fungal defence responses. This approach would contribute to a better understanding of fungi-fungivore counteradaptations and the implications they have for the ecological functions of fungi in decomposer communities 


\section{References}

Bleuler-Martínez, S., Schmieder, S., Aebi, M., Künzler, M., 2012. Biotin-binding proteins in the defense of mushrooms against predators and parasites. Appl. Environ. Microbiol. 78, 84857.

Böllmann, J., Elmer, M., Jens, W., Raidl, S., Reinhard, F.H., 2010. Defensive strategies of soil fungi to prevent grazing by Folsomia candida (Collembola). Pedobiologia. 53, 107-114.

Chang, P.., Cary, J.W., Bhatnagar, D., Cleveland, T.E., Bennetf, J.W., Linz, J.E., Woloshuk, C.P., Payne, G.A., 1993. Cloning of the Aspergillus parasiticus apa-2 gene associated with the regulation of aflatoxin biosynthesis. Appl. Environ. Microbiol. 59, 3273-3279.

Dempsey, D.A., Shah, J., Klessig, D.F., 1999. Salicylic acid and disease resistance in plants. CRC. Crit. Rev. Plant Sci. 18, 547-575.

Döll, K., Chatterjee, S., Scheu, S., Karlovsky, P., Rohlfs, M., 2013. Fungal metabolic plasticity and sexual development mediate induced resistance to arthropod fungivory. Proc. Roy Soc. B. 280, 20131219.

Fernandes, M., Keller, N.P., Adams, T.H., 1998. Sequence-specific binding by Aspergillus nidulans AflR, a C6 zinc cluster protein regulating mycotoxin biosynthesis. Mol. Microbiol. $28,1355-65$.

Hambäck, P.A., 2010. Density-dependent processes in leaf beetles feeding on purple loosestrife: aggregative behaviour affecting individual growth rates. Bull. Entomol. Res. 100, 605-11.

Heil, M., Bostock, R.M., 2002. Induced systemic resistance (ISR) against pathogens in the context of induced plant defences. Ann. Bot. 89, 503-512.

Karban, R., Baldwin, I.T., 1997. Induced responses to herbivory. Chicago: university of Chicago Press.

Leitner, M., Boland, W., Mithöfer, A., 2005. Direct and indirect defences induced by piercingsucking and chewing herbivores in Medicago truncatula. New Phytol. 167, 597-606.

Métraux, J.P., Boller, T., 1986. Local and systemic induction of chitinase in cucumber plants in response to viral, bacterial and fungal infections. Physiol. Mol. Plant Pathol. 28, 161-169.

Nielsen, T.H., Klejnstrup, M.L., Rohlfs, M., Anyaogu, D.C., Nielsen, J.B., Gotfredsen, C.H., Andersen, M.R., Hansen, B.G., Mortensen, U.H., Larsen, T.O., 2013. Aspergillus nidulans synthesize insect juvenile hormones upon expression of a heterologous regulatory protein and in response to grazing by Drosophila melanogaster Larvae. PLoS ONE 8, e73369.

Rohlfs, M., Albert, M., Keller, N.P., Kempken, F., 2007. Secondary chemicals protect mould from fungivory. Biol. Lett. 3, 523-5.

Ruijter, J.M., Ramakers, C., Hoogaars, W.M.H., Karlen, Y., Bakker, O., van den Hoff, M.J.B., Moorman, a F.M., 2009. Amplification efficiency: linking baseline and bias in the analysis of quantitative PCR data. Nucleic Acids Res. 37, e45. 
Schefe, J.H., Lehmann, K.E., Buschmann, I.R., Unger, T., Funke-Kaiser, H., 2006. Quantitative real-time RT-PCR data analysis: current concepts and the novel "gene expression's CT difference" formula. J. Mol. Med. (Berl). 84, 901-10.

Sokal, R., Rohlf, F., 1995. Biometry New York. NY WH Free. Co.

Spiteller, P., 2008. Chemical defence strategies of higher fungi. Chemistry 14, 9100-9110.

Stötefeld, L., Scheu, S., Rohlfs, M., 2012. Fungal chemical defence alters density-dependent foraging behaviour and success in a fungivorous soil arthropod. Ecol. Entomol. 37, 323329.

Tanney, J.B., Hutchison, L.J., 2012. The production of nematode-immobilizing secretory cells by Climacodon septentrionalis. Mycosciencie 53, 31-35.

Trienens, M., Keller, N.P., Rohlfs, M., 2010. Fruit, flies and filamentous fungi - experimental analysis of animal - microbe competition using Drosophila melanogaster and Aspergillus mould as a model system. Oikos 119, 1765-1775.

Woloshuk, C.P., Foutz, K.R., Brewer, J.F., Bhatnagar, D., Cleveland, T.E., Payne, G.A, 1994. Molecular characterization of aflR, a regulatory locus for aflatoxin biosynthesis. Appl. Environ. Microbiol. 60, 2408-14. 


\section{Chapter 4}

Fungal allelopathy influences fungusfungivore interactions by suppressing Aspergillus nidulans anti-fungivore defence 


\begin{abstract}
Fungus-fungivore interrelationships are embedded in complex communities and are thus likely to be affected simultaneously by multiple mutualistic and antagonistic interactions with other community members. Fungal allelopathy, chemical interference competition between species of fungi, is one such common interaction in microbial decomposer communities. Drosophila flies are commonly associated with mutualistic yeast, organisms well known to produce metabolites with antifungal activity. In this chapter it is hypothesized that yeasts influence the expression of mechanisms underlying antifungivore resistance in the mycotoxigenic mould Aspergillus nidulans and thereby negatively affect the mould's ability to withstand insect grazing. To test this hypothesis, A. nidulans was exposed to Saccharomyces cerevisiae volatiles. The effect of yeast volatiles on the anti-fungivore resistance were checked by combining organismic experiments with molecular genetic (qRT-PCR) and biochemical analyses (HPLC-MS). The results show that allelopathic metabolites released by $S$. cerevisiae strongly affects morphological and chemical differentiation of A. nidulans. This phenotypic shift leads to a consistently reduced capacity of the mould to harm the fly larvae and impairment of the inducibility of fungal genes involved in resistance to insect grazing. This study thus supports the notion that fungal allelopathy, by modifying chemical properties of the insects' developmental niche, can alter the sign and strength of trophic links and confirms that heterogeneity in the outcome of fungus-grazer interactions is linked to variation in inducible anti-fungivore defence.
\end{abstract}




\section{Introduction}

Interactions between fungi and invertebrate grazer are ubiquitous in most ecosystem. However, this interrelationship is affected by other biotic interactions such as competition between invertebrate host fungi and other microbes e.g. bacteria and yeast (Droby et al., 1989; Spraker et al., 2014). Chemical interference competition, commonly known as allelopathy, is based on the biosynthesis of metabolites, which probably has evolved due to competition for limiting factors $e . g$. nutrients and space (Droby et al., 1989; Nunes et al., 2001). Yeast, for example, produce several bioactive metabolites with antifungal activity. Some compounds diffuse into the growing substrate, while volatile organic compounds (VOCs) (Droby et al., 2002; Fernandes et al., 1998; Liu et al., 2007) enter the gas phase. Yeast volatiles e.g. alcohols, aldehydes or esters, are common breakdown products of fermenting fruits that suppress growth of several moulds, e.g. Penicillum, Botrytis or Alternaria (Chan and Tian, 2005; Spadaro et al., 2002; Wilson et al., 1993). Such compounds are assumed to confer a fitness advantage against competitors, and have thus been suggested to have evolved as a competitive mechanism (Thomson et al., 2005). Notably, the evolution of such mechanism in yeast might influence organisms associated with them e.g. saprophagus Drosophila flies. Drosophila melanogaster flies are wellknown for breeding on fermenting fruits and have evolved tolerance of substrates with high levels of alcohols (David et al., 1976; Mercot et al., 1994). Adaptation to alcoholrich resources provides fruit breeder species a competitive advantage over non-fruit breeder species. Moreover, Drosophila flies are nutritional dependent on yeast. Yeast provides them essential nutrients like vitamins and sterols (Sang, 1978) which play an essential role in the development and survival of Drosophila larvae (Anagnostou et al., 2010; Starmer and Aberdeen, 1990). In addition, yeasts detoxify plant metabolites by metabolizing toxic fatty acids or 2-propanol, further enhancing fly fitness (Starmer et al., 1982, 1986). Yeasts in turn use the flies as a dispersion vectors, which compensates for the absence of active spore dispersal mechanisms (Gilbert, 1980).

Filamentous mould fungi are common co-inhabitants of the Drosophila's larval habitat. Many of such moulds produce toxic secondary metabolites that detrimentally affect Drosophila larvae (Trienens et al., 2010; chapter 2). However, the presence of yeast on plant tissue inhibits moulds growth (Bleve et al., 2006). Despite the wealth of evidence that yeast volatiles have the potential to impair mould growth, it is unknown if and how fungal allelopathy affects the anti-fungivore resistance of moulds. In this chapter, the 
extent to which the morphological and chemical properties of a mycotoxigenic mould (Aspergillus nidulans) and their corresponding molecular genetic mechanisms are affected by allelopathic interactions with a yeast (Saccharomyces cerevisiae) and correlate these changes with the grazing success of D. melanogaster larvae are tested. Thereby, it is hypothesised that the larvae will be able to use the mould as a food source as fungal allelopathy suppresses anti-fungivore defence mechanisms.

In a number of preliminary experiments it was verified that Saccharomyces cerevisiae can inhibit $A$. nidulans growth. By varying the culture medium it turned out that inhibition is likely to be due to presence of sucrose in the medium (Figure 1).

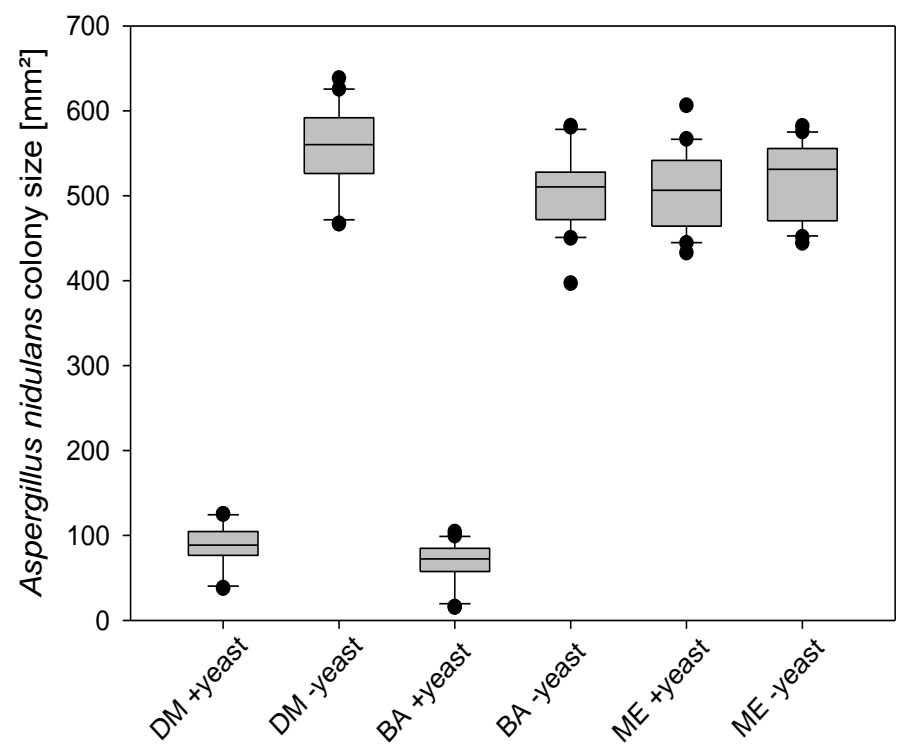

Figure 1. Differences in Aspergillus nidulans colony size when exposed to Saccharomyces cerevisiae metabolites cultivated in sucrose-rich medium and sucrose-deficient media. A. nidulans colony size is heavily affected when exposed to yeast metabolites in Drosophila medium (DM) and banana medium (BM), but not in malt extract medium (ME). The difference among these three media is the presence/absence of sucrose. DM and BA are sucrose-rich medium, however, ME is sucrose-deficient medium. Therefore, the drop of the colony size of A. nidulans when exposed to yeast was likely due to the sugar content in the media.

Another preliminary experiment revealed that $A$. nidulans growth is arrested for a couple of days when the mould is co-cultivated in a common airspace with yeast on sucrose-rich medium. Afterwards, A. nidulans colonies produce massively aerial hyphae forming large cotton-like colonies displaying the so called "fluffy phenotype" (Wieser et al., 1994; Spraker et al., 2014) (Figure 2). Moreover, mould colonies exposed to yeast volatiles do not form conidia (Figure 2). 


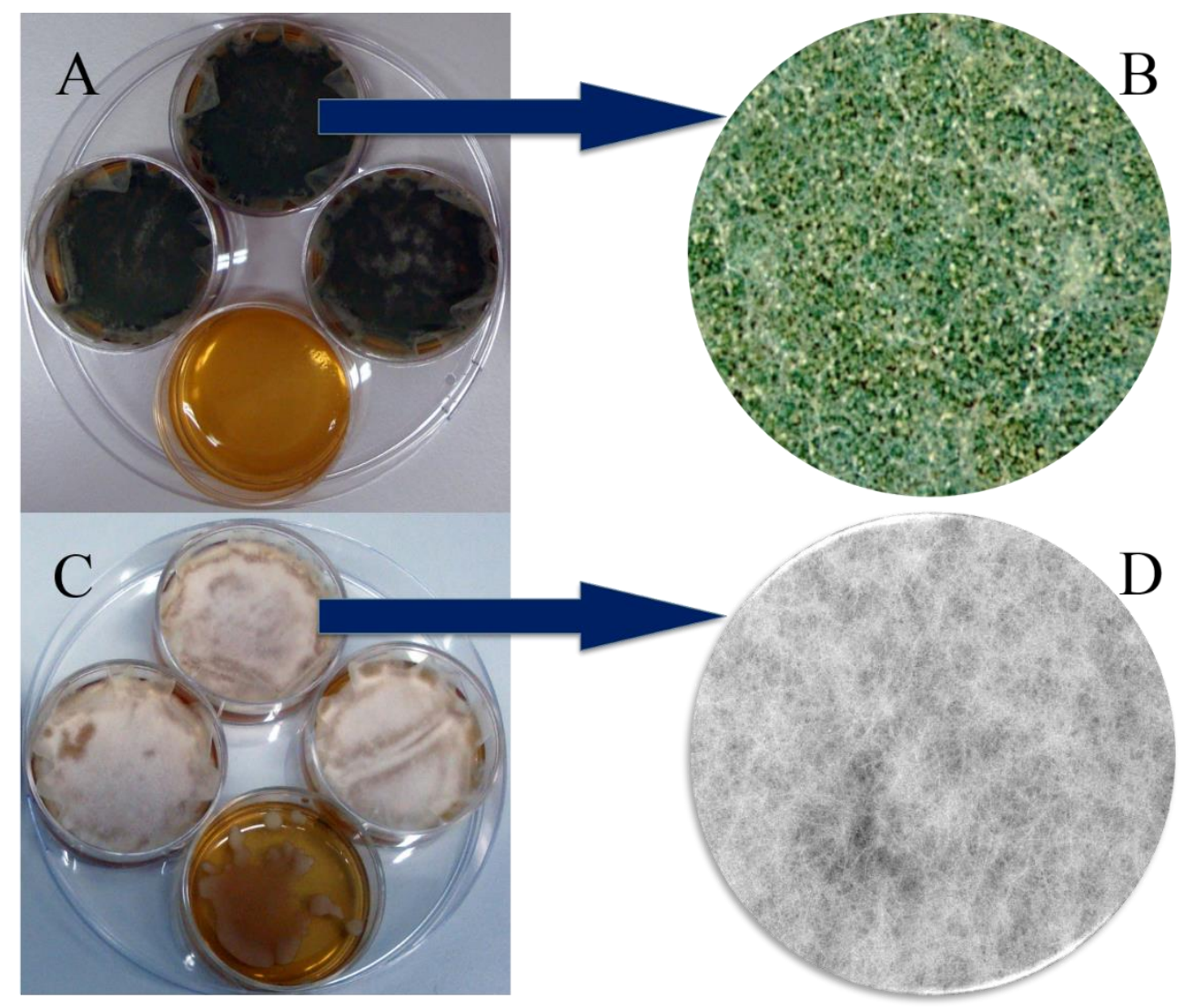

Figure. 2. Effect of Saccharomyces cerevisiae volatiles on the morphology of Aspergillus nidulans. Aspergillus nidulans was co-cultivated in a common airspace with a plate containing ringer solution (Panel A) as a control and with $S$. cerevisiae (Panel C) as a treatment, both in malt extract agar medium (MEA) + sucrose medium. Panel A shows 4-day-old A. nidulans colonies mycelium largely covered by conidia, as revealed by microscopic examination (Panel B). Co-cultivation with S. cerevisiae (Panel C) resulted in a fluffy phenotype (aconidial aerial hyphae mat) after 4 days (Panel D). Images from Panel A and C were taken with digital camera, DCS-W170 (Sony, Japan). Images from panel B and D were taken with stereomicroscope, Discovery V8, Zeiss, Germany, equipped with a digital camera system, AxioCam Icc1, Zeiss, Germany.

Apparently, the absence of conidia in fluffy A. nidulans mutants correlates with a decrease in mycotoxin formation (Hicks et al., 1997). The mechanisms regulating conidiation and sterigmatocystin production in A. nidulans have been shown by characterization of the protein kinase catalytic subunit pkaA (Shimizu and Keller, 2001). Deletion of $p k a A$ leads to hyperconidiation, whereas the overexpression of $p k a A$ inhibits $\operatorname{brlA}$ and aflR expression. The suppression of $\operatorname{brlA}$ and $a f l R$ expression leads to a reduction of conidiation and mycotoxin production since these genes encode for a pathway-specific transcription factors, conidiation and sterigmatocystin biosynthesis respectively. Because anti-fungivore resistance is thought to be mediated by secondary metabolites, the suppression of $p k a A$ expression might impair the anti-fungivore resistance by decreasing conidiation and sterigmatocystin production (Figure 3) (Shimizu and Keller, 2001). 


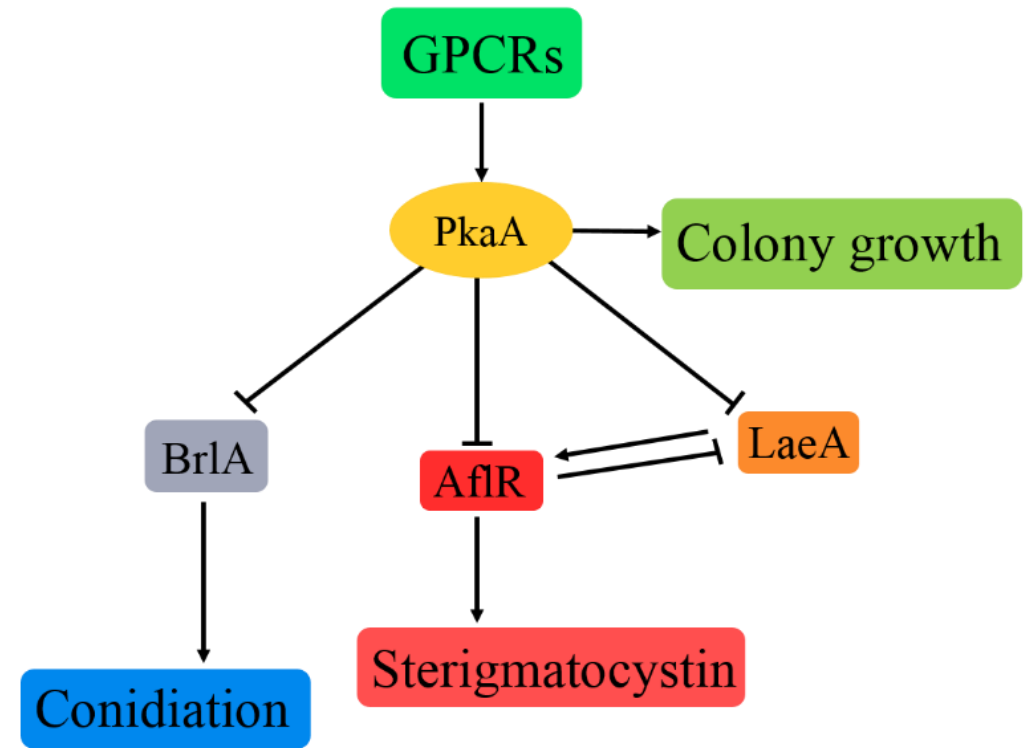

Figure 3. Mechanisms underlying the regulation of conidiation, growth and sterigmatocystin biosynthesis in Aspergillus nidulans. GPCRs, G-protein coupled receptors, perceive external stimulus and transmit the signal to the heterotrimeric G-proteins. These proteins relay and propagate the signal to different regulatory proteins to coordinate a response in fungi (Morris and Malbon, 1999). PkaA in A. nidulans, is the primary PKA that positively regulates vegetative growth and spore germination but negatively controls asexual sporulation and production of sterigmatocystin, a potent anti-insectan mycotoxins. PkaA blocks transcriptional activation of conidiation and secondary metabolite biosynthesis by blocking BrlA and AflR. Furthermore, PkaA exhibits negative control over AflR indirectly by inhibition of LaeA (Calvo et al., 2002; Scheidegger and Payne, 2003; Shimizu and Keller, 2001).

To gain insights into the molecular and chemical basis of yeast metabolite-mediated changes and what the consequences are for insect grazing efficiency, a series of experiments were run to test (i) whether the altered morphology of A. nidulans is caused by habitat-dependent release of allelopathic yeast metabolites, (ii) whether the altered morphology of A. nidulans is related to changes in the expression of genes involved in signal transduction, regulation of conidiation and secondary metabolite formation, (iii) whether the chemical phenotype of A. nidulans is affected as well, (iv) whether grazing of Drosophila larvae induces the expression of "fungivore resistance" genes and (v) whether the outcome of the grazer-mould interaction is shifted in favour of the fly larvae. By explicitly interlinking fungal allelopathy with changes in the morpho-chemical phenotype of A. nidulans and altered resistance to insect grazing, this study provides evidence that non-trophic intra-guild interactions may be of utmost relevance for the shape of trophic links in decomposer communities and corroborates the hypothesis that fungus-fungivore interactions are regulated by an inducible anti-fungivore defence. 


\section{Materials and Methods}

\subsection{Culture of organisms.}

The Drosophila melanogaster culture used in the experiments originated from 113 isofemale lines caught in Kiel, Germany, in 2006. Sterile larvae were prepared following routine methods (Trienens et al., 2010).

The A. nidulans strain used in the experiments was a wild type isolate (RDIT 2.3) (Bok and Keller, 2004). Cultivation of fungi and harvesting of conidia followed published protocols (Trienens et al., 2010; Chapter 2). Fungi were incubated at $25{ }^{\circ} \mathrm{C}$ in constant darkness. Shortly, wild type A. nidulans (veA1; RDIT2.3) was cultured on sterilised malt extract medium (MEA) (9 g malt, $1.5 \mathrm{~g}$ peptone and $6 \mathrm{~g}$ agar in $300 \mathrm{ml}$ deionised water) at $25^{\circ} \mathrm{C}$ and constant darkness. After 7 days, mature conidia were scraped off in $5 \mathrm{ml}$ of autoclaved ringer solution $(2.58 \mathrm{~g} \mathrm{NaCl}, 90 \mathrm{mg} \mathrm{CaCl} 2,105 \mathrm{mg} \mathrm{KCl}$ in $300 \mathrm{ml}$ deionised rohflswater) containing Tween $80(0.1 \%)$ with a sterilised scoop. A haemocytometer (Neubauer Improved) was used to count and subsequently adjust the suspension to a titre of 10,000 conidia per $\mu 1$. Conidia suspensions were not kept longer than 2 weeks at $4{ }^{\circ} \mathrm{C}$.

The S. cerevisiae strain used in the experiments was DSM70449. Cultivation of S. cerevisiae followed routine protocols (Anagnostou et al., 2010) at $25^{\circ} \mathrm{C}$ in constant darkness. Briefly, S. cerevisiae suspension was obtained from a glycerol stock kept at $-80^{\circ}$ C. S. cerevisiae liquid cultures grew overnight (12 hours) in $50 \mathrm{ml}$ of sterilized $\mathrm{ME}$ Bouillon (1.8 g malt extract, $1.8 \mathrm{~g}$ glucose, $1.8 \mathrm{~g}$ maltose, and $0.66 \mathrm{~g}$ yeast extract in 300 $\mathrm{ml}$ deionised water), at room temperature with constant agitation. The suspension was then pelleted by centrifugation at $3500 \mathrm{rpm}$ and washed in equal volume of sterilized distilled water. This step was then repeated. A haemocytometer (Neubauer Improved) was employed to count and subsequently adjust the suspension to a titre of 1500 cells per $\mu$ l. Yeast suspensions were not kept longer than 2 weeks at $4^{\circ} \mathrm{C}$.

\subsection{Yeast volatile profile analysis in sucrose-rich and sucrose-deficient media.}

\section{Volatile profile analysis of Saccharomyces cerevisiae}

To analyse the volatile profile of $S$. cerevisiae cultivated in sucrose-deficient medium, 8 sterilized vessels were filled with $20 \mathrm{ml}$ of sterilized MAE. Then $50 \mu \mathrm{l}$ of S. cerevisiae suspension were inoculated and uniformly distributed over the surface by rotating the tubes manually. Tubes were sealed with foil and incubated for 4 days at $25^{\circ} \mathrm{C}$ in constant darkness. All these steps were done under sterile conditions by using a biological safety 
cabinet with laminar flow (Thermo Scientific, USA). The volatile profile of S. cerevisiae cultivated in sucrose-rich medium was analysed in parallel. It was then used sterilized MEA $+18.75 \mathrm{~g}$ sucrose. The procedure for the sucrose-rich medium treatment followed the same steps as those for the sucrose-deficient medium treatment previously described. Sixteen vessels were finally employed for the experiment, sucrose-rich treatments $(n=8)$ and sucrose-deficient treatment $(\mathrm{n}=8)$. Volatile organic compounds (VOCs) produced by yeast under sucrose-rich and sucrose-deficient media were sampled by means of headspace solid-phase microextraction (SPME) (Pawliszyn, 2000). Compounds were analysed and identified by gas-chromatography mass-spectroscopy (GC/MS). Due to the molecular weights and polarity of the analytes, an $85 \mu \mathrm{m}$ CarbonxenTM/ Polydimethylsiloxane (PDMS) StableFlexTM solid phase micro-extraction (SPME) fiber was used. Yeast volatiles were sampled at room temperature by placing the fiber through the foil into the headspace. The SPME fibres were exposed to the yeast headspace for 30 min and subsequently transferred to the $\mathrm{GC}$ injection port at $250^{\circ} \mathrm{C}$ of temperature. The GC was coupled to a mass spectroscope (Agilent Technologies, 5973N, Palo Alto, USA).

\section{GC/MS parameters}

The carrier gas of the GC was ultrapure helium at a flow rate of $1.0 \mathrm{ml}$ per minute. Volatiles were separated in a non-polar HP-5MS column (Agilent) (30 m in length with $0.25 \mathrm{~mm}$ internal diameter having a film thickness of $0.25 \mu \mathrm{m}$ ). The oven temperature was programmed for an initial temperature of $-30^{\circ} \mathrm{C}$ for $1.5 \mathrm{~min}$, followed by an increase in temperature of $6^{\circ} \mathrm{C}$ per min up to $130^{\circ} \mathrm{C}$. Then an increase of $30^{\circ} \mathrm{C}$ per min up to $200^{\circ} \mathrm{C}$, which was maintained for $3 \mathrm{~min}$. The MS was operated in the scan mode in a range of 20-345 amu, a source temperature of $230^{\circ} \mathrm{C}$, and electron ionization mode at $70 \mathrm{eV}$. The chromatograms were analysed with MSD ChemStation Data Analysis (version D.02.00.275, Agilent Technologies), AMDIS (Automated Mass Spectral Deconvolution and Identification System, version 2.66, Gaithersburg, MD), and NIST Mass Spectral Search Program (database version, NIST 08, software version 2.0f).

\subsection{Effect of single yeast volatiles on Aspergillus nidulans fitness parameters.}

\section{Saccharomyces cerevisiae metabolites}

Those S. cerevisiae volatiles that were significantly produce in higher amounts or synthesized de novo by adding sucrose to the medium from the previous experiment were synthesized and delivered by different companies e.g. Aldrich and Merck, and prepared 
to the concentration of $10^{-1}$ (1:10 yeast VOC mixed with paraffin). Additionally, two control compounds, 2-methylbutanal and phenylethylacetate were included in the experiment. 2-methylbutanal is produced by the media and its volume is reduced in the presence of yeast. Phenylethylacetate is usually produced by yeast but it was not detected in the previous experiment (Table 1).

Table 1. Compounds tested against Aspergillus nidulans

\begin{tabular}{|l|l|l|}
\hline \multicolumn{2}{|c|}{ Compounds } & CAS Number \\
\hline Aliphatic alcohols & Isobutylalcohol & $78-83-1$ \\
\cline { 2 - 3 } & Isoamylalcohols & $123-51-3$ \\
& & $137-32-6$ \\
\hline Aldehydes & $2-m e t h y l b u t a n a l$ & $96-17-3$ \\
\hline Acetates & Ethylacetate & $141-78-6$ \\
\cline { 2 - 3 } & Isobutylacetate & $110-19-0$ \\
\cline { 2 - 3 } & Isoamylacetates & $123-92-2$ \\
& & $624-41-9$ \\
\cline { 2 - 3 } & Phenylethylacetate & $103-45-7$ \\
\hline \multirow{4}{*}{ Esters } & Ethylpropanoate & $105-37-3$ \\
\cline { 2 - 3 } & Ethylbutyrate & $105-54-4$ \\
\cline { 2 - 3 } & Ethylhexanoate & $123-66-0$ \\
\cline { 2 - 3 } & Ethyldecanoate & $110-38-3$ \\
\hline
\end{tabular}

Aspergillus nidulans handling and confrontation assays with autentic yeast volatiles Plates $(\varnothing=35 \mathrm{~mm})$ were filled with $3 \mathrm{ml}$ sterilized MAE + sucrose. A piece of $\mathrm{KOH}-$ treated and sterilised cellophane was placed on the solid medium. Each plate was then dot inoculated with $1 \mu \mathrm{l}$ conidia suspension. Plates contained the final concentration of $10^{4}$ conidia per plates.

To expose A. nidulans tissue to single yeast volatile, sterile circular filter papers were placed in $(\varnothing=90 \mathrm{~mm})$ plates together with two plates $(\varnothing=35 \mathrm{~mm})$ containing $A$. nidulans. Afterwards, $100 \mu \mathrm{l}$ of yeast metabolite at $10^{-1}$ concentration were pipetted on the circular filter paper. The $90 \mathrm{~mm}$ plates were closed and sealed with parafilm so that volatiles could not leak out. Each treatment contained 5 biological replicates. Control colonies of A. nidulans were set up in the same manner as treatments, but they were exposed to a filter paper containing $100 \mu \mathrm{l}$ of paraffin (control). After 3 days, biomass, number of conidia and fungal area were quantified. Each colony was photographed with a digital camera DCS-W170 (Sony, Japan) and with a stereomicroscope (Discovery V8, Zeiss, Germany) equipped with a digital camera system (AxioCam Icc1, Zeiss, Germany). To calculate fungal area, the images were analyzed by ImageJ software. Then, fungal tissue 
was scraped with a scalpel and lyophilized for 24 hours. The tissue was then weighted with a balance (Fisher FI110, Germany). One colony of $A$. nidulans from each biological replicate from each treatment was filled with $2 \mathrm{ml}$ of ringer solution containing Tween $80(0.1 \%)$. The fungal tissue was carefully scraped off with a scoop. Then $1 \mathrm{ml}$ of the solution was pipetted into a $1.5 \mathrm{ml}$ Eppendorf tube. Afterwards, $2 \mu 1$ were introduced into a haemocytometer to count the conidia. Two technical replicates from the same colony were counted.

\subsection{Yeast volatile influenced Aspergillus nidulans metabolic profile analysis.}

\section{Handling of Saccharomyces cerevisiae and Aspergillus nidulans}

For the inoculation of $S$. cerevisiae, plates $(\varnothing=35 \mathrm{~mm})$ were filled with $3 \mathrm{ml}$ of sterilized MEA medium + sucrose. Then each plate was inoculated with $100 \mu 1$ of S. cerevisiae suspension. Plates were closed with the lids and incubated for 12 hours at $25^{\circ} \mathrm{C}$ and constant darkness.

For the inoculation of $A$. nidulans, plates $(\varnothing=35 \mathrm{~mm})$ were filled with $3 \mathrm{ml}$ of sterilized MEA + sucrose. The medium was covered by a piece of sterilized and cooked cellophane. Then each plate was inoculated with $100 \mu$ l of conidia suspension. The plates were rotated to spread the suspension across the whole cellophane. Plates were closed with lids and incubated for 12 hours at $25^{\circ} \mathrm{C}$ in constant darkness.

\section{Fungus-fungus confrontation assay}

After 12 hours of incubation separately, 2 colonies of $A$. nidulans were co-culture with one colony of $S$. cerevisiae in a $90 \mathrm{~mm}$ plate as a yeast-challenged colonies. Plates $(\varnothing=90$ $\mathrm{mm}$ ) were close and sealed with parafilm to ensure that yeast volatiles will not leak out through the thin gap left between the lid and the plate. For unchallenged colonies (control), 2 colonies of $A$. nidulans were co-culture with 1 plate $(\varnothing=35 \mathrm{~mm})$ containing only MEA medium + sucrose and inoculated with $100 \mu$ lof ringer solution and placed in a $90 \mathrm{~mm}$ plate. Plates $(\varnothing=90 \mathrm{~mm})$ were close and sealed with parafilm. Plates were then incubated for 8 days at $25^{\circ} \mathrm{C}$ in constant darkness. After the confrontation, colonies of A. nidulans were scraped off with a scalpel and snap-frozen in liquid nitrogen. Two colonies of $A$. nidulans were pooled to generate a biological replicate, having finally $\mathrm{n}=5$ unchallenged biological replicates and $n=5$ yeast-challenged biological replicates. Afterwards, the tissue was lyophilized for 24 hours using a freeze-dryer (Zirbus VaCo 2, Germany). 


\section{Metabolic profile analysis of yeast volatile influenced Aspergillus nidulans}

Metabolic profile analysis was performed essentially as described previously (Döll et al., 2013). In brief, fungal metabolites were extracted by adding $1 \mathrm{ml}$ of acetonitrile/water $(84 / 16, \mathrm{v} / \mathrm{v})$ to $100 \mathrm{mg}$ of lyophilized tissue. For targeted and non-targeted metabolite analysis and MS fragmentation a reverse-phase HPLC system coupled with an ion trap mass spectrometer (500-MS, Varian) equipped with an electrospray ionization (ESI) source (Ratzinger et al., 2009) was used. Data processing encompassed background reduction, peak identification, peak alignment and normalization, which followed standard protocols (Laurentin et al., 2008).

\subsection{Yeast volatile influenced Aspergillus nidulans gene expression analysis.}

\section{Fungus-fungus confrontation assay}

Aspergillus nidulans and S. cerevisiae were inoculated and incubated for 12 hours separately. Afterwards, 2 colonies of A. nidulans were co-culture in a $90 \mathrm{~mm}$ plates with 1 colony of $S$. cerevisiae to generate the challenged samples. Plates $(\varnothing=90 \mathrm{~mm})$ were closed and sealed with parafilm to ensure that yeast volatiles will not leak out the plate. Challenged samples were incubated for 8 days. To generate the unchallenged samples (control), 2 colonies of $A$. nidulans were co-culture with one plate $(\varnothing=35 \mathrm{~mm})$ containing only MEA medium + sucrose and $100 \mu \mathrm{l}$ of ringer solution in a $90 \mathrm{~mm}$ plates. Plates $(\varnothing=90 \mathrm{~mm})$ were closed and sealed with parafilm. Unchallenged samples were incubated for 36 hours (maximum time before colonies start to conidiate). Then colonies were scraped off with a scalpel and snap-frozen in liquid nitrogen. Two colonies of A. nidulans were pooled to generate a biological replicate, having finally $n=5$ unchallenged biological replicates and $n=5$ challenged biological replicates. Colonies were lyophilized for 24 hours before the tissue was powdered with a mortar and pestle. For RNA isolation, $10 \mathrm{mg}$ of fungal tissue was treated with $1 \mathrm{ml}$ TRIzol® Reagent (Ambion) and possible genomic DNA contamination was subsequently digested with TURBO DNA-free (Ambion). RNA quantity and purity were determined by measuring absorbance at $\mathrm{A}_{260 / 280}$ with a plate reader (Tecan M200, Germany). RNA integrity was determined by formaldehyde denaturating agarose gel $(0.65 \%)$. To ensure that the RNA samples were completely free of DNA contaminations after DNA digestion, standard PCR combined with polyacrylamide (PAA) gel analysis was run. No DNA bands were revealed on the gels meaning that the RNA samples were free of genomic DNA (for further details see chapter 2). 


\section{Quantitative Real-Time Reverse Transcription PCR (qRT-PCR)}

Quantitative real-time RT-PCR was essentially done in the same manner as described in chapter 2. In brief, primer sequences were designed with Primer Premier Software (Premier Biosoft) and synthesized and provided by Eurofins (http://www.eurofins.de). BLAST searches were conducted to ensure the specificity of amplification. Moreover, PCR and melting curve analysis of all PCR products were conducted and additionally, all PCR products were sequenced to ensure that only gene products of interest were amplified (See chapter 2 for more details). Table 2 lists the primer sequences used in this experiment.

Table 2. Primer list.

\begin{tabular}{|c|c|c|c|}
\hline $\begin{array}{l}\text { Gene } \\
\text { (ID) }\end{array}$ & '5 $\rightarrow 3$ ' & $\begin{array}{l}\text { Predicted } \\
\text { amplicon size }\end{array}$ & $\begin{array}{c}\text { Melting } \\
\text { temperature } \mathbf{T}_{\mathrm{m}} \\
\left({ }^{\circ} \mathrm{C}\right)\end{array}$ \\
\hline $\begin{array}{l}\text { laeA } \\
\text { (AN0807) }\end{array}$ & $\begin{array}{l}\text { (F)GCTCCTATTCAGCCTCCG } \\
\text { (R)ATGACACTACCGCAACCC }\end{array}$ & $131 \mathrm{bp}$ & 89.6 \\
\hline $\begin{array}{l}\text { aflR } \\
\text { (AN7820) }\end{array}$ & $\begin{array}{l}\text { (F)GTCTCCGAATACTTCCACCT } \\
\text { (R)ATGCCATCCATACCCTCA }\end{array}$ & $114 \mathrm{bp}$ & 86.0 \\
\hline $\begin{array}{l}p k a A \\
\text { (AN6305) }\end{array}$ & $\begin{array}{l}\text { (F)AACCACCGCTACTATGCC } \\
\text { (R)GGAAAGGATGCCTGACG }\end{array}$ & $115 \mathrm{bp}$ & 84.7 \\
\hline $\begin{array}{l}\text { brlA } \\
\text { (AN0973) }\end{array}$ & $\begin{array}{l}\text { (F)GTTGGCACGGAGCAGGAT } \\
\text { (R)CGGGCATAGGCATTCG }\end{array}$ & $159 \mathrm{bp}$ & 89.8 \\
\hline Luciferase & $\begin{array}{l}\text { (F)CCAGGGATTTCAGTCGATGT } \\
\text { (R)AATCTGACGCAGGCAGTTCT }\end{array}$ & 183 bp cDNA & 81.2 \\
\hline
\end{tabular}

An external luciferase control RNA spike (Promega, L4561) was used for normalizing candidate RNA quantification (See chapter 2). The qRT-PCR was performed in a Strategen Mx3000P engine (Agilent) using SYBR Green (Lonza) under the PCR conditions described in chapter 2. PCR efficiencies $(\mathrm{E})$, threshold fluorescence $\left(\mathrm{R}_{\mathrm{CT}^{-}}\right.$ values), and initial fluorescence $\left(\mathrm{R}_{0}\right)$ were determined directly from the PCR kinetic curves. To compare the expression of candidate genes in unchallenged and yeastchallenged samples, $\mathrm{R}_{0}$, which is the equivalent of the initial amount of candidate mRNA in a sample (Schefe et al., 2006) was used. For the results of each qRT-PCR the quantity equivalent, $R_{0}$, of the candidate gene was considered relative to independent $R_{0}$ for the

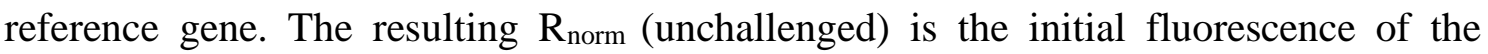
candidate gene normalized to the reference gene in the control sample and $R_{\text {norm }}$ (yeastchallenged) that in the A. nidulans colonies exposed to S. cerevisiae. 


\subsection{Inducible resistance in the yeast volatile influenced mould by larval grazing.}

Aspergillus nidulans and S. cerevisiae were incubated for 12 hours separately. For unchallenged samples (control), two colonies of A. nidulans were co-cultured with one colony of $S$. cerevisiae in a $90 \mathrm{~mm}$ plates. Plates $(\varnothing=90 \mathrm{~mm})$ were closed and sealed with parafilm to prevent that yeast volatiles will leak out of the plate. Unchallenged samples were incubated for 8 days at $25^{\circ} \mathrm{C}$ in constant darkness. To obtain insect-challenged samples, A. nidulans colonies were co-incubated with one colony of S. cerevisiae for only 7 days. Forty sterile larvae were added to each A. nidulans colony and incubated for 24 hours. At an age of 8 days challenged and unchallenged samples were scraped off with a scalpel and snap-frozen in liquid nitrogen. Two colonies of A. nidulans were pooled to generate a biological replicate, having finally $n=5$ unchallenged samples and $n=5$ challenged samples. The tissue was lyophilized for 24 hours and powdered with a mortar and pestle. RNA analysis and quantitative Real-Time Reverse Transcription PCR were performed essentially as described in the previous experiment.

\subsection{Larval development on yeast volatile influenced Aspergillus nidulans colonies.}

Drosophila melanogaster larvae development on yeast volatile influenced A. nidulans colonies was performed in twin-vials. Plastic vials were filled with either fruit agar medium (50\% mashed banana, 50\% water $+15 \mathrm{~g} / \mathrm{l}$ agar) or MEA + sucrose medium. Aspergillus nidulans was spot inoculated on fruit agar medium with $1 \mu 1$ of 1000 conidia per $\mu 1$ suspension. Mould free controls were inoculated with $1 \mu l$ of sterile ringer solution. S. cerevisiae was inoculated in the MEA + sucrose medium with $20 \mu 1$ of 3000 cells per $\mu 1$ suspension. Both setups were incubated separately at $25^{\circ} \mathrm{C}$ and constant darkness for 48 hours. Afterwards, one fruit agar and one MEA + sucrose vial were joined by connecting the two lids of the vials. The MEA + sucrose vial was on top of fruit vial. Lids were equipped with holes to enable gas exchange between the vials. Dripping of yeast from the top into the bottom vial was not observed in any experimental unit. After 96 hours of further incubation, 10 sterile D. melanogaster larvae were transferred into the mould vials. Migration of larvae from bottom into the top vials was prevented by gauze. This experiment was performed with 16 replicates.

\subsection{Statistical analysis}

To test the differences when sucrose was added to the medium, the effect of $S$. cerevisiae volatiles on the anti-fungivore defence of $A$. nidulans and the effect of the larval grazing 
on the inducible anti-fungivore resistance of the yeast volatile influenced A. nidulans, multivariate analysis of variance (MANOVA) on ranks were run. To test the effect of yeast volatiles on $A$. nidulans metabolic profile a multivariate analysis of variance (MANOVA) was run. To test the effect of S. cerevisiae volatiles on A. nidulans fitness parameters (conidiation, fungal growth and biomass) a multivariate analysis of covariance (MANCOVA) was carried out.

\section{Results}

\subsection{Yeast volatile profile analysis on sucrose-rich and sucrose-deficient media.}

Overall, a larger volume of volatiles was released by S. cerevisiae growing on sucroserich medium (7719.1 ppmV \pm 208.9 vs. 19142.5 ppmV \pm 187.9 ; t-test, $\mathrm{P}<0.001)$. The addition of sucrose to the malt extract medium had a significant effect on the production of yeast-specific volatiles (MANOVA, Pillai's $F_{3,12}=44.78, P=0.0047$ ). The volatile profiles revealed a "standard" set of metabolites characteristic of fermenter yeasts (Becher et al., 2012), such as alcohols, aldehydes, esters, and acetates. Eleven out of 14 compounds were formed in excess or appeared de novo under sucrose-rich conditions (Table 3). Yet not all compounds were affected equally as the fold changes in response to sucrose differs significantly among the identified volatiles (MANOVA on ranks, $\mathrm{P}<0.001$; Table 3). 
Table 3. Profiles of volatile compounds characteristic of Saccharomyces cerevisiae growing on sucrose-deficient or sucrose-rich malt extract (ME) agar.

\begin{tabular}{|c|c|c|c|c|c|}
\hline & & $\begin{array}{l}\text { sucrose-deficient } \\
\text { ME agar }\end{array}$ & $\begin{array}{l}\text { sucrose-rich } \\
\text { ME agar }\end{array}$ & & \\
\hline Compound & CAS & $\mathrm{ppmV} \pm \mathrm{SE}$ & $\operatorname{ppmV} \pm \mathrm{SE}$ & P-values & $\begin{array}{l}\text { fold changes } \\
\pm \mathrm{SE}\end{array}$ \\
\hline \multicolumn{6}{|l|}{ Aliphatic alcohols } \\
\hline Ethanol & $64-17-5$ & $4676.0 \pm 348.2$ & $12165.1 \pm 140.6$ & $<0.001$ & $2.7 \pm 0.3$ \\
\hline Isobutylalcohol & $78-83-1$ & $295.2 \pm 21.0$ & $243.6 \pm 10.6$ & 0.021 & - \\
\hline "Isoamylalcohols"* & $\begin{array}{l}123-51-3 \\
137-32-6\end{array}$ & $2052.3 \pm 101.7$ & $2854.0 \pm 44.6$ & $<0.001$ & $1.4 \pm 0.1$ \\
\hline \multicolumn{6}{|l|}{ Aldehydes } \\
\hline Acetaldehyde & $75-07-0$ & $104.7 \pm 12.3$ & $189.4 \pm 37.1$ & 0.147 & - \\
\hline \multicolumn{6}{|l|}{ Acetates } \\
\hline Ethylacetate & $141-78-6$ & $362.9 \pm 53.1$ & $1383.3 \pm 30.7$ & $<0.001$ & $4.4 \pm 0.6$ \\
\hline Isobutylacetate & $110-19-0$ & $13.3 \pm 4.2$ & $100.2 \pm 5.1$ & $<0.001$ & $19.5 \pm 6.0$ \\
\hline "Isoamylacetates"* & $\begin{array}{l}123-92-2 \\
624-41-9\end{array}$ & $82.6 \pm 15.0$ & $1628.0 \pm 96.5$ & $<0.001$ & $26.5 \pm 6.3$ \\
\hline \multicolumn{6}{|l|}{ Esters } \\
\hline Ethylpropanoate & $105-37-3$ & $42.4 \pm 9.9$ & $76.7 \pm 2.8$ & 0.010 & - \\
\hline Ethylbutyrate & $105-54-4$ & $7.1 \pm 1.6$ & $56.8 \pm 1.9$ & $<0.001$ & $13.0 \pm 3.6$ \\
\hline Ethylhexanoate & $123-66-0$ & $21.7 \pm 0.4$ & $330.8 \pm 16.9$ & $<0.001$ & $259.0 \pm 45.1$ \\
\hline Ethyloctanoate & $106-32-1$ & n.d. & $116.4 \pm 10.5$ & & "de novo" \\
\hline Ethyldecanoate & $110-38-3$ & n.d. & $20.4 \pm 2.2$ & & "de novo" \\
\hline \multicolumn{6}{|l|}{ Aromates } \\
\hline Phenylethylalcohol & $100-42-5$ & $18.4 \pm 3.6$ & $45.0 \pm 2.5$ & $<0.001$ & $3.2 \pm 0.6$ \\
\hline Styrene & $60-12-8$ & $62.1 \pm 6.5$ & $35.5 \pm 2.2$ & $<0.001$ & $0.6 \pm 0.1$ \\
\hline
\end{tabular}

\subsection{Effect of single yeast volatile on Aspergillus nidulans fitness parameters.}

Saccharomyces cerevisiae volatiles had a significant overall effect on A. nidulans fitness parameters (conidia, area and biomass) (MANCOVA, Wilks' lambda $F_{18,187}=9.481$; $\mathrm{P}<0.001)$. It remains true even when the effect of different experimental series were removed, although there were significant differences between series (MANCOVA, Wilks 'lambda $\left.\mathrm{F}_{3,66}=33.894 ; \mathrm{P}<0.001\right)$. 
S. cerevisiae volatiles had a significant effect on fitness parameters (conidia, colony growth and biomass) (MANCOVA between subjects, conidia $\left(\mathrm{F}_{6,68}=16.141 ; \mathrm{P}<0.001\right)$, fungal growth $\left(\mathrm{F}_{6,68}=9.203 ; \mathrm{P}<0.001\right)$, and biomass $\left(\mathrm{F}_{6,68}=23.682 ; \mathrm{P}<0.001\right)$.

In general, all the single yeast volatiles tested against $A$. nidulans decreased conidiation, but interestingly, ethylacetate and 2-methylbutanal induced striking effects. While ethylacetate enhanced aberrant conidiation, 2-methylbutanal heavily suppressed it. Moreover, among all the volatiles tested against $A$. nidulans fungal growth, 2-methylbutanal was the volatile that most strongly inhibited fungal growth. The yeast volatiles tested against $A$. nidulans biomass had in general a negative effect, however, among them, 2-methylbutanal massively suppressed fungal biomass development (Figure 4). 

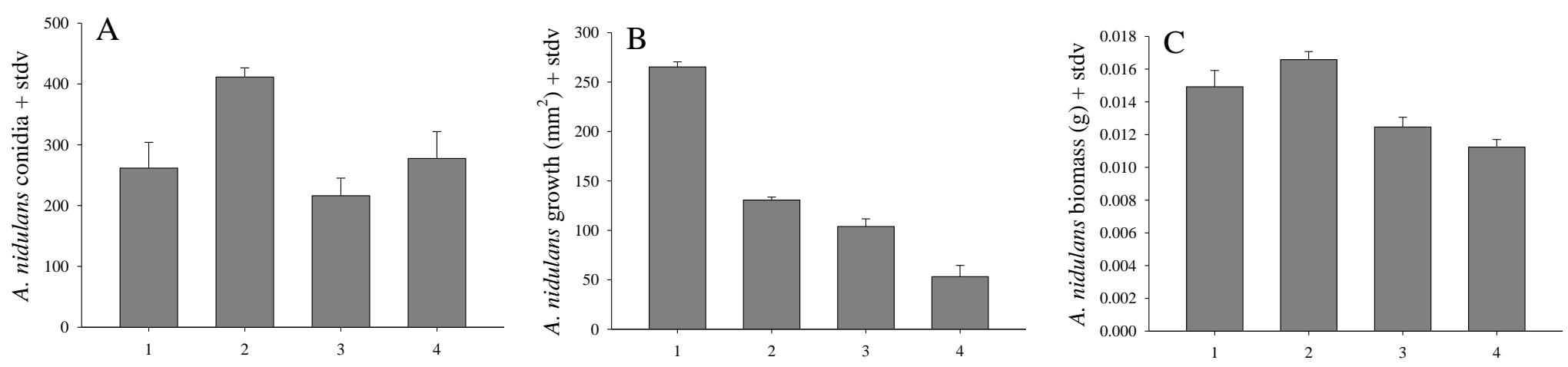
1. Paraffin
2. Ethylacetate
3. Isoamylalcohols
4. Isoamylacetates
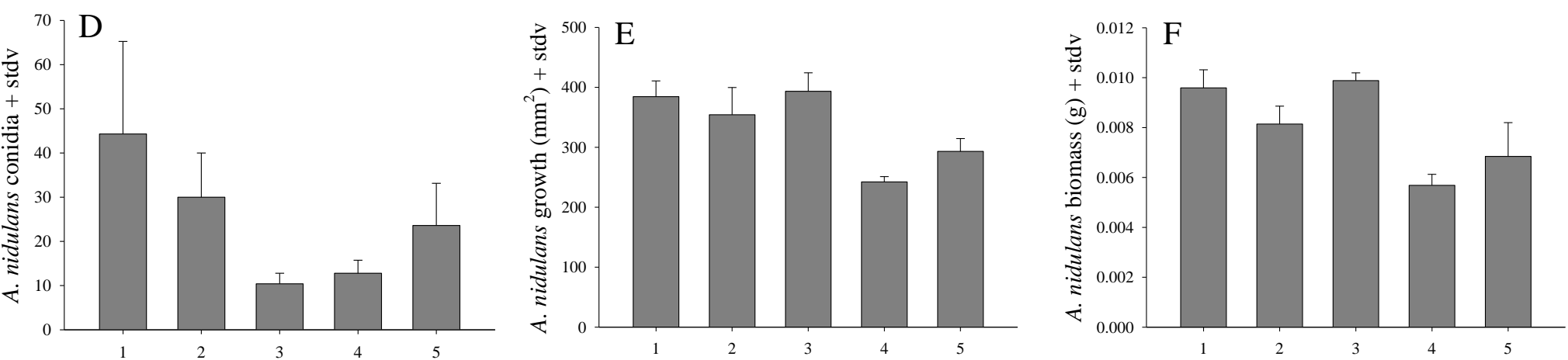

1. Paraffin

2. Ethyloctanoate

3. Ethyldecanoate

4. Ethylhexanoate

5. Phenylethylaceate
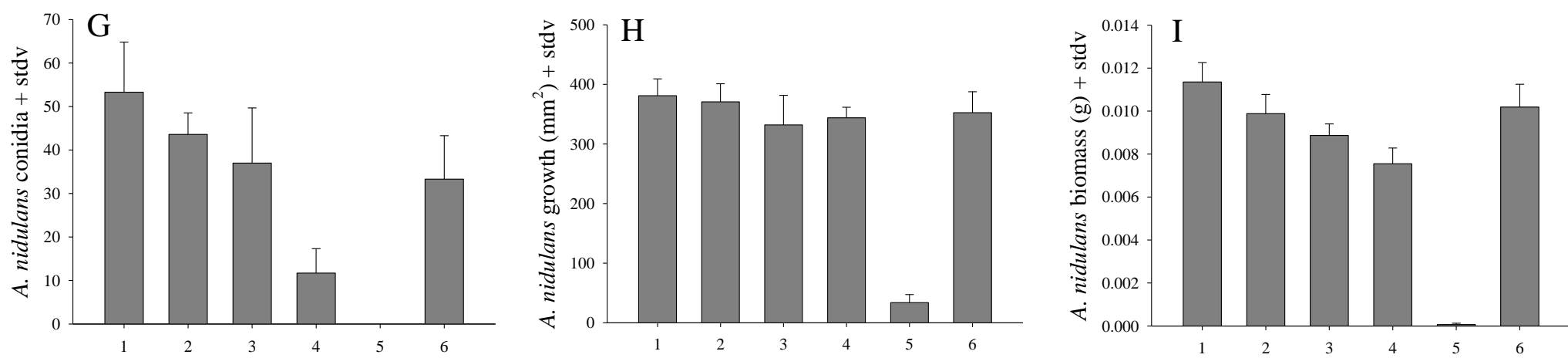

1. Paraffin

2. Ethylpropanoate

3. Isobutylacetate

4. Ethylbutyrate

5. 2-methylbutanal

6. Isobutylalcohol

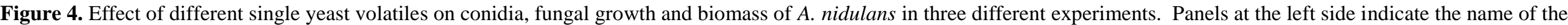
compounds tested against $A$. nidulans. 


\subsection{Yeast volatile influenced Aspergillus nidulans metabolic profile analysis.}

Saccharomyces cerevisiae volatiles had an overall effect on the A. nidulans metabolic profile (MANOVA, Wilks'Lamba $\mathrm{F}_{6,3}=103.021$, $\mathrm{P}=0.001$ ). Sterigmatocystin was not synthesized in neither unchallenged nor challenged colonies, however, austinol and dehydroaustinol were synthesized in unchallenged colonies but not in the yeast volatileinfluenced A. nidulans colonies (challenged). Emericellamide $\mathrm{E}$ and $\mathrm{F}$ present a onefold lower signal in the challenged colonies, however, results revealed that the effect produced by yeast volatiles in emericellamide E was not significant. Emericellamide C and D had almost fivefold and sevenfold lower signal in the challenged colonies relative to that of unchallenged colonies respectively. Separate univariate ANOVAs on the outcome variable revealed a suppressing effect of $S$. cerevisiae volatiles on the formation of emericellamide C, D, and F but not of emericellamide E (Figure 5).
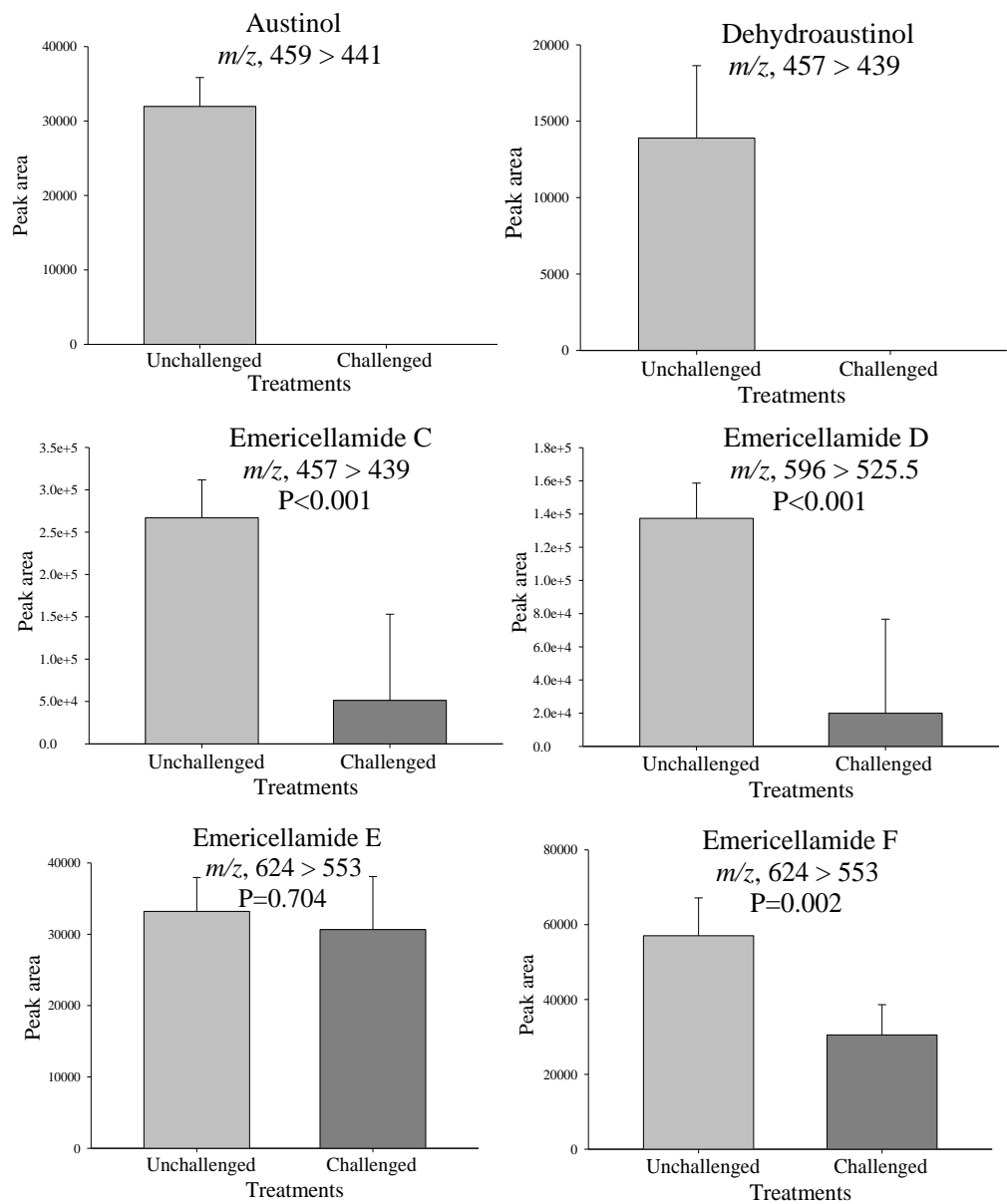

Figure 5. Quantification of $\boldsymbol{A}$. nidulans secondary metabolites by HPLC-MS/MS. Peak area of ion chromatograms of secondary metabolites for unchallenged (control) and challenged (yeast volatile treated) fungal colonies ( $n=5$ per treatment). 


\subsection{Yeast volatile influenced Aspergillus nidulans gene expression analysis.}

Saccharomyces cerevisiae volatiles had an overall effect on candidate gene expression (MANOVA, Wilks'Lamba $\mathrm{F}_{4,5}=20.623, \mathrm{P}=0.003$ ). Moreover, separate univariate ANOVAs on the outcome variable revealed a significant effect of $S$. cerevisiae volatiles on $b r l A$ and $p k a A$ gene expression, however, the expression levels of $l a e A$ and $a f l R$ were not affected by the treatment (Figure 6).
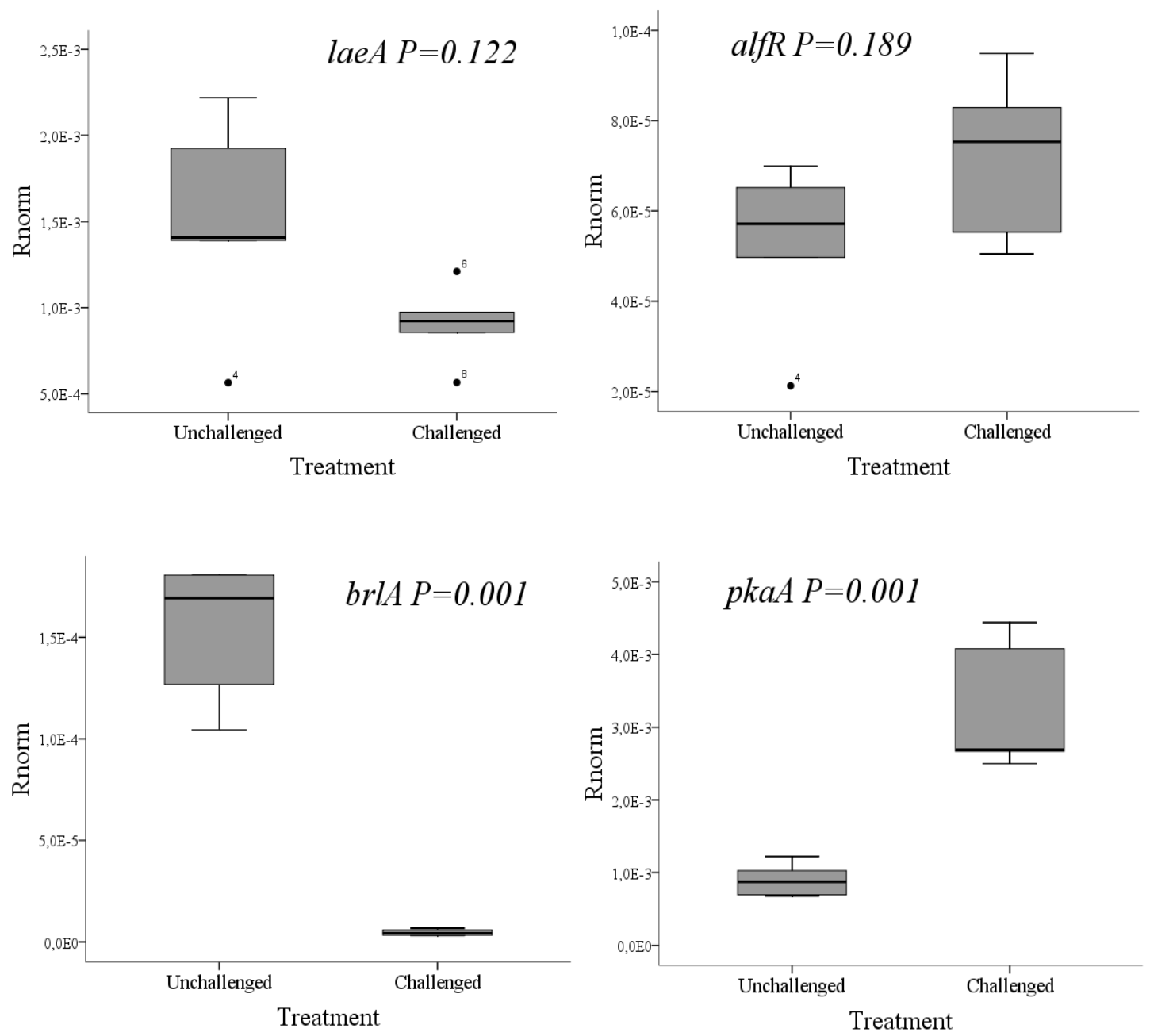

Figure 6. Box-plots depicting Rnorm values of $l a e A$, aflR, brlA and $p k a A$ gene expression as a function of A. nidulans control (unchallenged) and yeast volatile influenced A. nidulans (challenged). Solid lines indicate medians.

\subsection{Inducible resistance in the yeast volatile influenced mould by larval grazing.}

Drosophila melanogaster larvae did not have a significant effect on the candidate gene expression (MANOVA, Wilks 'Lambda $\mathrm{F}_{4,5}=0.049, \mathrm{P}=0.994$ ) (Figure 7). 

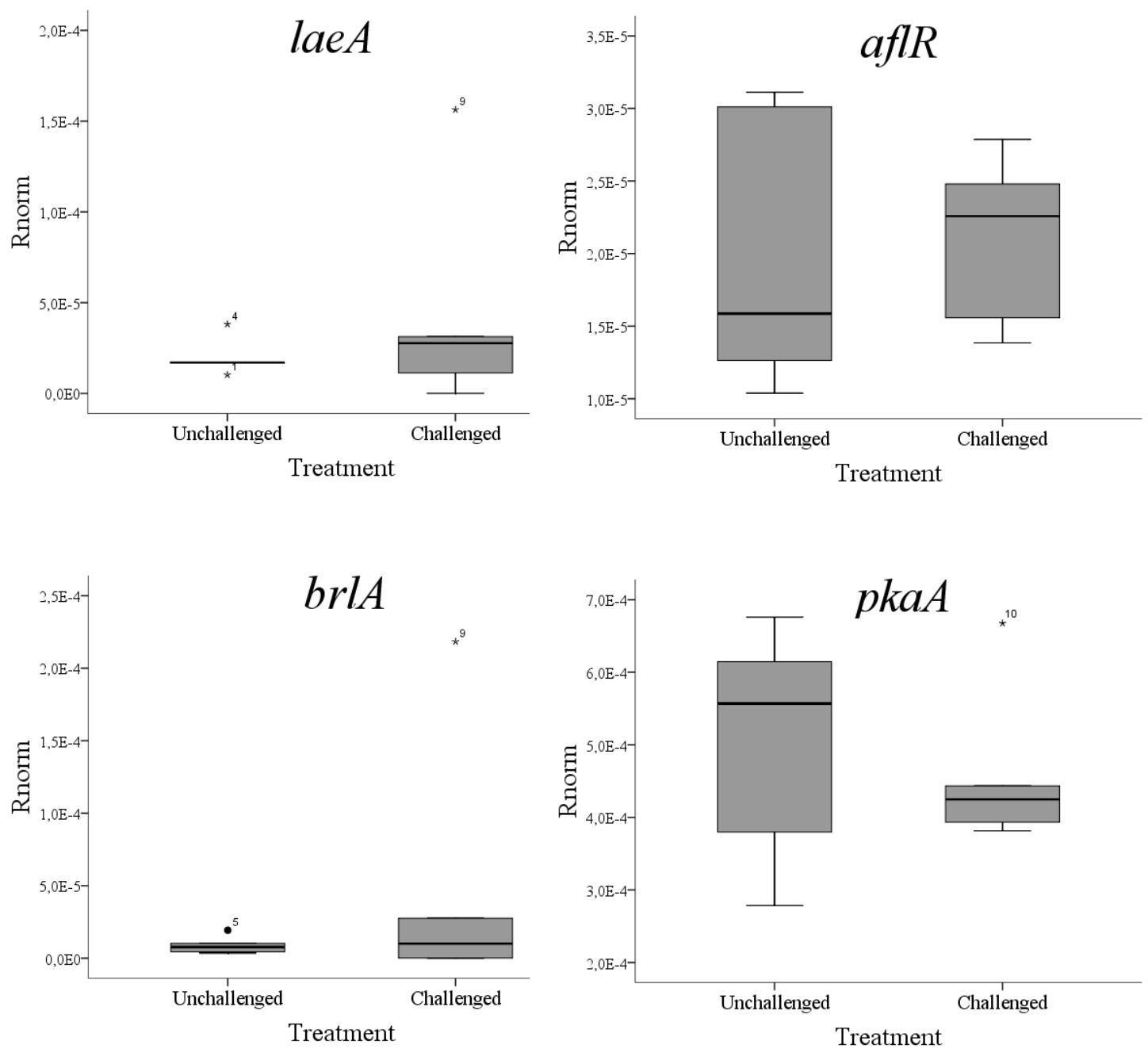

Figure 7. Box-plots depicting Rnorm values of laeA, aflR, brlA and $p k a A$ gene expression as a function of yeast volatile influenced $A$. nidulans control (unchallenged) and yeast volatile influenced A. nidulans + D. melanogaster larvae grazing (challenged). Solid lines indicate medians.

\subsection{Larval development on yeast volatile influenced Aspergillus nidulans colonies.}

In mould-free and in yeast-free substrates larvae were found not to reach the pupal stage, so no fly emergence was observed, however, the average of eclosed flies on yeast volatile influenced A. nidulans was $0.48 \pm 0.032$ SE.

\section{Discussion}

Even though several comprehensive studies on fungal allelopathy have shown detrimental effects on mould growth (Batista et al., 2010; Bleve et al., 2006), it has remained unknown how morphological and biochemical changes in the target fungus influence its capacity to resist fungivore grazing. 
Building on previously made observations that $S$. cerevisiae growing on medium with relatively high amounts of mono- or disaccharides inhibits the growth of A. nidulans, the present study reveals substantial differences of volatile organic compounds released by the yeast on sucrose-rich and sucrose-poor culture medium. Generally, a larger volume of volatiles, common breakdown products of fermenting fruits (alcohols, aldehydes, esters and acetates), released by $S$. cerevisiae on sucrose-rich medium appears to be of relevance for the effects on mould fitness.

Interestingly, several detailed studies, usually motivated by the perspective to control mould contamination of food and feed stuff, show that in particular, large quantities of many of such microbe-borne volatiles have moderate to strong anti-mould properties, and they often induce a "fluffy" aconidial phenotype in the target fungus (Chang et al., 2014; Fredlund et al., 2004; Masoud et al., 2005; Spraker et al., 2014). Moreover, a large body of evidence indicates that this obviously common mould response to microbial volatiles is not a peculiar phenomenon relevant for applied settings only, but it appears to be part of a general restriction of fungal growth in decomposer systems (Garbeva et al., 2011).

The results from testing single yeast volatiles against $A$. nidulans suggest that S. cerevisiae volatiles had a significant overall effect on A. nidulans fitness parameters (conidia, growth and biomass), however, they do not support the hypothesis that a single yeast volatile induces the aconidial fluffy phenotype in A. nidulans. None of the individual compounds tested induced the specific mould phenotype that could be observed under the influence of the whole bouquet released by the living yeast in the coculture assays. It should be noted, however, that there might be a complex interaction between different compounds and their concentration, which would make it extraordinarily difficult to determine the specific combination of yeast metabolites that caused the mould response observed in this study. Thus far, one can conclude that sucrose-dependent quantitative changes, in some or a combination of yeast volatiles, are the main allelopathic factor affecting growth and morphological differentiation of A. nidulans.

Yeast volatiles had a profound effect on the metabolic profile of $A$. nidulans. In particular, austinol and dehydroaustinol, meroterpenoids produced from polyketide and terpenoid precursors (Lo et al., 2012; Kataoka et al., 2011) were absent in yeast volatile-exposed colonies. Interestingly, emericellamides, compounds that have antibiotic activity (Sanchez et al., 2012), were present in challenged colonies, but the amounts were lower 
compared to unchallenged colonies. The absence of austinol and dehydroaustinol may be of particular relevance for the capacity of the mould to resist fungivore, as related compounds have been demonstrated to have insect neurotoxic effects (Kataoka et al., 2011). Further support for a role of these compounds in the anti-fungivore defence of A. nidulans has been provided by Döll et al. (2013). When exposed to the grazing by Folsomia candida (collembola), A. nidulans was found to produce higher amounts of both the meroterpenoids and the emericellamides, which was accompanied by an enhanced capacity to repel the arthropods. Even though the detailed role of these compounds in repelling and/or harming invertebrate grazers remains to be investigated, the present study indicates suppression of a versatile chemical element of the mould's anti-fungivore defence response.

Notably, gene expression results from the yeast volatile influenced A. nidulans experiment partially support the hypothesis that fungal allelopathy suppresses $A$. nidulans conidiation and secondary metabolite biosynthesis. The results indicate that fungal allelopathy caused a significant up-regulation in the expression level of $p k a A$. This protein positively regulates vegetative growth but negatively regulates asexual conidiation by blocking BrlA (See Figure 3) (Shimizu and Keller, 2001). In agreement with this, the expression level of $b r l A$ is significantly down-regulated relative to the level of its constitutive expression in unchallenged colonies. This result is of relevance because reduced levels of conidiation means that the $b r l A$, gene coding for the conidiation-specific transcription factor $\mathrm{BrlA}$, is minimally transcribe leading to an aconidial phenotype typical feature from A. nidulans fluffy phenotype (Adams et al., 1998; Yu et al., 2006). Moreover, PkaA regulates negatively secondary metabolite biosynthesis by blocking AflR and LaeA (See Figure 3) (Shimizu and Keller, 2001). In contrast to our expectations, no significant response to fungal allelopathy was revealed at the gene expression levels of the secondary metabolite genes $l a e A$ and $a f l R$, which would at first glance suggest no effect of fungal allelopathy on A. nidulans secondary metabolism. One has to keep in mind though, that gene expression data were obtained from 8-day-old yeast-affected and 2-day-old control colonies to compare morphologically similar phenotypes. Given this design, our results indicate no age-dependent activation of these genes and in consequence a massive impact on secondary metabolite (see above).

Additionally, results from inducible resistance in the yeast volatile influenced mould by larval grazing experiment revealed that fungal allelopathy strongly affects A. nidulans 
anti-fungivore defence, which seems to be in a strong state of arrest since the grazing of D. melanogaster did not activate the mechanisms underlying the anti-fungivore defence that were shown to be up-regulated by the grazing of the same fungivore in Chapter 2. The grazing of $D$. melanogaster larvae did not significantly affect the expression levels of the candidate genes laeA, aflR, brlA and $p k a A$, the same genes of which in chapter 2 gene expression levels were significantly up-regulated by the grazing of the larvae. A finally negative influence of fungal allelopathy on anti-fungivore defence in A. nidulans is supported by the results from larval development on yeast volatile influenced A. nidulans colonies experiment, which revealed that $50 \%$ of the larvae exposed to the yeast volatile influenced Aspergillus nidulans colonies developed into adult flies. However, results from chapter 2 showed that the same fungus exposed to same fungivore under undisturbed conditions killed $100 \%$ of the larval population. This result indicates that fungal allelopathy turns the fatal fungus into a suitable diet and thus positively influences Drosophila melanogaster development. Significant induced changes in the expression levels of genes involved in signalling and conidiation leading to changes in the metabolic profile suggest a significant shift of $A$. nidulans phenotype by fungal allelopathy that helps the larvae to cope better with the mould. Although fungal allelopathy has a positive influence on the larval development, still $50 \%$ of the larvae died. Several reasons must be involved in this result for instance, the lack of nutrients, competition for limited nutritional resources or because alternative secondary metabolite pathways might be still activated.

Our data show that a habitat-specific blend of yeast metabolites has allelopathic properties which suppress the ability of $A$. nidulans to launch an effective defence response against grazing by Drosophila larvae. This in turn results in an immense benefit to the insects as the obstruction of the defence response converts the fatal mould into an edible fungus. This effect appears to be driven by the misexpression of functionally well-characterised and ecologically important fungal "defence" genes coupled with the suppression of inducible specialised metabolites. Our study thus provides a first mechanistic glimpse into how common allelopathy can affect "normal" physiological reactions of fungi and thereby regulates the outcome of trophic interactions with invertebrate grazers. Finally, it is tempting to hypothesise that understanding the context-dependent nuances of allelopathic intra-guild relationships is important for ecosystem processes, as understanding when and how allelopathy sets in may help predicting dynamic shifts in 
the strength and sign of fungus-grazer interactions and thereby changes in the energy pathways through food webs. Future studies may thus include a broad range of fungal (and fungus-bacteria) interactions to investigate the general role of chemical mediators in shaping multitrophic invertebrate-microbe communities. 


\section{References}

Adams, T.H., Wieser, J.K., Yu, J.H., 1998. Asexual sporulation in Aspergillus nidulans. Microbiol. Mol. Biol. Rev. 62, 35-54.

Anagnostou, C., Dorsch M., Rohlfs, M., 2010. Influence of dietary yeasts on Drosophila melanogaster life history traits. Entomol. Exp. Appl. 136, 1-11.

Batista, M., Leonardo, F., Pozzobon, M., Fabio, P., 2010. Volatile organic compounds produced by Saccharomyces cerevisiae inhibit the in vitro development of Guignardia citricarpa, the causal agent of citrus black spot. World J. Microbiol. Biotechnol. 26, 925-932.

Becher, P.G., Flick, G., Rozpędowska, E., Schmidt, A., Hagman, A., Lebreton, S., Larsson, M.C., Hansson, B.S., Piškur, J., Witzgall, P., Bengtsson, M., 2012. Yeast, not fruit volatiles mediate Drosophila melanogaster attraction, oviposition and development. Funct. Ecol. 26, 822-828.

Bleve, G., Grieco, F., Cozzi, G., Logrieco, A., Visconti, A., 2006. Isolation of epiphytic yeasts with potential for biocontrol of Aspergillus carbonarius and A. niger on grape. Int. J. Foof Microbiol. 108, 204-209.

Bok, J.W., Keller, N.P., 2004. LaeA, a regulator of secondary metabolism in Aspergillus spp. Eukaryot. Cell 3, 527-535.

Calvo, A.M., Wilson, R.A., Bok, J.W., Nancy, P., Keller, N.P., 2002. Relationship between secondary metabolism and fungal development. Microbiol. Mol. Biol. Rev. 66, 447-459.

Chan, Z., Tian, S., 2005. Interaction of antagonistic yeasts against postharvest pathogens of apple fruit and possible mode of action. Postharvest Biol. Technol. 36, 215-223.

Chang, P., Scharfenstein, L.L., Mack, B., Yu, J., 2014. Transcriptomic profiles of Aspergillus flavus CA42, a strain that produces small sclerotia, by decanal treatment and after recovery. Fungal Genet. Biol. 68, 39-47.

David, J.R., Bocquet, C., Arens, M., 1976. Biological role of alcohol dehydrogenase in the tolerance of Drosophila melanogaster to aliphatic alcohols: utilization of an ADH-Null mutant. Biochem. Genet. 14, 989-997.

Döll, K., Chatterjee, S., Scheu, S., Karlovsky, P., Rohlfs, M., 2013. Fungal metabolic plasticity and sexual development mediate induced resistance to arthropod fungivory. Proc. Biol. Sci. $280,1-8$.

Droby, S., Chalutz, E., Wilson, C.L., Wisniewski, M., 1989. Characterization of the biocontrol activity of Debaryomyces hansenii in the control of Penicillium digitatum on grapefruit. Can. J. Microbiol. 35, 794-800.

Droby, S., Vinokur, V., Weiss, B., Cohen, L., Daus, a, Goldschmidt, E.E., Porat, R., 2002. Induction of resistance to Penicillium digitatum in grapefruit by the yeast biocontrol agent Candida oleophila. Phytopathology 92, 393-9.

Fernandes, M., Keller, N.P., Adams, T.H., 1998. Sequence-specific binding by Aspergillus nidulans AflR, a C6 zinc cluster protein regulating mycotoxin biosynthesis. Mol. Microbiol. 28, 1355-65. 
Fredlund, E., Druvefors, U.Ä., Olstorpe, M.N., Passoth, V., Schnürer, J., 2004. Influence of ethyl acetate production and ploidy on the anti-mould activity of Pichia anomala. FEMS Microbiol. Lett. 238, 133-137.

Garbeva, P., Hol, W.H.G., Termorshuizen, A.J., Kowalchuk, G.A., Boer, W. de, 2011. Fungistasis and general soil biostasis - A new synthesis. Soil Biol. Biochem. 43, 469-477.

Gilbert, D.G., 1980. Dispersal of yeasts and bacteria by Drosophila in a temperate forest. Oecologia 46, 135-137.

Hicks, J.K., Yu, J.H., Keller, N.P., Adams, T.H., 1997. Aspergillus sporulation and mycotoxin production both require inactivation of the FadA $\mathrm{G}$ alpha protein-dependent signaling pathway. EMBO J. 16, 4916-23.

Kataoka, S., Furutani, S., Hirata, K., Hayashi, H., Matsuda, K., 2011. Three austin family compounds from Penicillium brasilianum exhibit selective blocking action on cockroach nicotinic acetylcholine receptors. Neurotoxicology 32, 123-129.

Laurentin, H., Ratzinger, A., Karlovsky, P., 2008. Relationship between metabolic and genomic diversity in sesame (Sesamum indicum L.). BMC Genomics 9, 250.

Liu, X., Wang, J., Gou, P., Mao, C., Zhu, Z.-R., Li, H., 2007. In vitro inhibition of postharvest pathogens of fruit and control of gray mold of strawberry and green mold of citrus by aureobasidin A. Int. J. Food Microbiol. 119, 223-229.

Lo. HC., Entwistle. R., Guo. CJ., Ahuja. M., Szewczyk. E., Hung. JH., Chiang. YM., Oakley. BR., W.C., 2012. Two separate gene clusters encode the biosynthetic pathway for the meroterpenoids, austinol and dehydroaustinol in Aspergillus nidulans. J. Chem. Ecol. 134, $4709-4720$.

Masoud, W., Poll, L., Jakobsen, M., 2005. Influence of volatile compounds produced by yeasts predominant during processing of Coffea arabica in East Africa on growth and ochratoxin A (OTA) production by Aspergillus ochraceus. Yeast 22, 1133-42.

Mercot, H., Defaye, D., Capy, P., Pla, E., David, J.R., 1994. Alcohol tolerance, ADH activity, and ecological niche of Drosophila species. Evolution. 48, 746-757.

Morris, A.J., Malbon, C.C., 1999. Physiological regulation of G protein-linked signaling. Physiol. Rev. 79, 1373-1430.

Nunes, C., Usall, J., Teixidó, N., Miró, M., Viñas, I., 2001. Nutritional enhancement of biocontrol activity of Candida sake (CPA-1) against Penicillium expansum on apples and pears. Eur. J. Plant Pathol. 107, 543-551.

Pawliszyn, J., 2000. Theory of solid-phase microextraction. J. Chromatogr. Sci. 38, 270-8.

Ratzinger, A., Riediger, N., Tiedemann, A. Von, Karlovsky, P., 2009. Salicylic acid and salicylic acid glucoside in xylem sap of Brassica napus infected with Verticillium longisporum. J. Plant Res. 122, 571-579.

Sanchez, J.F., Somoza, A.D., Keller, P., Wang, C.C.C., 2012. Advances in Aspergillus secondary metabolite research in the post-genomic area. R. sociaety Chem. 29, 351-371. 
Sang, J., 1978. The nutritional requirements of Drosophila., in: In the genetics and biology of Drosophila. pp. 159-192.

Schefe, J.H., Lehmann, K.E., Buschmann, I.R., Unger, T., Funke-Kaiser, H., 2006. Quantitative real-time RT-PCR data analysis: current concepts and the novel "gene expression's CT difference" formula. J. Mol. Med. 84, 901-10.

Scheidegger, K.A., Payne, G.A., 2003. Unlocking the secrets behind secondary metabolism: A review of Aspergillus flavus from pathogenicity to functional genomics. J. Toxicol. TOXIN Rev. 22, 423-459.

Shimizu, K., Keller, N.P., 2001. Genetic involvement of a cAMP-dependent protein kinase in a $\mathrm{G}$ protein signaling pathway regulating morphological and chemical transitions in Aspergillus nidulans. Genetics 157, 591-600.

Spadaro, D., Vola, R., Piano, S., Gullino, M.L., 2002. Mechanisms of action and efficacy of four isolates of the yeast Metschnikowia pulcherrima active against postharvest pathogens on apples. Postharvest Biol. Technol. 24, 123-134.

Spraker, J.E., Jewell, K., Roze, L. V, Scherf, J., Ndagano, D., Beaudry, R., Linz, J.E., Allen, C., Keller, N.P., 2014. A volatile relationship: profiling an inter-kingdom dialogue between two plant pathogens, Ralstonia Solanacearum and Aspergillus Flavus. J. Chem. Ecol.

Starmer, W., Aberdeen, V., 1990. The nutritional importance of pure and mixed cultures of yeasts in the development of Drosophila mulleri larvae in Opuntia tissues and its relationship to host plant. In: Ecological and evolutionary genetics of Drosophila. 145-160.

Starmer, W., Phaff, H., Miranda, M., 1982. The yeast flora associated with the decaying stems of columnar cacti and Drosophila in North America. Evol. Biol. 14, 269-295.

Starmer, W.T., Barker, J.S., Phaff, H.J., Fogleman, J.C., 1986. Adaptations of Drosophila and yeasts: their interactions with the volatile 2-propanol in the cactus-microorganismDrosophila model system. Aust. J. Biol. Sci. 39, 69-77.

Thomson, J.M., Gaucher, E.A., Burgan, M.F., De Kee, D.W., Li, T., Aris, J.P., Benner, S.A., 2005. Resurrecting ancestral alcohol dehydrogenases from yeast. Nat. Genet. 37, 630-5.

Trienens, M., Keller, N.P., Rohlfs, M., 2010. Fruit, flies and filamentous fungi - experimental analysis of animal - microbe competition using Drosophila melanogaster and Aspergillus mould as a model system. Oikos 119, 1765-1775.

Wieser, J., Lee, B.N., Fondon, J.W., Adams, T.H., 1994. Genetic requirements for initiating asexual development in Aspergillus nidulans. Curr. Genet. 27, 62-9.

Wilson, C.L., Wisniewski, M.E., Droby, S., Chalutz, E., 1993. A selection strategy for microbial antagonists to control postharvest diseases of fruits and vegetables. Sci. Hortic. 53, 183189.

Yu, J., Mah, J., Seo, J., 2006. Growth and developmental control in the model and pathogenic Aspergilli. Eukaryot. Cell 5, 1577-1584. 


\section{Part III.}

General discussion 


\section{Chapter 5}

\section{General discussion}




\section{General discussion}

Many phenotypic changes have been suggested and often demonstrated to be related with defence strategies. Changes in fungal growth characteristics in response to arthropod grazing (e.g. compensatory growth) has repeatedly been observed (Bretherton et al., 2006) and might be interpreted in the light of a fungal strategy to tolerate grazers rather than fending them off. Grazing-induced changes in secondary metabolism that increases the capacity to kill or repel animals might be an alternative route of defence against fungivores. Interestingly, inducible resistance as related to fungal secondary metabolite formation has remained to date unknown. The results in chapter 2 demonstrate that grazing of Drosophila melanogaster larvae induces a phenotype in the mould Aspergillus nidulans that killed the larvae more rapidly than non-induced colonies. The phenotypic shift in resistance to fungivory was accompanied by significant changes in the expression levels of genes involved in different molecular pathways that lead to the biosynthesis of secondary metabolites e.g. laeA, ausA and eas B. This study thus supports by the results of Döll et al. (2013), where changes in the metabolic profile of A. nidulans challenged by Folsomia candida grazing revealed higher levels of sterigmatocystin, austinol, dehydroaustinol, and emericellamides compared to that of the unchallenged colonies. Although sterigmatocystin has been suggested to be the most relevant toxin in the antifungivore defence of A. nidulans, studies done by Trienens and Rohlfs (2012) demonstrate that mutants lacking specific steps along the sterigmatocystin pathway do not to reduce larval survival, but turned out to be even more detrimental to the insects. Our study also revealed that at this early stage of the confrontation, stcA, a gene coding for an early step of the sterigmatocystin pathway, was not differentially expressed. Therefore, it was hypothesised that other compounds, probably unknown or recently discovered but not identified ones (Döll et al., 2013) are involved in mediating resistance against fungivores. Interestingly, the transcription of ipnA, a gene coding for the isopenicillin-N synthase involved in the production of penicillin, was up-regulated under D. melanogaster grazing. It was then assumed that the production of penicillin is related to anti-bacterial resistance rather than to anti-fungivore defence, since wounds caused by insect grazing possibly provide entrance for parasitic or pathogenic bacteria. The results of this chapter demonstrated a direct link between changes in resistance to grazing and regulation of fungal secondary metabolism, but at the same time, revealed an obviously 
complex chemical response that deserves further attention for identifying the ultimate agents of anti-fungivore chemical defences in this model system.

Although one may assume that grazing by fungivores should always enhance antifungivore defence in fungi capable of inducible resistance, results shown in chapter 3 revealed that intense feeding damage suppresses key mechanisms underlying antifungivore resistance in A. nidulans. While feeding of $D$. melanogaster larvae induces the expression levels of genes involved in the regulation and biosynthesis of A. nidulans secondary metabolites, strong grazing pressure by isopods, Oniscus asellus, turned out to suppress the expression of laeA and aflR. This result supports the hypothesis proposed by Stötefeld et al. (2012), namely that the feeding damage caused by high densities of collembola suppresses the anti-fungivore defence of A. nidulans, which allows the animals to achieve more efficient per-capita consumption rates in groups compared singly foraging collembolans. Taking the results of chapter 2 and 3 together, grazer-specific inducible changes in anti-fungivore defence mechanisms that lead to both enhanced as well as reduced resistance appear to be important characteristics of fungus-fungivore interrelationships. These bipartite grazing-induced dynamics might have an important role in affecting intraguild as well as multitrophic interactions.

Fungus-fungivore interactions do not take place in isolation but are embedded in complex multi-species communities that might influence a fungus' ability to launch an efficient defence response. In particular, competing microbes like yeast and bacteria are wellknown for hampering growth of mould and for inducing morphological aberration (Bleve et al., 2006; Spraker et al., 2014); these effects are frequently caused by chemical interference competition, also known as allelopathy. In chapter 4 it was demonstrated that yeast volatile organic compounds influence the morphological and chemical phenotype of $A$. nidulans and thereby its ability to launch the previously described inducible resistance. The direct consequence of the yeast-mediated anti-fungivore defence inactivation in A. nidulans was that D. melanogaster larvae were able to use the mould as a suitable food source and develop into adult flies. In simple terms: fungal allelopathy turned the usually fatal mould into an edible fungus.

This "edible" A. nidulans phenotype shows a strikingly altered morphology characterised by enhanced formation of aerial hyphae but no conidiation. The morphological alteration appeared to be induced by a combination of yeast volatiles and was accompanied by substantial changes in the expression of genes involved in intra-cellular signalling and 
regulation of conidiation. Genes involved in the regulation of secondary metabolites and resistance against fungivore, laeA and $a f l R$, were not significantly affected. In contrast to the previously demonstrated inducibility of these genes, expression levels of laeA and $a f l R$ were not affected by insect grazing when colonies were exposed to yeast volatiles. This result indicates that fungal allelopathy prevents insect-induced changes in the fungal secondary metabolism as controlled by epigenetic and pathway-specific secondary metabolite regulators. Moreover, the absence of austinol and dehydroaustinol and lower levels of emericellamides in yeast volatile influenced $A$. nidulans indicate a reduced ability of the mould to build a constitutive chemical shield. The combined effect of the demonstrated lack of inducible resistance and the constitutively reduced chemical diversity appears to be a very likely explanation for why Drosophila larvae are able to use allelopathy-affected mould colonies as a suitable diet that allows them to develop into adults. Chapter 4 thus highlighted the potential impact of fungal allelopathy in determining the outcome of fungus-fungivore interactions. Yet many details need to be disentangled in future studies. For instance, it still remains unknown which specific role austinol, dehydroaustinol and emericellamides play in mediating direct resistance, whether the phenotypic shift is a specific response of $A$. nidulans to yeast volatiles or whether this phenomenon is of general relevance in more complex fungus-fungivore communities.

The results shown in this thesis demonstrate that fungal resistance against grazers is highly dynamic and responds to multiple environmental changes by altering parts of the signalling and secondary metabolite pathways. These changes were revealed by molecular, biochemistry and organismic methods and thus link the already described molecular mechanisms of secondary metabolite regulation (Keller et al., 2005) with the suggested inducible defence in fungi (Rohlfs and Churchill, 2011; Spiteller, 2008). Currently, the only study, that proposes an inducible anti-fungivore defence in another fungal system is the work done by Bleuler-Martínez et al. (2011). Bleuler-Martínez et al. (2011) suggest that carbohydrate-binding lectins formed by the mushroom Coprinopsis cinerea mediate resistance against grazers. To test for the toxicity of the lectins, they forced different non-fungal but bacterial feeders to graze on recombinant $E$. coli expressing fungal lectins. Even though some of the lectins turned out to be toxic to Caenorhabditis elegans, to Aedes aegypti larvae, and to Acanthamoeba castellanii, nematode, arthropod and amoeba, respectively, this study suffers a conceptual lack since 
non-fungal feeders might be highly susceptible to fungal lectins, and the influence of lectins on "real" fungal feeding invertebrates was not tested. Nonetheless, the study demonstrates that grazing by the nematode Aphelenchus avenae induces the transcription of genes encoding for lectins and the production of the proteins. Thus, the data presented in this thesis are the first demonstrating the concept of inducible resistance in a fungal organism. It would now be of great interest to test whether this principle occurs in other fungal systems, its influence on different fungivores, and how the experimentally observed reciprocity contributes to decomposer food web dynamics.

\section{Outlook}

The results shown in this thesis together with the work done by Döll et al. (2013) and Nielsen et al. (2013) provide first insights into the dynamic connection between resistance to fungivore grazing and the molecular mechanisms regulating fungal morphology and secondary metabolism. They open up new vistas for the study of fungus-fungivore interactions, under controlled laboratory conditions as well as in the field. As outlined in chapter 1, fungus-grazer interactions are thought to share many similarities with herbivore-plant systems, so hypotheses can be derived from herbivore-plant ecology theory. For instance, herbivorous insects detect plant volatiles by an olfactory system that is extremely sensitive and shows a high degree of specificity to plant volatiles (Bruce and Pickett, 2011; De Bruyne and Baker, 2008). Comparatively little is known about the ability of fungivores to perceive volatiles associated with resistance of fungi to resist grazing. For example, collembolan fitness and food choice very much depends on fungal secondary metabolites (Rohlfs et al., 2007; Scheu and Simmerling, 2004), yet only few studies demonstrated the ability of collembola to perceive fungal secondary metabolites (Bengtsson et al., 1991, 1988). Additionally, the study by Staaden et al. (2011) suggested that collembola are able to discriminate between toxic and non-toxic fungi based of olfactory information. Fungal volatile-guided food choice in other dominant fungivores of the soil system, such as oribatid mites or nematodes, have almost entirely been ignored.

In this context, another interesting aspect to be tested is whether fungal volatiles attract the natural enemies of fungivores, in particular when fungi are under grazing attack. This phenomenon has repeatedly been demonstrated for some plant systems, which has been termed "indirect defence" (Dicke et al., 1999; Kessler and Baldwin, 2001). This indirect defence was assigned to volatiles derived from enzymatic degradation of fatty acids, 
which contributes to a chemically rich pool of so-called oxylipins (Dicke et al., 1999). In chapter 2 the up-regulation of genes encoding for enzymes involved in fungal oxylipin biosynthesis when $A$. nidulans is grazed by D. melanogaster larvae was demonstrated, which suggests that changes in oxylipins might be involved in the fungal response to fungivory. Whether they are involved in hormonal signalling or in the anti-fungivore inducible direct and indirect defence needs to be resolved.

To be able to differentiate between wound- and grazing-induced changes in fungal resistance it would be necessary to explore whether fungivores secrete specific compounds that work as elicitors triggering the anti-fungivore defence as it has been demonstrated for plant-herbivore interactions (e.g. Mattiacci et al., 1995; Turlings et al., 2000). Chapter 2 as well as those by Döll et al. (2013) strongly suggested the existence of such elicitors.

In conclusion, the results of this thesis demonstrated for the first time that inducible resistance is an important factor affecting the outcome of a model fungus-fungivore interaction. Alterations in the fungal secondary metabolite profile are likely to be the ultimate cause that keeps fungivores in check. Future studies that go beyond the A. nidulans system will deepen our understanding of the mechanistic intricacies of fungal secondary metabolite regulation in interactions with grazers. Strikingly, the functioning of inducible resistance appears to be quite susceptible to variation in grazing intensity and chemically mediated intraguild interactions. Therefore, determining the role of fungal inducible resistance in affecting multi-species communities and food-web dynamics remains to be the major future task. 


\section{References}

Bengtsson, G., Erlandsson, A., Rundgren, S., 1988. Fungal odour attracts soil collembola. Soil Biol. Biochem. 20, 25-30.

Bengtsson, G., Hedlund, K., Rundgren, S., 1991. Selective odor perception in the soil collembola Onychiurus armatus. J. Chem. Ecol. 17, 2113-2125.

Bleuler-Martínez, S., Butschi, A., Garbani, M., Wälti, M.A., Wohlschlager, T., et al., 2011. A lectin-mediated resistance of higher fungi against predators and parasites. Mol. Ecol. 20, 3056-3070.

Bleve, G., Grieco, F., Cozzi, G., Logrieco, A., Visconti, A., 2006. Isolation of epiphytic yeasts with potential for biocontrol of Aspergillus carbonarius and A. niger on grape. Int. J. Food Microbiol. 108, 204-209.

Bretherton, S., Tordoff, G.M., Jones, T.H., Boddy, L., 2006. Compensatory growth of Phanerochaete velutina mycelial systems grazed by Folsomia candida (Collembola). FEMS Microbiol. Ecol. 58, 33-40.

Bruce, T.J.A., Pickett, J.A., 2011. Perception of plant volatile blends by herbivorous insects Finding the right mix. Phytochemistry 72, 1605-1611.

De Bruyne, M., Baker, T.C., 2008. Odor detection in insects: volatile codes. J. Chem. Ecol. 34, 882-897.

Dicke, M., Gols, R., Ludeking, D., Posthumus Maarten A., 1999. Jasmonic acid and herbivory differentially induce carnivore - attracting plant volatiles in lima bean plants. J. Chem. Ecol. 25, 1907-1922.

Döll, K., Chatterjee, S., Scheu, S., Karlovsky, P., Rohlfs, M., 2013. Fungal metabolic plasticity and sexual development mediate induced resistance to arthropod fungivory. Proc. Biol. Sci. 280, 20131219.

Keller, N.P., Turner, G., Bennett, J.W., 2005. Fungal secondary metabolism - from biochemistry to genomics. Nat. Rev. Microbiol. 3, 937-47.

Kessler, A., Baldwin, I.T., 2001. Defensive function of herbivore-induced plant volatile emissions in nature. Science. 291, 2141-2144.

Mattiacci, L., Dicke, M., Posthumust, M.A., 1995. ß-Glucosidase: an elicitor of herbivoreinduced plant odor that attracts host-searching parasitic wasps. Proc. Natl. Acad. Sci. USA 92, 2036-2040.

Nielsen, T.H., Klejnstrup, M.L., Rohlfs, M., Anyaogu, D.C., Nielsen, J.B., Gotfredsen, C.H., Andersen, M.R., Hansen, B.G., Mortensen, U.H., Larsen, T.O., 2013. Aspergillus nidulans synthesize insect juvenile hormones upon expression of a heterologous regulatory protein and in response to grazing by Drosophila melanogaster Larvae. PLoS ONE 8, e73369.

Rohlfs, M., Albert, M., Keller, N.P., Kempken, F., 2007. Secondary chemicals protect mould from fungivory. Biol. Lett. 3, 523-5. 
Rohlfs, M., Churchill, A.C.L., 2011. Fungal secondary metabolites as modulators of interactions with insects and other arthropods. Fungal Genet. Biol. 48, 23-34.

Scheu, S., Simmerling, F., 2004. Growth and reproduction of fungal feeding Collembola as affected by fungal species, melanin and mixed diets. Oecologia 139, 347-353.

Spiteller, P., 2008. Chemical defence strategies of higher fungi. Chemistry 14, 9100-9110.

Spraker, J.E., Jewell, K., Roze, L. V, Scherf, J., Ndagano, D., Beaudry, R., Linz, J.E., Allen, C., Keller, N.P., 2014. A volatile relationship: profiling an inter-kingdom dialogue between two plant pathogens, Ralstonia Solanacearum and Aspergillus Flavus. J. Chem. Ecol.

Staaden, S., Milcu, A., Rohlfs, M., Scheu, S., 2011. Olfactory cues associated with fungal grazing intensity and secondary metabolite pathway modulate Collembola foraging behaviour. Soil Biol. Biochem. 43, 1411-1416.

Stötefeld, L., Scheu, S., Rohlfs, M., 2012. Fungal chemical defence alters density - dependent foraging behaviour and success in a fungivorous soil arthropod. Ecol. Entomol. 37, 323329.

Trienens, M., Rohlfs, M., 2012. Insect-fungus interference competition - The potential role of global secondary metabolite regulation, pathway-specific mycotoxin expression and formation of oxylipins. Fungal Ecol. 5, 191-199.

Turlings, T.C.J., Alborn, H.T., Loughrin, J.H., Tumlinson, J.H., 2000. Volicitin, an elicitor of maize volatiles in oral secretion of Spodoptera exigua: Isolation and bioactivity. J. Chem. Ecol. 26, 189-202. 


\section{Acknowledgements}

With these lines I want to express my sincere gratitude to those I am greatly indebted. First of all, I wish to thank my supervisor Dr. Marko Rohlfs for his guidance, enthusiasm, for supervising me, giving me the opportunity to work in his group and supporting my research with helpful suggestions and advice.

I also want to express my gratitude to Prof. Dr. Stefan Scheu for being an excellent head leader, for his effort as a referee of this dissertation and for accepting me as a part of the AG.

I would like to thank PD Dr. Maraun, PD. Dr. Gansert, PD. Dr. Hövemeyer and Prof. Dr. Schütz for kindly accepting to be in my examination committee. I am also grateful to PD Dr. Gansert for all the time he had invested in explaining me all the protocols required to submit this dissertation.

I express thanks to the whole working group for providing me a nice atmosphere during these years at the institute. I am especially thankful to Dr. Jousset for his help in the lab and in my professional career. Thanks to Dr. Davis for his advice during the end of my $\mathrm{PhD}$.

I especially want to express my thanks and love to my beloved parents for their endless support during my doctoral studies, great love, but especially for believing in me. Thanks for your constant help and for being always present in the good and bad moments despite the long distance that was separating us for so many years. I am indebted to you. I also want to express my gratitude and at the same time to dedicate this work to the memory of my beloved aunt, my second mother, for her infinite love and wonderful advice. You will be always in my heart. Many thanks to my siblings, brother in law and to my nephew for your unconditional love and cheerful talks. Thanks for being always available to listen to me from the other side of the telephone line regardless of day or time. I really hope and wish that soon no distance will stand between us.

I wish to thank all my friends around Spain and Germany, especially those living in Göttingen who kept me alive during these years, for all the support, wonderful conversations, innumerable international dinners, laughter and marvellous trips, thanks to Juan, Elena, Alexandra, Ane, Hanna, Silvia, Niko, Johana, Amanda and Gisela, but my very sincere gratitude goes to my soul mate Mahmood, my unconditional friend, who was always there. Today I can say that I have a second family in Germany. 
Finally, my heartfelt thanks go to my love, José, for his unconditional support, help and infinite love, especially during the hardest months of my $\mathrm{PhD}$. Thanks for your always helpful and nice words, for motivating me and believing in me. Thanks for everything you have taught me in this time. Thanks for all the good moments, funny trips and amazing adventures we had and for all adventures we still have to live. This would not have been possible without you. 


\section{List of publications}

Caballero Ortiz, S., Trienens, M., Rohlfs, M., 2013. Induced fungal resistance to insect grazing: reciprocal fitness consequences and fungal gene expression in the Drosophila-Aspergillus model system. PLoS ONE 8, e74951. 


\section{Thesis declaration}

I hereby declare that this dissertation has been written independently. All persons contributing to the manuscripts have been named so. All sentences or passages quoted from other people's work have been specifically acknowledged by clear crossreferencing. I further declare that the work has not been submitted for the purpose of academic examination, either in its original or similar form, anywhere else.

Silvia Caballero Ortiz

Göttingen, October 2014 
